\title{
Chromophore-independent roles of Drosophila opsin apoproteins and visual cycle components
}

\author{
Dissertation \\ for the award of the degree \\ "Doctor rerum naturalium" (Dr.rer.nat.) \\ of the Georg-August-Universität Göttingen \\ within the doctoral program \\ of the Georg-August University School of Science (GAUSS) \\ submitted by \\ Radoslaw Katana
}

from Zielona Góra, Poland

Göttingen, 2018 
Thesis Committee

\section{Prof. Dr. Martin Göpfert}

Department of cellular neurobiology,

University of Göttingen

Prof. Dr. André Fiala

Department of molecular neurobiology of behavior, University of Göttingen

\section{Members of the Examination Board}

\section{Prof. Dr. Martin Göpfert}

Department of cellular neurobiology, University of Göttingen

Prof. Dr. André Fiala

Department of molecular neurobiology of behavior University of Göttingen

Further members of the Examination Board:

\section{Dr. Manuela Schmidt}

Emmy Noether-Nachwuchsgruppe somatosensory signaling and systems biology, Max Planck Institute of Experimantal Medicine

\section{Prof. Dr. Jörg Großhans}

Institute of biochemistry and molecular cell biology,

University Medical Center Göttingen

\section{Dr. Jan Clemens}

Neural computation and behavior group, European Neuroscience Institute

\section{Dr. Gerd Vorbrüggen}

Departmen of molecular development, Max Planck Institute for Biophysical Chemistry

Date of oral examination: November $23^{\text {rd }}, 2018$ 
I herewith declare that the Phd thesis entitled "Chromophore-independent roles of Drosophila opsin apoproteins and visual cycle components" was written independently, with no other sources and aids than quoted.

Radoslaw Katana

Göttingen, October $19^{\text {th }}, 2018$ 


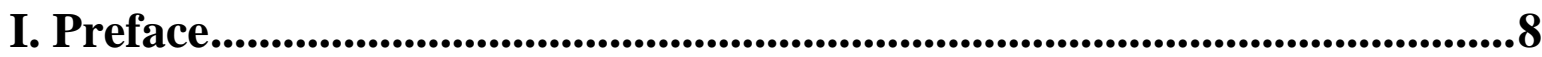

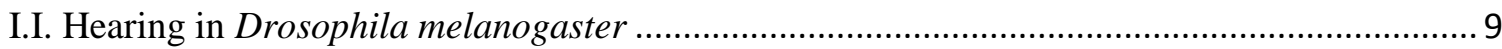

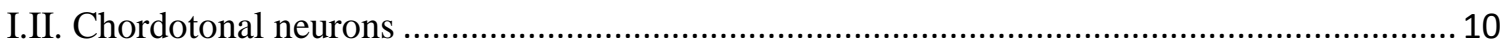

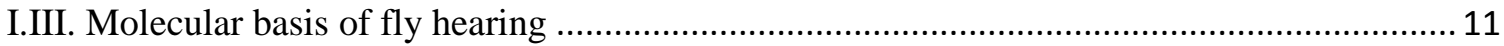

II. Materials and methods ............................................................................13

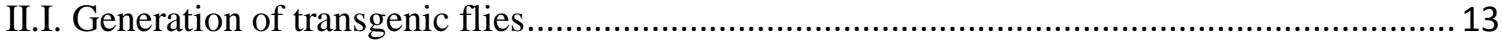

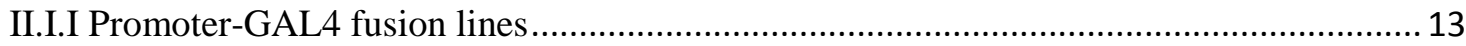

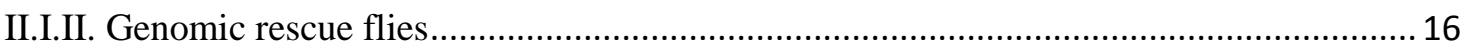

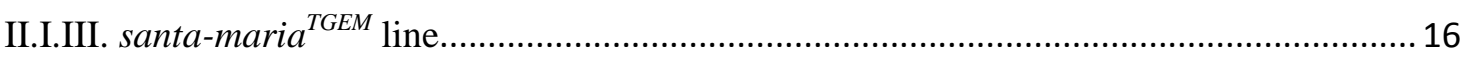

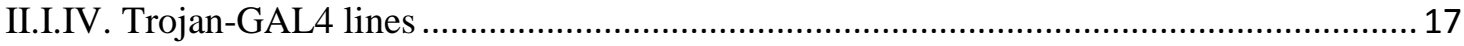

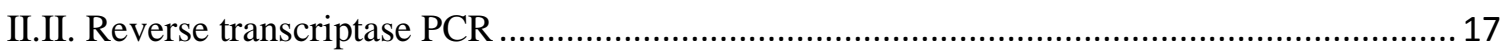

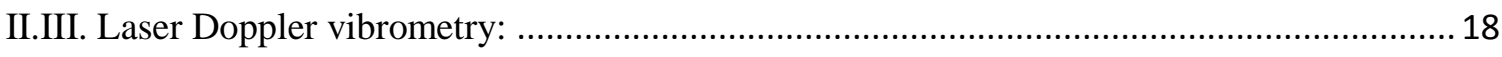

II.IV. Prolonged depolarizing afterpotential (PDA) recordings: ............................................... 20

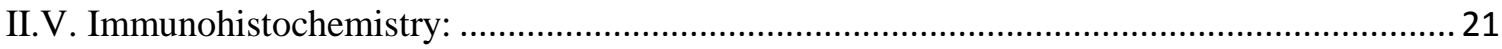

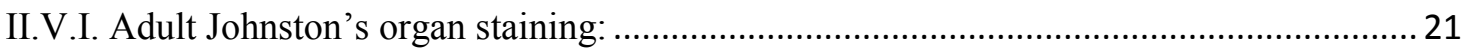

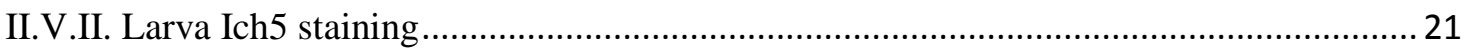

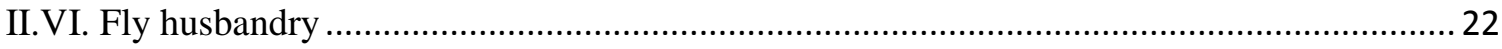

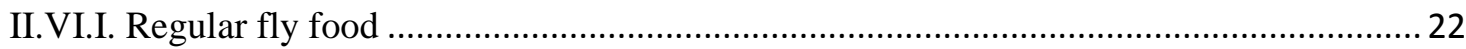

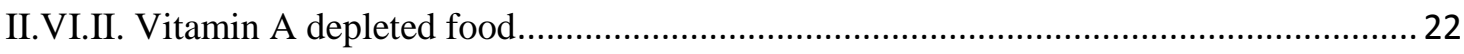

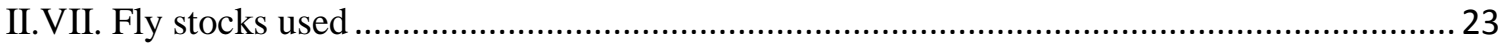

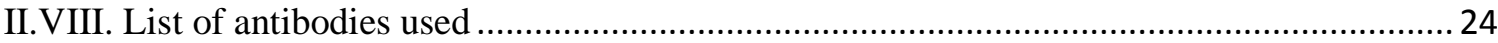

\section{Chapter 1: Chromophore-independent roles of Drosophila opsin} apoproteins and visual cycle components. .....................................................25

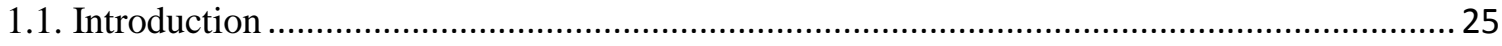

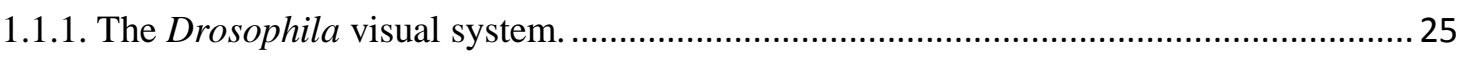

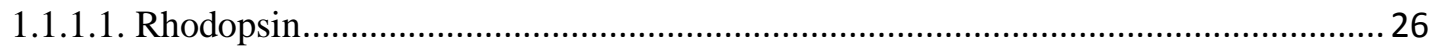

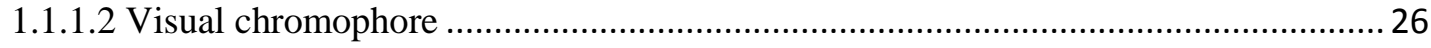

1.1.1.3 Chromophore generation pathway and recycling ................................................. 27

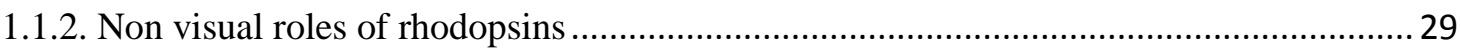

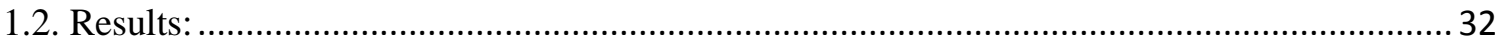

1.2.1 Scavenger receptor class B - SANTA-MARIA in Drosophila hearing .......................... 32 


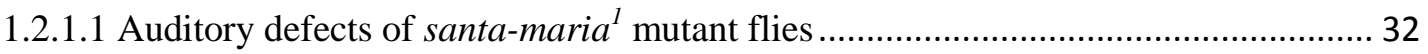

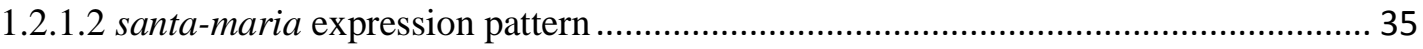

1.2.1.3. Localization of TRP channels in santa-maria ${ }^{l}$ mutants.......................................... 37

1.2.1.4. Tissue specific rescue of santa-maria mutants ..................................................... 40

1.2.2. Relevance of the chromophore generation pathway for fly audition ............................. 42

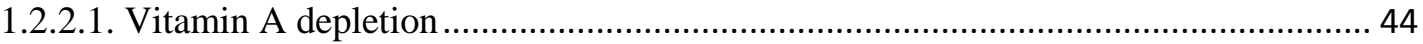

1.2.3. Auditory importance of the genes implicated in chromophore processing and recycle.. 47

1.2.3.1. PINTA is functionally involved in auditory process ............................................. 47

1.2.3.2 nina $G$ function and expression in chordotonal organs .............................................. 51

1.2.3.3 Genes of chromophore recycling pathway in fly hearing ........................................ 56

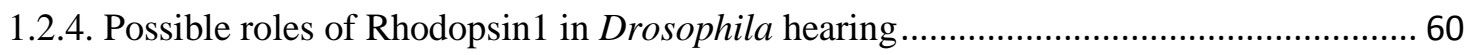

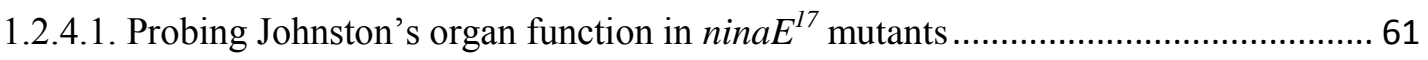

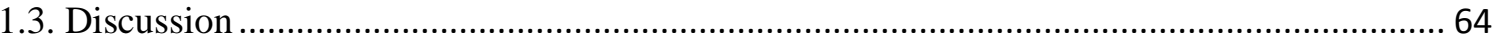

1.3.1. Eliminating key genes of chromophore synthesis left hearing unaffected..................... 64

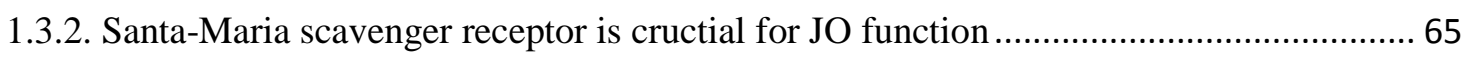

1.3.3. Auditory organ function is dependent on the proteins previously implicated is

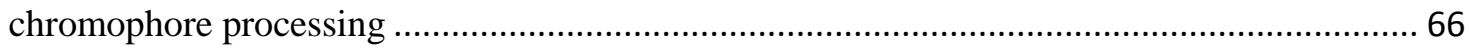

1.3.4. Genes of chromophore recycling pathway are functionally involved in hearing ............67

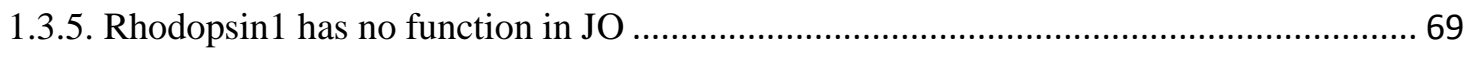

Chapter 2: Identifying novel genes in Drosophila hearing...........................70

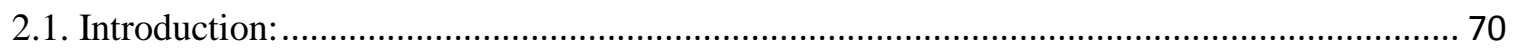

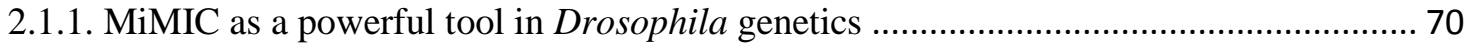

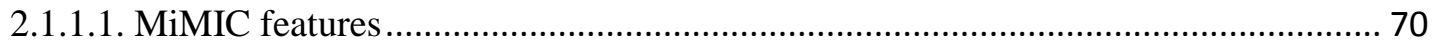

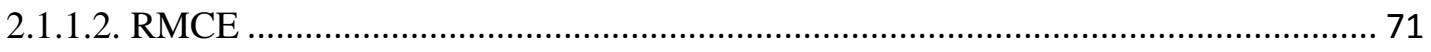

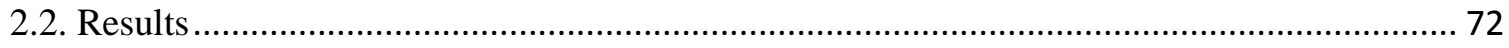

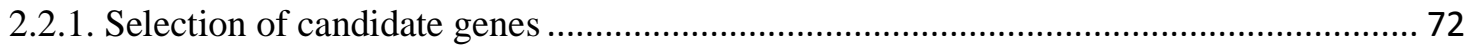

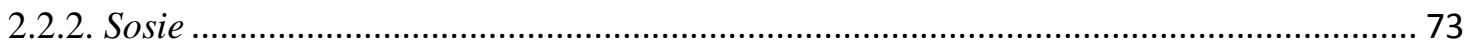

2.2.2.1. Hearing in sosie mutant flies is severely impaired ............................................. 73

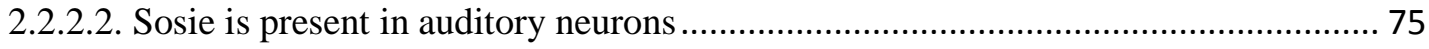

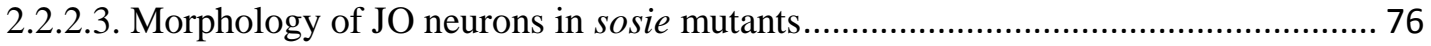

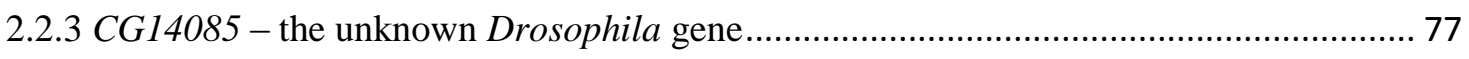

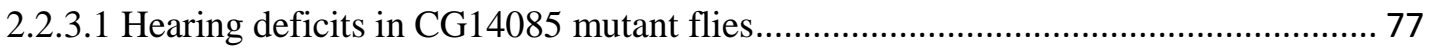


2.2.2.2. $C G 14085$ is expressed in chordotonal organs ..................................................... 79

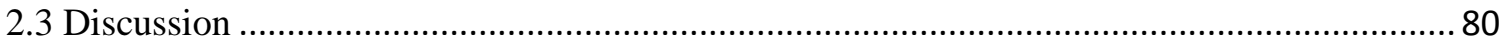

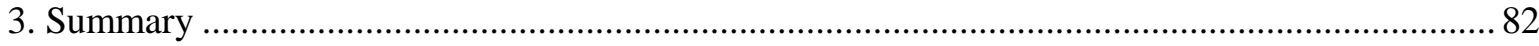

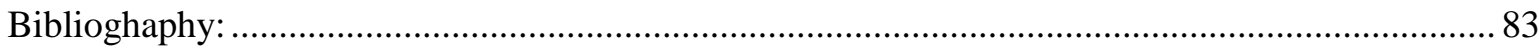

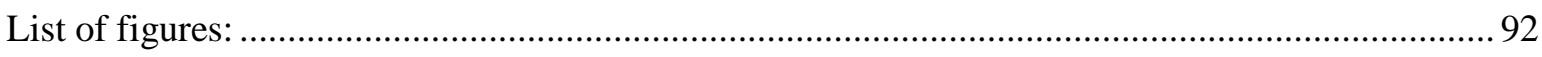

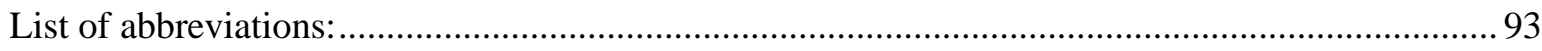

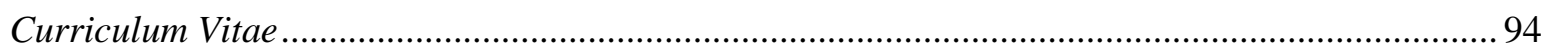

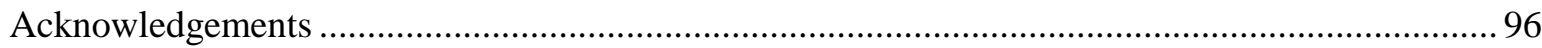




\section{Preface}

Animal perception of surrounding environment relies on sensing external sensory information with different sensory modalities (Keeley, 2002). This includes: vision, hearing, taste, smell and touch. Between these, hearing and touch are based on conversion of mechanical stimuli into electrochemical activity in the process called mechanotransduction (Albert et al., 2007). To facilitate detection of the mechanical force animals developed specialized mechanosensory organs such as chordotonal organs found in insects. The most extensively studied chordotonal organ in Drosophila is Johnston's organ (JO), which plays a major role in fly hearing (Yack, 2004). Although, anatomically fly auditory organs and vertebrates ears are vastly different, they actually share numerous genetic and functional parallels (Senthilan et al., 2012). The most remarkable example of genetic resemblance is interchangeable role of Drosophila helix-loop-helix transcription factor atonal (ato) that specifies JO sensory neurons and its mammalian homolog Math that determine development of hair cells in vertebrate ears (Wang et al., 2002). Mouse Mathl can functionally substitute ato in the flies lacking ato and vice versa, suggesting conserved role of both proteins (Wang et al., 2002). Furthermore, mechanotransduction machinery of JO neurons and hair cells seem to be based on the same components including gaiting springs that convey force to the mechanically gated ion channels and adaptation motors (Senthilan et al., 2012).

Interestingly, mechanosensory organs as they may seem very distinct from photoreceptors in Drosophila eye, actually were shown to share the same evolutionary origin (Fritzsch et al., 2007). Early in the development they are specified by previously mentioned proneural gene atonal (Jarman and Groves, 2013). Moreover, molecules that previously were solely known as photosensors in Drosophila retina - Rhodopsins seem to be involved in sensing more cues than light (Leung and Montell, 2017). This canonical light sensors are also involved in adult hearing, larval proprioception and thermosensation (Senthilan et al., 2012; Shen et al., 2011; Sokabe et al., 2016; Zanini et al., 2018). 


\section{I.I. Hearing in Drosophila melanogaster}

Hearing in insect serves two main roles: communication and courtship (Todi et al., 2004). In Drosophila mating behavior male flies produce a courtship song by extending and fanning one of its wings to attract a female and stimulate other males to sing and court (Greenspan, 2000; Yoon et al., 2013). These songs are species specific and compose of two main components: sine and pulse which fall in the frequency range of 100-300 $\mathrm{Hz}$ (Dickson, 2008).

In Drosophila adults hearing organs are located on both sides of the head, between the eyes and are called Antennae (Yack, 2004). Each antenna is composed of three main segments. The first segment (scape) is the smallest one and comprises muscles to actively position the whole organ (Figure 1). The second antennal segment (pedicel) harbors the Johnston's organ, an array of ca. 500 stretch receptive chordotonal neurons that are used to detect sound, wind and gravity (Göpfert and Robert, 2002). The third segment (funicel) serves for olfaction and together with stiffly coupled branched structure called arista forms a sound receiver (Göpfert and Robert, 2002). The sound receiver is connected with the second antennal segment via a hook which allows rotational movement of the whole structure in response to particle velocity of sound (Albert and Göpfert, 2015). These vibrations result in mechanical stress that is applied on chordotonal neurons in $2^{\text {nd }}$ antennal segment leading to their activation (Göpfert and Robert, 2001).

JO neurons can be classified into 5 classes (A-E) based on their projections in the antennal mechanosensory and motor center (AMMC) in the brain (Azusa Kamukouchi, Tkashi Shimada, 2006). The most sensitive subpopulation of neurons belong to class A and $\mathrm{B}$, they mainly respond to sound-induced antennal deflections and are needed for hearing (Kamikouchi et al., 2009). In the other hand, CE class of neurons are activated by higher antennal deflection caused by gravity and wind (Yorozu et al., 2009). 


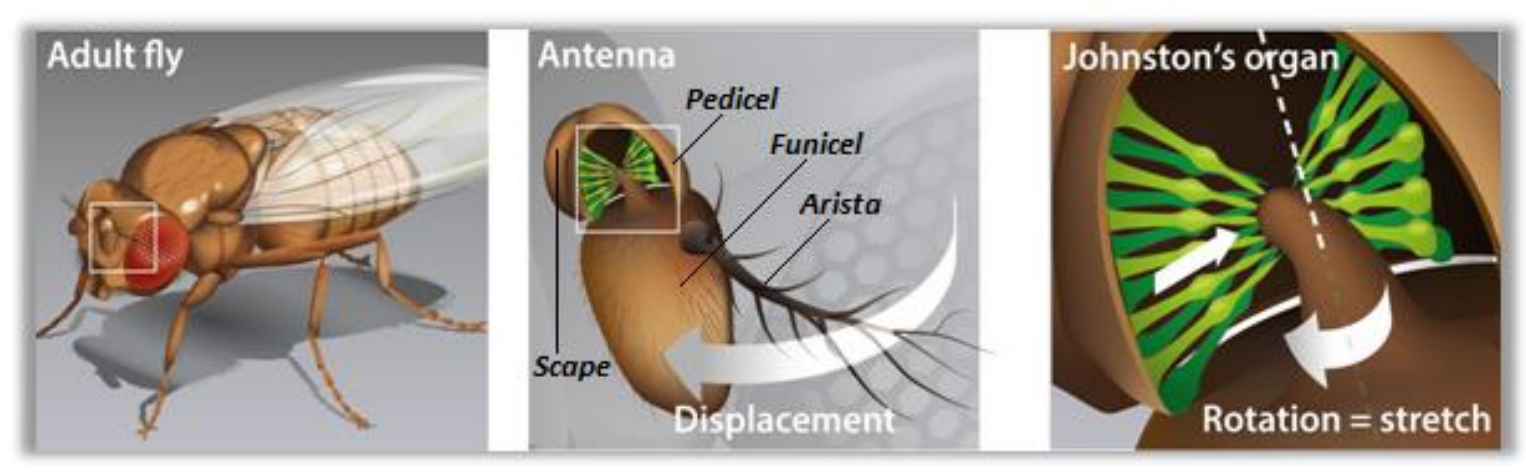

Figure 1. Hearing organ of Drosophila.

On the right: sketch of Drosophila adult fly. Magnified view on antenna: the first segment (scape), the second segment (pedicel), the third segmant (funicel) and the arisa. On the left: $2^{\text {nd }}$ antennal segment anatomy. In green are mechanosensitive JO neurons which are suspended between the antennal hook and the cuticule. Rotation of the sound receiver causes activation of the neurons. Modified from Dr. C. Spalthoff.

\section{I.II. Chordotonal neurons}

The biggest chordotonal organ (cho) in adult Drosophila is JO that consists of mechanosensory neurons organized in units called scolopidia (Figure 2) (Kamikouchi et al., 2009). Each scolopidium comprises of two to three monodendric, ciliated sensory neurons associated with three accessory cells: ligament cell, scolopale cell and cap cell (Brewster and Bodmer, 1995). The ligament cell supports the neuron by attaching it to the cuticule on its proximal end, whereas the cap cell is responsible for apical attachment to the $3^{\text {rd }}$ antennal segment joint (Albert and Göpfert, 2015). The scolopale cells on the other hand wraps around cilium forming a sealed scolopale space filled with an extracellular lymph enriched in $\mathrm{K}^{+}$ions that creates a proper environment for mechanotransduction (Caldwell and Eberl, 2002). Additionally, scolopale cells are endowed with actin enriched rods which protects the neuronal dendrite and presumably creates initial tension of the cilium (Todi et al., 2004).

Chordotonal sensory neurons can be also found in Drosophila larvae where they form: lateral pentaloscolopidial organ LCh5 (Figure 2 right), single lateral organ LCH1, and two ventral organs $\mathrm{VChA}$ and $\mathrm{VChB}$ that are used for proprioception (Halachmi et al., 
2016). The most extensively studied is LCh5 organ that consists of an array of 5 scolopidia units and set of accessory cells that share the same morphological and functional properties as the ones seen in adult JO (Styczynska-Soczka and Jarman, 2015).

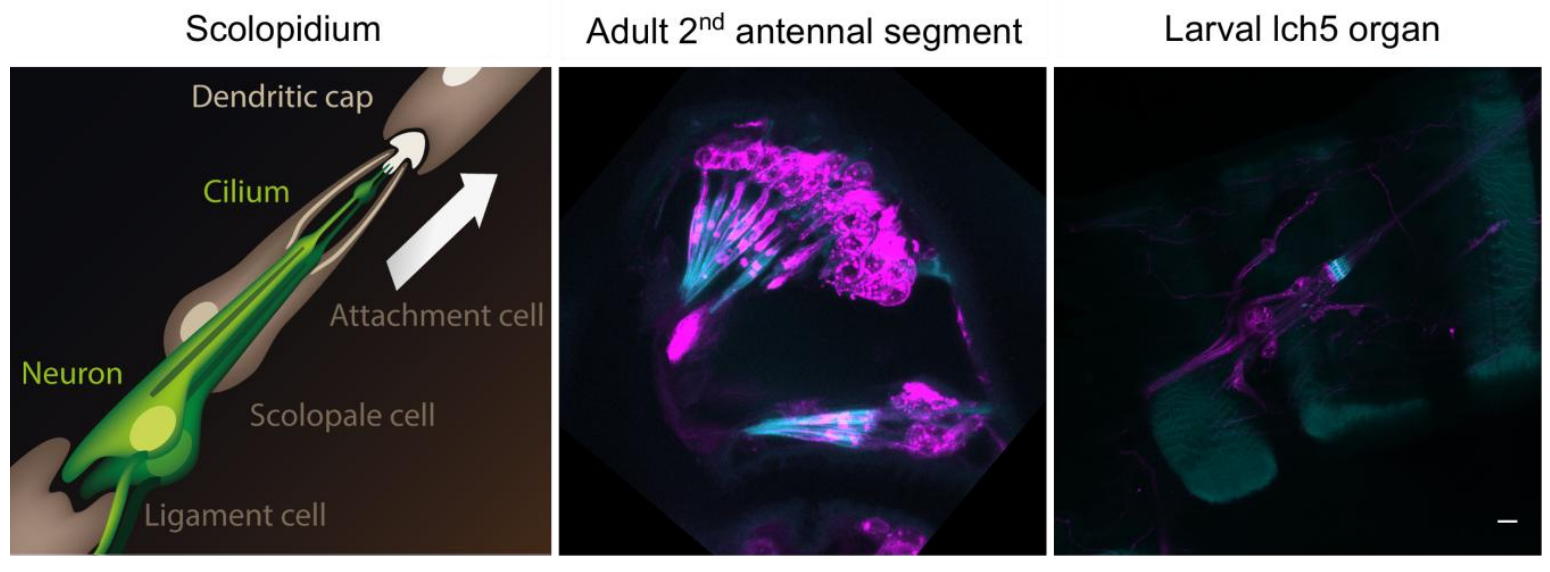

Figure 2. Chordotonal organs in Drosophila

Left: Sketch of the scolopidium. Mechanosensory chordotonal neurons are colored green and accessory cell in brown. Modified from Dr. Spalthoff. Middle and right: Immunohistochemical staining of the adult JO and larval pentaloscolopidial (lch5), respectively. Neurons are shown in magenta and scolopale rods in cyan. Scale bar $10 \mu \mathrm{m}$.

\section{I.III. Molecular basis of fly hearing}

The mechanical force that acts on the sound receiver causes vibrations on the joint between funiculus hook and dendritic cap attachment of auditory neurons in the $2^{\text {nd }}$ antennal segment (Albert and Göpfert, 2015). These vibrations are conveyed to the mechano-electrical transduction (MET) channels which resides in the distal part of the chordotonal sensory neuron (Bokolia and Mishra, 2015). In flies, these mechanotransduction channels of JO neurons are considered to be directly gated as their electrical response to sound stimuli show a delay of less than $1 \mathrm{~ms}$, which is too short for second-messenger cascade (Albert et al., 2007). Direct gating of these channels is further supported by observation of characteristic gating compliance in response to rapid deflection of sound receiver (Nadrowski et al., 2008). 
Even though, cilia of Johnston's organ mechanosensory neurons display ' $9+0$ ' microtubule axonemes arrangement, which are usually considered as immotile due to lack of central pair of microtubules, they are endowed with dynein arms that support their motility (Karak et al., 2015). Thus, Drosophila sound receiver show spontaneous, self sustained motions in absence of stimulus (Göpfert and Robert, 2003). These motions can be monitored by tracking the antennal movement using the laser Doppler vibrometer, that permits direct and noncontact measurements of antennal vibration velocity (Robert and Göpfert, 2002). Fly antennae are broadly tuned, with the highest peak at the frequency of around $250 \mathrm{~Hz}$, which matches the dominant frequency of the courtship song (Göpfert and Robert, 2002). In response to sound stimuli JO neurons actively boost antennal vibrations enhancing the antennal sensitivity to faint sounds by a factor of 10 (Göpfert et al., 2006). The origin of this mechanical amplification derives from the coaction between the mechanotransduction channels and previously mentioned axonemal dyneins motors (Karak et al., 2015).

There are 3 known MET ion channels implicated in Drosophila hearing: No mechanoreceptor potential C (NOMPC), Inactive (Iav) and Nanchung (Nan) (Bokolia and Mishra, 2015). They belong to transient receptor potential (TRP) superfamily of ion channels, whereas NOMPC is a single member of TRPN subfamily, Iav and Nan belongs to TRPV subfamily (Bokolia and Mishra, 2015). NOMPC was proposed to play a main role in mechanotransduction complex of JO neurons (Effertz et al., 2011). In absence of NOMPC hearing is severely impaired as evidenced by complete loss of JO neurons motility, abolished mechanical amplification and lack of sound-evoked action potentials in antennal nerve (Effertz et al., 2011). However, when stimulated with louder sounds nompC mutatnts show residual nerve potential that probably comes from activation of less sensitive mechanotransduction channels in CE class of JO neurons (Effertz et al., 2012). NOMPC occurs is the dendritic tips of JO neurons, whereas Iav and Nan are present more proximal in the cilium forming heteromultimeric transduction channel (Kim et al., 2003). Thus, these two TRPV channels are not considered as main mechanotransduction channels, rather they act downstream of NOMPC (Zhang et al., 2015). They seem to negatively control NOMPC dependent amplification as nan and iav mutants flies show excessive fluctuation power and increase of the mechanical amplification gain (Göpfert et al., 2006). 


\section{Materials and methods}

\section{II.I. Generation of transgenic flies}

\section{II.I.I Promoter-GAL4 fusion lines}

To generate the GAL4 promoter fusion construct of particular genes their upstream genomic regions of $\sim 2 \mathrm{~kb}$ were amplified. The primers were design as follows:

\begin{tabular}{|c|l|}
\hline pinta & $\begin{array}{l}\text { F: 5'-CCTCTAGAGCAACCAGTTGCAGCAAAAC-3' } \\
\text { R: 5'-CCGGATCCCGTTGATCTGCGGATTGG-3' }\end{array}$ \\
\hline ninaG & $\begin{array}{l}\text { F: 5'-CCTCTAGAGCCATTGAGCCACTGGATA-3 } \\
\text { R: 5'-CCGGATCCACTCCCATTGCTGTTTTTGG-3' }\end{array}$ \\
\hline Pdh & $\begin{array}{l}\text { F: 5'-CCTCTAGACAATGCCCACTAGATGGG } \\
\text { R: 5'-CCGAATCCGCGAAAGGACATCTTGGTCT-3' }\end{array}$ \\
\hline
\end{tabular}

The forward and reverse primer contains Xba1 and BamH1 restriction site respectively. Extra $\mathrm{CC}$ was added to 5' end of each primer to facilitate enzymatic digestion.

\section{Genomic DNA extraction}

Genomic DNA was extracted from flies using DNeasy Blood \& Tissue Kit from Qiagen. Homogenization was made by crushing $20 w^{1118}$ flies in $180 \mu 1$ of buffer ALT together with $20 \mu \mathrm{l}$ of proteinase K using the QiagenTissueLyser LT homogenizator. The homogenate was incubated at $56^{\circ} \mathrm{C} 1000 \mathrm{rpm}$ overnight on the Thermoshaker. Following washing steps were done according to the DNeasy protocol. After DNA elution in the pure water the nucleic acid concentration was measured using the Thermo Scientific Nanodrop 1000. 


\section{PCR amplification:}

Desired DNA sequences were amplified using GoTaq ${ }^{\circledR}$ G2 Green Master Mix.

The reaction mixes were prepared on ice as follows:

For a $50 \mu 1$ reaction volume:

\begin{tabular}{|c|c|c|}
\hline Component: & Volume & Final conc. \\
\hline GoTaq® G2 Green Master Mix, 2x & $25 \mu \mathrm{l}$ & $1 \mathrm{x}$ \\
\hline Upstream primer & $1 \mu \mathrm{l}$ & $0,5 \mu \mathrm{M}$ \\
\hline Downstream primer & $1 \mu \mathrm{l}$ & $0,5 \mu \mathrm{M}$ \\
\hline DNA template & $2 \mu \mathrm{l}$ & $\sim 500 \mathrm{ng}$ \\
\hline Nuclease-Free Water & $21 \mu \mathrm{l}$ & N.A \\
\hline
\end{tabular}

PCR tubes were placed in the Bio-Rad MyIQ thermal cycler and PCR conditions were set. Protocol for PCR reaction:

\begin{tabular}{|c|c|c|}
\hline Step & Time $(\min : s e c)$ & Temperature $\left({ }^{\circ} \mathrm{C}\right)$ \\
\hline Initialization & $3: 00$ & 95 \\
\hline Dentaturation & $0: 15$ & 95 \\
\hline Annealing & $0: 30$ & 57 \\
\hline Elongation & $1: 30$ & 72 \\
\hline Final elongation & $7: 00$ & 72 \\
\hline
\end{tabular}

Steps B1,B2,B3 were repeated 30 times

\section{Restriction digestion:}

After PCR the samples were cleaned using a NucleoSpin ${ }^{\circledR}$ Gel and a PCR Clean-up kit from Machery-Nagel. DNA samples and pPTGAL vector were then digested in 1x Fast digest buffer containing BamH1 and Xba1 restriction enzymes at $37^{\circ} \mathrm{C}$ for 2 hours. 


\section{Gel electrophoresis:}

Digested DNA samples and pPTAGAL vector were loaded in the $1 \%$ agarose gel containing $2.5 \mu 1$ of Roti ${ }^{\circledR}-G e l S t a i n$ reagent for detection of nucleic acids. The gel was placed in the Bio-Rad Wide Mini Sub Cell GT electrophoresis apparatus filled with 1x TBE buffer. A Thermo Scientific Gen ruler DNA ladder was added into one of the wells. The gel was run at $100 \mathrm{~V}$ for 1 hour. A single bands of DNA construct and pPTAG vector of correct size was excised from the gel, weight and cleaned using the NucleoSpin ${ }^{\circledR}$ Gel and the PCR Clean-up kit from Machery-Nagel.

\section{Ligation:}

The insert and the vector ( $5 \mu 1$ each) were added to $10 \mathrm{x}$ ligation buffer in presence of $1 \mu 1 \mathrm{~T} 4 \mathrm{DNA}$ ligase. Ligation was carried overnight at $4^{\circ} \mathrm{C}$.

\section{Transformation:}

Aliquots of XL1-Blue competent cells were thawed on ice for $20 \mathrm{~min} .15 \mu 1$ of the ligation reaction was carefully added to the cells and incubated on ice for $15 \mathrm{~min}$. Then, the cells were heat shocked at $42^{\circ} \mathrm{C}$ for $60 \mathrm{sec}$ and incubated for $10 \mathrm{~min}$ on ice. Then, $200 \mu \mathrm{l}$ of SOB medium was added and incubated for 1hour in the Innova 40 shaker incubator with 1000rpm agitation. The bacteria cultures were poured on the LB agar plates containing ampicillin antibiotic, streaked to obtain single bacterial colonies and left to grow in $37^{\circ} \mathrm{C}$ chamber overnight. On the next day single colonies were picked and added to liquid LB medium and incubated overnight in $37^{\circ} \mathrm{C}$ bacteria shaker.

\section{Mini-prep from bacterial culture:}

After successful transformation, $2 \mathrm{ml}$ of bacterial overnight cultures were spun down, and the supernatant was taken out. The next steps were performed according to the NucleoSpin ${ }^{\circledR}$ Plasmid kit from Machery-Nagel. The final samples were digested and run on the gel as in previous steps for verification of correct insert and vector sizes. 


\section{Sequencing:}

Samples of total volume of $16 \mu 1$ and concentration of $100 \mathrm{ng} / \mu 1$ were sequenced by the MPI-Sequencing Facility in Hermann-Rein-Str. 3, 37075 Goettingen, Germany. After sequence verification constructs were sent to BestGene ${ }^{\circledR}$ for embryo injections.

\section{II.I.II. Genomic rescue flies}

Genomic rescue flies were made using BACPAC clones ordered from $\mathrm{P}(\mathrm{acman})$ resource centre. To generate pinta rescue a clone no. CG321-22H03 was used that contains $\sim 65 \mathrm{~kb}$ of the $3^{\text {rd }}$ chromosome of wild-type fly including pinta locus. For generation of $p d h$ rescue $\mathrm{CH} 322-23 \mathrm{P} 06$ clone was used that contains $\sim 22 \mathrm{~kb}$ including $p d h$ locus. The clones were directly send for embryo injection to BestGene.

\section{II.I.III. santa-maria ${ }^{T G E M}$ line}

TGEM vector phase 0 (addgene \#62891) was targeted into $1^{\text {st }}$ coding intron of santa-maria gene by homologus recombination using CRISPR/Cas strategy (Diao et al., 2015). The guide RNA was: GACTCGCGCCAATTGAGAGG CGG and the primers to amplify the left and the right homology arms were as follows:

Left arm:

Forward primer: TCCCGATAAGCGATAAGTGC

Reverse primer: GGCACTCCCAGTTGTTCTTC

Right arm:

Forward primer: AAGCAATAGCATCACAAATTTCAC 
Reverse primer: TCCACAGTTTCCACATAATCCA

The experiment was carried out by GenetiVision.

\section{II.I.IV. Trojan-GAL4 lines}

MiMIC flies: $\operatorname{sosie}^{M I 1265}$ and $C G 14085^{M I 11086}$ were obtained from Bloomington Stock Centre. invivo Recombinase Mediated Cassette Exchange (RMCE) was performed to replace MiMIC cassette with triple donor construct pC-(loxP2-attB2-SA-T2A-Gal4Hsp70) 3 cassette through series of genetic crosses (Diao et al., 2015). The detailed crossing scheme can be find in Figure S1B. (Diao et al., 2015). YFP-positive larvae were collected and the lines were established.

\section{II.II. Reverse transcriptase PCR}

\section{RNA extraction:}

To extract total RNA from the antenna and the heads, $50 w^{1118}$ flies were transferred to a $10 \mathrm{ml}$ falcon tube and snap frozen using liquid nitrogen. In order to disintegrate different body parts, flies were vortexed for $5 \mathrm{sec}$ then incubated in liquid nitrogen. This step was repeated several times. Set of sieves with mesh sizes of: $710 \mu \mathrm{m}, 425 \mu \mathrm{m}, 250 \mu \mathrm{m}$, $125 \mu \mathrm{m}$ were pre-chilled in $-80^{\circ} \mathrm{C}$ for $30 \mathrm{~min}$ and kept on dry ice. Whole material from falcon tubes was transferred on to the upper sieve. After vigorous shaking pure heads were retained on the $425 \mu \mathrm{m}$ sieve whereas $2^{\text {nd }}$ antenna segments passed through all sieves on the bottom sieve pan. Material was then collected to eppendorf tubes containing a lysis buffer and homogenized in the TissueLyser LT. RNA was extracted using NucleoSpin ${ }^{\circledR}$ RNA Clean-up XS kit according to a manufacture protocol. RNA concentration was determined using Nanodrop spectrophotometer. 


\title{
cDNA synthesis and PCR:
}

The RNA was converted to complementary cDNA using Qiagen QuantiTect ${ }^{\circledR}$ Reverse Transcription Kit. The cDNA was amplified by PCR using following primers:

\author{
F: 5'-CAAAACACAATGGAGAGGTACG-3'
}

R: 5'-GCACATGGACCAGATGGA-3'

\section{II.III. Laser Doppler vibrometry:}

\section{Fly mounting:}

The fly was mounted on the top of plastic rod using Icosane. In order to minimized any vibration coming from head, abdomen and wings they were fixed using dental glue. In order to avoid antenna movement the $1^{\text {st }}$ segment was fixed to head capsule. As a results, the only vibrating part was a sound receiver made of $3^{\text {rd }}$ antennal segment and its arista. To diminish any external vibration the whole setup was placed on the air table.

\section{Free fluctuations recordings:}

The free fluctuations were recorded using Politec Leaser Doppler Vibrometer (PSV400) by pointing the laser beam on the tip of the arista. In the absence of any external stimuli the only forces that act on the arista are thermal motions and intrinsic properties of sound receiver. The LDV allows very precise measurements of antennal velocity. A Fast Fourier Transform (FFT) of the velocity time trace was performed by the LDV software to extract frequency dependent velocity characteristic of the antenna fluctuations and power spectra. The power spectral density (PSD) of the fluctuations was calculated by integrating 
fluctuation power of frequencies between 100 and 1,500 Hz. The frequency where antennal fluctuations reached its peak was considered as individual best frequency (Ibf).

\section{Sound-induced antennal responses:}

A loudspeaker was used to generate pure tones of desired frequency. An attenuator was used to manipulate the sound intensity from 6-96 dB. An Emkay NR 3158 pressuregradient microphone was used to directly measure sound particle velocity at the position of the fly antenna. The antennal displacements were measured at the frequency matching fly Ibf. Amplification gains were calculated by dividing antennal displacement by microphone response. The ratio between the lowest and the highest gain was considered as a amplification gain. Compound action potentials (CAP) were monitored via electrolytically sharpened tungsten electrodes. The recording electrode was placed between $1^{\text {st }}$ antennal segment and the head capsule near the antennal nerve and the reference electrode in the thorax. The antennal CAP responses of each individual were normalized, plotted against sound particle velocity or antennal displacement and fitted using Hill-equation. The hearing thresholds were defined as a sound particle velocity or antennal displacement that correlates to $10 \%$ of maximum CAP amplitude from the Hill fit. 


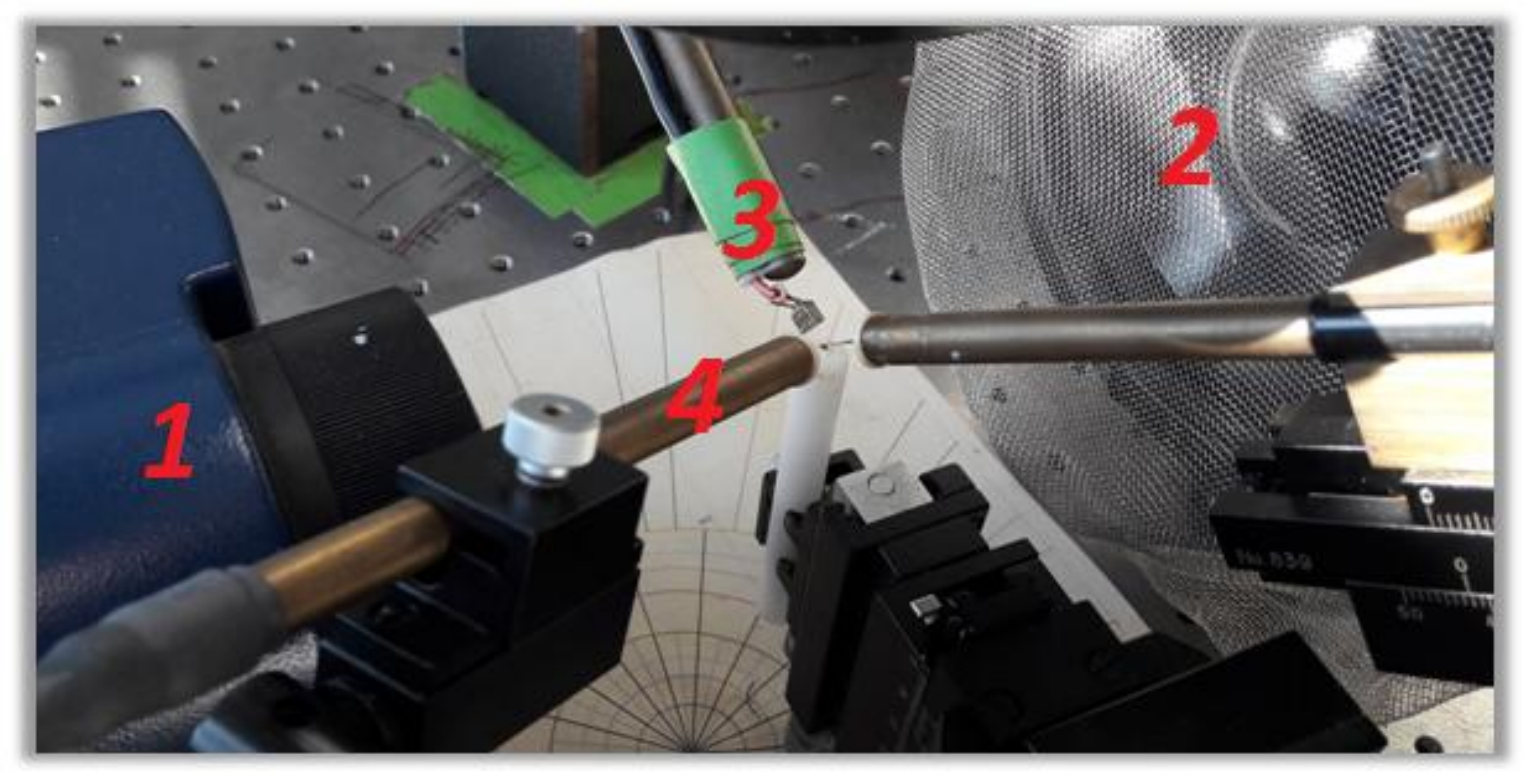

Figure 3. Experimental setup to probe antennal mechanics and electrophisiology.

Picture showing experimental setup. Fly is mounted on the top of plastic rod. (1) Laser Doppler Vibrometer (LDV), (2) speaker, (3) microphone, (4) electrodes.

\section{II.IV. Prolonged depolarizing afterpotential (PDA) recordings:}

In order to observe PDA phenotype in flies, ERG recordings were performed. Drosophila fly was mounted on plastic rod in similar way as described in (2.3.1). The blue light (470nm) and orange light (590nm) was delivered by Superluminescent LED (catalog no. LB W5SN-GYHZ-25-Z, LY W5SN-JYKY-46, Mouser electronics). LED's were mounted ca. $10 \mathrm{~cm}$ in front of the fly. The resulted ERG traces were recorded via tungsten electrode inserted in the eye and reference electrode placed in thorax. Fly was adopted in complete darkness for $5 \mathrm{~min}$ and stimulated with sequence of light pulses orange-blue-blueorange-orange, each pulse 10s long with 10 seconds dark intervals. 


\section{II.V. Immunohistochemistry:}

\section{II.V.I. Adult Johnston's organ staining:}

The flies were anaesthetized on the $\mathrm{CO}_{2}$ pad. The heads were dissected and fixed in $4 \%$ PFA $+0,3 \%$ PBST $\mathrm{pH} 7.4$ for $1 \mathrm{hr}$ RT. Then, the heads were embedded in preheated gelatin-albumin solution in small silicon moulds, cooled down at $4^{\circ} \mathrm{C}$ for $5 \mathrm{~min}$ and post fixated in $6 \%$ PFA at $4{ }^{\circ} \mathrm{C}$ overnight. On the next day blocks were incubated for 20 min in methanol and then transferred to PBS pH 7.4. The fly antennae were then cut in $40 \mu \mathrm{m}$ slices using Leica vibrotome and proceed with antibody staining.

The section were blocked in blocking solution for $1 \mathrm{hr}$ RT and then incubated with primary antibody diluted in the same solution at $4^{\circ} \mathrm{C}$ overnight with constant agitation. On the next day sections were washed 4 times in $0,05 \%$ PBST for $20 \mathrm{~min}$, followed by incubation with secondary antibodies diluted in $0,05 \%$ PBST for $3 \mathrm{hr}$. Then, the sections were washed 4 times in $0,05 \%$ PBST for 20 min and once in DABCO solution for 10 min. The samples were then mounted on the glass slides in DABCO and stored at $4^{\circ} \mathrm{C}$ until subjected for confocal imaging using Leica SP2 confocal microscope. The images were analyzed and processed using ImageJ software.

\section{II.V.II. Larva Ich5 staining}

Larva was put on the petri dish filled with PBS pH 7.4 and cut parallel to the body axis, the guts were removed leaving body wall neurons exposed. The preparation was washed 3 times for $10 \mathrm{~min}$ in PBS and then, fixed with 4\% PFA in 0,3\% PBST for 40 min RT. The tissue was washed 3 times for 30 min in PBS pH 7.4 then, washed once again with $0.3 \%$ PBST for 20 min. Larval filet was then incubated in the blocking solution for $1 \mathrm{hr}$ RT. The primary antibodies were diluted in the blocking solution and incubated with the sample overnight at $4^{\circ} \mathrm{C}$ with agitation. On the next day samples were washed 5 times with 0.1\% PBST for 20 min. Secondary antibodies were diluted in PBST and incubated with samples for $4 \mathrm{hr}$ RT and washed again in PBST thrice for $20 \mathrm{~min}$, and finally mounted on the glass slides with DABCO. 


\section{II.VI. Fly husbandry}

\section{II.VI.I. Regular fly food}

Standard fly composition:

\begin{tabular}{|l|l|}
\hline Ingredients: & Quantity: \\
\hline dry yeasts & $1000 \mathrm{~g}$ \\
\hline sugar & $1000 \mathrm{~g}$ \\
\hline salt & $40 \mathrm{~g}$ \\
\hline agar & $120 \mathrm{~g}$ \\
\hline flour & $500 \mathrm{~g}$ \\
\hline apple juice & 21 \\
\hline propionic acid & $60 \mathrm{ml}$ \\
\hline
\end{tabular}

Ingredients needed to prepare 141 of fly food.

To prepare 141 of standard fly food, $120 \mathrm{~g}$ of Agar was soaked in 51 of water overnight. On the next day $500 \mathrm{~g}$ flour, $1000 \mathrm{~g}$ yeast $40 \mathrm{~g}$ salt, $1000 \mathrm{~g}$ sugar were mixed in 6 liters of water and 21 of apple juice was added. The whole mixture was boiled at $100{ }^{\circ} \mathrm{C}$ in the Varioklav ${ }^{\circledR}$ Steampot DT44580604. When the temperature lowers to $65^{\circ} \mathrm{C} 60 \mathrm{ml}$ of propionic acid was added. Immediately after that empty vials were filled with $\sim 10 \mathrm{ml}$ of food. After cooling down overnight at $4^{\circ} \mathrm{C}$ the vials were closed with mite free plugs.

The flies were grown at $18^{\circ} \mathrm{C}$ or $25^{\circ} \mathrm{C}$ incubator with $60 \%$ humidity in $12 \mathrm{~h}$ light dark cycles. The flies were kept in plastic vials $1 / 4$ filled with fly food.

\section{II.VI.II. Vitamin A depleted food}

To prepare Vitamin A free fly food $2 \mathrm{~g}$ of agar was added to $100 \mathrm{ml}$ of water and boiled for $2 \mathrm{~min} .10 \mathrm{~g}$ of dry yeast and $10 \mathrm{~g}$ of sugar was added and boiled for 10 more 
minutes with stirring. After the temperature drops to $\sim 60^{\circ} \mathrm{C} 20 \mathrm{mg}$ of cholesterol was added. Then the food was poured to vials and used in deprivation assays.

\section{II.VII. Fly stocks used}

\begin{tabular}{|c|c|c|}
\hline Genotype: & Symbol: & Source: \\
\hline$w^{1118}$ & $w^{1118}$ & Lab stock \\
\hline$w[*] ; \operatorname{ninaD}[1] / S M 1$ & $\operatorname{ninaD}^{\prime}$ & BL 42244 \\
\hline$w[*] ;$ santa-maria[1] & santa-maria ${ }^{I}$ & BL 24520 \\
\hline $\begin{array}{l}w[1118] ; P\{y[+t 7.7] \\
w[+m C]=G M R 90 A 05-G A L 4\} a t t P 2 \\
\text { santa-maria GAL4 }\end{array}$ & santa-maria-GALA & BL 46905 \\
\hline $\begin{array}{l}w[*] ; \text { santa-maria }[1] ; P\{w[+m C]=U A S- \\
\text { santa-maria. } W\} 3\end{array}$ & UAS-santa-maria & BL 24519 \\
\hline$w[*] ; \operatorname{ninaB}^{360 d}$ & $\operatorname{ninaB}^{360 d}$ & $\begin{array}{l}\text { Kindly provided by Prof. } \\
\text { O'Tousa }\end{array}$ \\
\hline$w[*] ;$ sna $[$ Sco]/CyO; pinta[1] & pinta $^{l}$ & BL 24860 \\
\hline$w[*] ;$ pinta-GALA/TM3 & Pinta-GALA & self made \\
\hline$w[*] ; \operatorname{nina}^{P 330}$ & $\operatorname{nina} G^{P 330}$ & $\begin{array}{l}\text { Kindly provided by Prof. } \\
\text { O'Tousa }\end{array}$ \\
\hline$w[*] ;$ ninaG-GALA/TM3 & ninaG-GALA & self made \\
\hline $\begin{array}{l}w[*] ; P\{w[+m C]=P d h[+t 1.5]\} 2 ; \\
T I\{w[+m W \cdot h s]=T I\} P d h[1] s t[1]\end{array}$ & $P d h^{l}$ & BL 32077 \\
\hline$w[*] ; P d h-G A L A / T M 3$ & Pdh-GALA & Self made \\
\hline$w[*] ; \operatorname{sr}[1] \operatorname{ninaE}[17]$ & ninaE $E^{17}$ & Kyoto DGGR 109599 \\
\hline$y[1] w[*] ; \operatorname{sr}[1] \operatorname{ninaE}[17]$ & ninaE $E^{17}$ & Kindly provided by Prof. Britt \\
\hline$w[*] ; r d h B^{I}$ & $r d h B^{I}$ & $\begin{array}{l}\text { Kindly provided by Prof. } \\
\text { Montell }\end{array}$ \\
\hline $\begin{array}{l}P\{w[+m C]=r d h B-G A L A . W\} 1, w[1118] ; \\
\text { sna[Sco]/CyO;TM2/MKRS }\end{array}$ & rdhB-GAL4 & BL 24501 \\
\hline$w[*] ;$ Dnai2-GALA & Dnai2-GALA & Kindly provided by Dr. Karak \\
\hline $\begin{array}{l}y[1] w[*] ; w g[S p-1] / C y O, P\{\text { Wee- } \\
P . p h 0\} \text { Bacc[Wee-P2O];P\{y[+t7.7] } \\
w[+m C]=20 X U A S-6 X G F P-M y c\} a t t P 2\end{array}$ & $U A S-G F P$ & BL 52261 \\
\hline $\begin{array}{l}w[1118] ; P\{w[+m C]=U A S- \\
\text { RedStinger }\} 4 / C y O\end{array}$ & UAS-nuclear RFP & BL 8546 \\
\hline$w[*] ;$ so[1] & $s o^{[1]}$ & BL 401 \\
\hline$\left.w L^{*}\right] ; P\{\text { pinta }\}^{+}$ & pinta $^{+}$ & Self made \\
\hline$w[*] ; P\{P d h\}^{+}$ & $P d h^{+}$ & Self made \\
\hline$w[*] ; P\left\{R h 1\left[y^{+}\right]\right\}$ninaE $E^{17}$ & ninaE rescue & Kindly provided by Prof. Britt \\
\hline $\begin{array}{l}y[1] w[*] ; M i\{P T- \\
\text { GFSTF.0\}alphaTub85E[MI08426- } \\
\text { GFSTF.0] }\end{array}$ & Tub85E-GFP & BL 60267 \\
\hline$w[*] ;$ Santa-maria ${ }^{T G E M}$ & Santa-maria ${ }^{T G E M}$ & Made by GenetiVision \\
\hline
\end{tabular}




\begin{tabular}{|c|c|c|}
\hline$y[1] w[*] ; M i\{M I C\}$ sosie $^{M I I 265}$ & sosie & BL 58547 \\
\hline$y[1] w[*] ; M i\{M I C\} C G 14085^{M 111086}$ & $C G 14085^{\text {MiMIC }}$ & BL 56121 \\
\hline$y[1] w[*] ;$ sosie $^{\text {Trojan }}-$ GAL4 & sosie $^{\text {Trojan }}$-GALA & Self made \\
\hline$y[1] w[*] ; C G 14085^{\text {Trojan }}-$ GALA & $\begin{array}{l}\text { CG14085 } \\
\text { GALA }\end{array}$ & Self made \\
\hline
\end{tabular}

\section{II.VIII. List of antibodies used}

Anti-GFP chicken, catalog no. GTX13970 GeneTex (1:1000)

Anti-RFP Rat, catalog no. 5F8, Chromotek (1:1000)

Anti- $\alpha$ Tub85E, kindly provided by Prof. Dr. A. Salzberg, (Halachmi et al., 2016) (1:500)

Anti-NOMPC rabbit, kindly provided by Prof. Dr. Yuh-Nung Jan (1:300)

Anti-Iav rat, kindly provided by Prof. Dr. Changsoo Kim (1:300)

Cy3-conjugated goat anti-HRP, catalog no. 123165021 Jackson ImmunoResearch (1:500)

Alexa Fluor 488 anti-chicken catalog no. A21316 ThermoFisher Scientific (1:300)

Alexa Fluor 488 anti-rabbit catalog no. A11008 ThermoFisher Scientific (1:300)

Alexa Fluor 633 anti-rabbit catalog no. A21094 ThermoFisher Scientific (1:300)

Alexa Fluor 633 Phalloidin catalog no. A22284 ThermoFisher Scientific (1:300) 


\section{Chapter 1: Chromophore-independent roles of Drosophila opsin apoproteins and visual cycle components.}

\subsection{Introduction}

\subsubsection{The Drosophila visual system.}

As in most insects the Drosophila vision is based on compound eye made of approximately 750 hexagonal, columnar units called ommatidia (Pak et al., 2012). Each ommatidium consists of 20 cells in which there are 8 photoreceptor cells (R1-R8) and set of accessory cells (Leung and Montell, 2017). The main photoreceptors R1-R6 occupy the outer part of ommatidium, whereas photoreceptors $\mathrm{R} 7 / \mathrm{R} 8$ are located in the centre part (Montell, 2012). There are also two types of accessory cells surrounding the photoreceptor cells: secondary retinal pigment cells $\left(2^{\circ} \mathrm{PC}\right)$ and tertiary retinal pigment cells $\left(3^{\circ} \mathrm{PC}\right)(\mathrm{Pak}$ et al., 2012). Each photoreceptor contains rhabdomere, which is a densely packed stack of membranes (microvili) where phototransduction takes place. These membranes are filled with the light sensor molecules - rhodopsins (Montell, 2012). The Drosophila genome encodes for 7 different rhodopsins with 6 expressed in photoreceptors (Grebler et al., 2017). The most abundant rhodopsin is Rhodopsin1 (Rh1) which is a product of the ninaE gene. It is present in photoreceptors R1 - R6 and absorbs maximally at 486nm (O'Tousa et al., 1985). Minor rhodopsins Rh3-R6 are expressed in photoreceptors R7-R8 and show maximal spectral sensitivity at 331, 355, 442 and $512 \mathrm{~nm}$ respectively (Salcedo et al., 2003). 


\subsubsection{Rhodopsin}

Rhodopsins belong to the G protein-coupled receptor (GPCR) family. They are made of an apoprotein molecule opsin and covalently linked light sensitive unit chromophore (Figure 4) (Wald, 1938, 1968). Opsins are expressed in photoreceptor cells and after maturation are embedded in the cell membrane by seven trasmembrane domains (Ozaki et al., 1993). The chromophore, 11-cis-hydroxy-retinal binds to lysine in the seventh transmembrane domain via Shiff base linkage (Vogt and Kirschfeld, 1984). Upon light stimulation, rhodopsin is activated to metarhodopsin by cis to trans photo-izomerization of the chromophore. This in turn leads to conformational changes in the opsin subunit that triggers GDP-GTP exchange in a heteromeric G-protein (Dolph et al., 1993). The effector molecule of heterometic G-protein in Drosophila is phospholipase C (PLC), which hydrolyzes phosphatidylinositol 4,5-bisphosphate (PIP2) resulting in opening of the TRP and TRPL ion channels (Scott et al., 1995).

\subsubsection{Visual chromophore}

All animals depend on dietary intake of Vitamin A and its precursors (provitamins, mainly $\beta$-carotene) to support the synthesis of the visual chromophore (Kiefer et al., 2002). In contrast to vertebrates where Vitamin $\mathrm{A}$ is implicated in multiple processes besides vision (Lane and Bailey, 2005), in Drosophila it is exclusively used in the retina for the chromophore synthesis (Wang, 2005). There, the visual chromophore serves two main functions. First, as mentioned previously, it captures light photons which activates rhodopsin and starts the visual cascade. Second, the chromophore is necessary for opsin synthesis in endoplastic reticulum, where it acts as a molecular chaperone (Colley et al., 1991). In absence of the chromophore opsin cannot exit the ER and eventually gets degraded (Wang et al., 2007). As a consequence, diminished rhodopsin levels leads to a severe vision deficiency and degeneration of photoreceptors R1 - R6. (O'Tousa JE1, Leonard DS, 1989). 


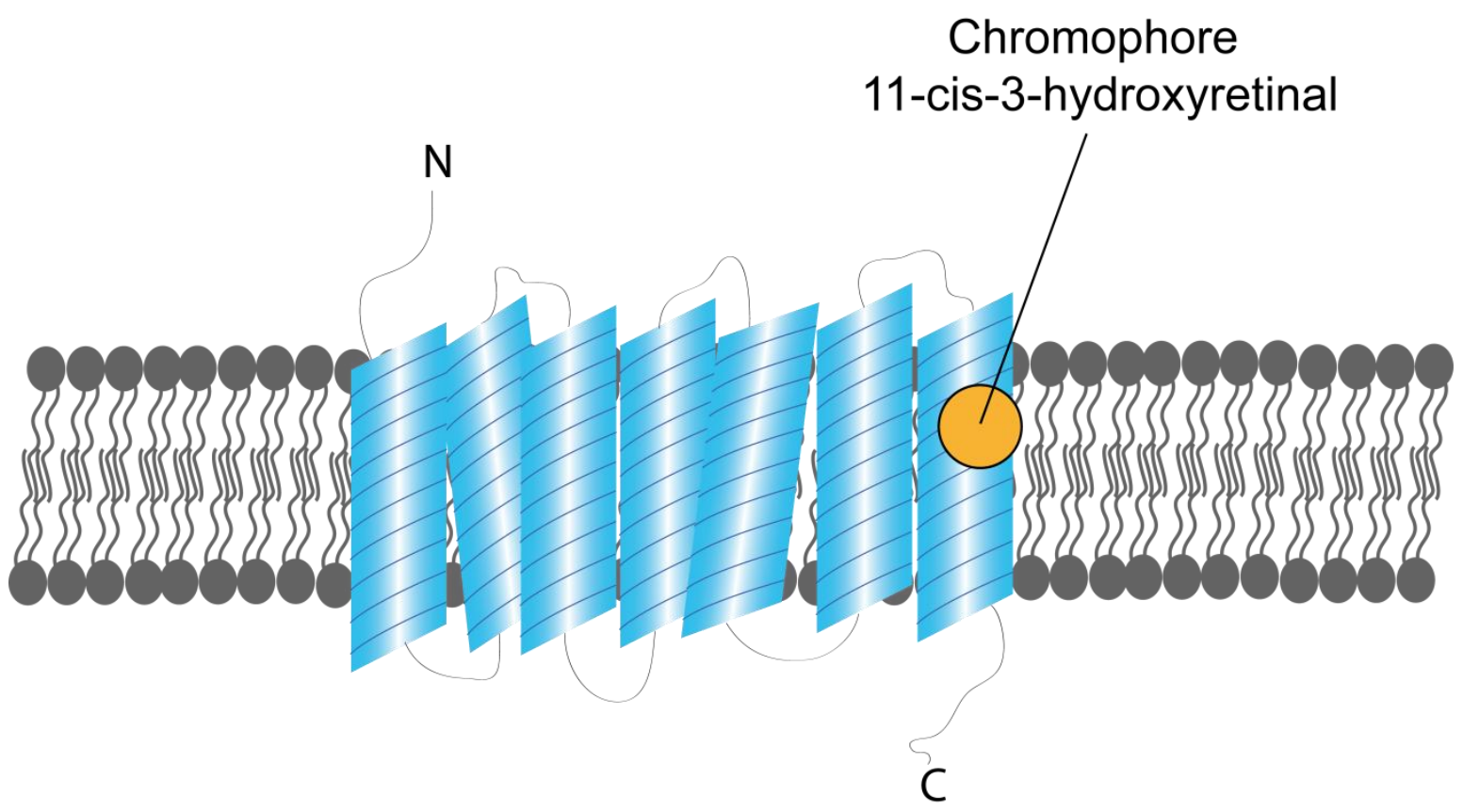

Figure 4. Rhodopsin sketch

Rhodopsin is composed of seven transmembrane domain protein- opsin and a light-sensitive chromophore 11cis-3-hydroxyretinal.

\subsubsection{Chromophore generation pathway and recycling}

The 11-cis-3-hydroxy-retinal synthesis pathway involves several proteins responsible for $\beta$-carotene uptake, cleavage, transport and multistep enzymatic reactions. The intake of carotenoids take place in the midgut, and depends on specialized scavenger receptor NINAD (Kiefer et al., 2002). It has a significant sequence homology to mammalian class B scavenger receptors, SR-BI and CD36 which besides participation in carotenoid uptake are also implicated in lipoproteins metabolism (Steinbrecher, 1999). However, flies seem to utilize it exclusively for $\beta$-carotene intake (Kiefer et al., 2002).

Later, $\beta$-carotene can be hydroxylated to form zeaxanthin $(3,3$-dihedroxy $\beta, \beta$ carotene) and subsequently stored in fat body or immediately used for further chromophore production (Giovannucci and Stephenson, 1999). Circulating $\beta$-carotene is then taken up by another scavenger receptor class B - SANTA-MARIA expressed in the neurons and glia in 


\subsection{Introduction}

the brain (Wang et al., 2007). Subsequently, the $\mathrm{C}_{40}$ carotenoid backbone chain is symmetrically cleaved yielding two $\mathrm{C}_{20}$ retinoids (all-trans retinal). This crucial reaction in chromphore synthesis is catalyzed by $\beta, \beta$-carotene-15,15'-monooxygenase (BCO) encoded by ninaB gene (Lintig and Vogt, 2000). Moreover, it was shown that NINAB also catalyzes the izomerization of all-trans to 11-cis retinal that can directly serve as a chromophore for opsin (Oberhauser et al., 2008). In blind ninaB mutant flies vision can be restored by supplying the flies with all-trans retinal, whereas ninaD and santa-maria mutants need $\beta$ carotene to bring back normal light perception (Wang et al., 2007).

The next player in biogenesis of the visual chromophore is PINTA- a retinoid binding protein (RBP) which belongs to CRAL-TRIO family of proteins (Wang, 2005). It is expressed in the retinal pigment cells in the eye where it preferentially binds retinol (Wang, 2005). Nonetheless, the cellular function of PINTA is still not well-defined (Pak et al., 2012). Subsequent steps of chromophore synthesis involve activity of NinaG (Sarfare et al., 2005). This protein belongs to the glucose-methanol-choline (GMC) oxidoreductase enzyme family and participates in the conversion of (3R)-3-hydroxyretinol to the $3 \mathrm{~S}$ enantiomer (Ahmad et al., 2006). In flies, only Rh1 utilize (3S)-3-hydroxyretinol as its chromophore, other rhodopsins use the $3 \mathrm{R}$ enantiomer. Thus, only $\mathrm{Rh} 1$ production is affected in nina $G$ mutant flies.

In flies, as in vertebrates, the photoconverted chromophore product 3-OH-all-transretinal dissociate from rhodopsin and is regenerated through the visual pathway (Wang et al., 2010). This pathway is crucial in Drosophila to maintain chromophore levels under carotenoid deficiency conditions that prevent them from generating the new chromophore. So far two dehydrogenases have been discovered to participate in the chromophore recycling: PDH (pigment cell dehydrogenase) and RDHB (retinal dehydrogenase) (Wang et al., 2010, 2012). The pathway also includes an unknown isomerase that converts all-trans3-hydroxyretinol to 11-cis-3-hydroxyretinol (Montell, 2012). All these enzymatic reactions occur in the photoreceptor accessory cells- retinal pigment cells (RPC). When exposed to constant light $P d h$ and $r d h B$ mutant flies show progressive retinal degeneration caused by chromophore depletion and as a consequence reduced Rh1 levels (Wang et al., 2012). 


\subsubsection{Non visual roles of rhodopsins}

During past 130 years rhodopsins were investigated extensively. Series of studies focused on describing protein structure, activation mechanism and the visual transduction cascade (Leung and Montell, 2017; Montell, 2012; Sakmar et al., 2002). A dogma was that opsins act exclusively as light sensors in photoreceptor cells. However, over the last years this has changed as more evidence suggests that Drosophila opsins also serve non visual functions.

In larvae, the main visual rhodopsin Rh1 was found to be implicated in temperature sensing (Shen et al., 2011). Wild-type larvae have a strong thermal preference to $18^{\circ} \mathrm{C}$ and their comfortable range is $19^{\circ}$ to $24^{\circ} \mathrm{C}$ (Kwon et al., 2008). Unexpectedly, rhl mutants turned out to be defective in temperature discrimination between $18^{\circ}$ and $24^{\circ} \mathrm{C}$ (Shen et al., 2011). This thermotactic behavior was independent of light, but turned out to require a chromophore since eliminating $\beta$-carotene form a diet or disrupting chromophore synthesis in santa-maria ${ }^{1}$ mutants cause comparable effects to rhl mutants. Hence, both opsin and its chromophore are needed for larval thermosensation. The authors suggested that in this case the chromophore may play a similar role as in adult photoreceptors, where besides being a light sensitive molecule it also serves as a chaperone for maturating opsin (Ozaki et al., 1993).

Later studies proposed that Rh5 and Rh6 are not only required in larval Bolwig's organ for light perception but also for thermal selection during last stage of larval development (Sokabe et al., 2016). Larvae experience a switch from Rh1 mediated thermosensation in early to mid $3^{\text {rd }}$ instar to multiple opsins like Rh5 and Rh6 in late $3^{\text {rd }}$ instar. These two opsins seem to function in trpAl expressing neurons in the brain and body wall. As with Rh1, Rh5 and Rh6 functions are light independent and depend on visual chromophore (Sokabe et al., 2016).

Another surprising finding was that opsins are crucial for mechanotransduction in adult flies (Senthilan et al., 2012). The work of Senthilan and colleagues in 2012 revealed that Rh5 and Rh6 are implicated in Drosophila auditory processing. Both are expressed in JO neurons where they contribute to mechanical amplification and sound-evoked electrical 


\subsection{Introduction}

responses. Mutation of either $r h 5$ or rh6 results in almost complete loss of JO neuron motility, abolished amplification gain and reduction in sound evoked potentials. Likewise, opsins in larval temperature discrimination, $\mathrm{Rh} 5$ and $\mathrm{Rh} 6$ also seem to require the visual chromophore for hearing in adults (Senthilan et al., 2012). Mutant flies for santa-maria gene show comparable auditory impairments to rh6 and rh5 mutants (Senthilan et al., 2012). Moreover, SANTA-MARIA seem to also operate in JO neurons since driving $U A S$ santa-maria transgene with chordotonal neurons specific driver JO15-GAL4 in santamaria $^{l}$ mutant background restored normal hearing (Senthilan et al., 2012).

Few years later opsins were reported to be involved in proprioreception in Drosophila larvae (Zanini et al., 2018). Authors showed that lack of Rh1 and Rh6 lead to severe crawling defects including reduction of speed, increase in turning frequency and longer time to advance one body length. Both opsins were shown to be present in proprioceptive pentameric chordotonal organs (lch5), the main organs providing locomotory feedback in larvae (Caldwell et al., 2003; Zanini et al., 2018). Each lch5 organ is comprised of five monodendritic sensory neurons and set of accessory cells, and Rh1 and Rh6 expression was restriced to dendrides of these neurons (Zanini et al., 2018). Interestingly, the correct ciliary localization of mechanotransduction channels NOMPC and IAV seem to depend on Rh1 and Rh6. In absence of these opsins NOMPC mislocalize from the ciliary tip leaking down into endolymph space, whereas IAV was absent in some cilia (Zanini et al., 2018). Furthermore, rhl and rh6 mutants show strong defects in cilium ultrastructure (Zanini et al., 2018). Larvae that lack SANTA-MARIA showed similar crawling phenotype to this of opsin mutants, thus their functions seem to be chrmophore dependent. Unlike opsin function in larval thermosensation where they were proposed to act as a thermosensors, in larval locomotion Rh1 and Rh6 seem to play structural role keeping a proper ciliary organization.

Based on these findings one can clearly say that rhodopsins are not just light sensors. Besides vision, they are used to sense different modalities like hearing, thermosensation and proprioception. To serve these non visual functions, rhodopsins seem to require a visual chromophore, most probably for rhodopsin maturation and trafficking. Chromophore necessity for non-visual functions was investigated either by retinal depletion 
or testing santa-maria mutants. However, even though SANTA-MARIA is needed for $\beta$ carotene uptake in the brain, the initial substrate intake takes place in the gut and is mediated by the NINAD scavenger receptor.

This thesis focused on testing the hypothesis of chromophore dependent auditory roles of opsins. This was achieved by analyzing genes involved in chromophore synthesis, their expression patterns and by nutritional depletion of $\beta$-carotene. I also tested whether the main visual opsin Rh1 is needed for hearing, as in larval chordotonal organs for proprioception. 


\subsection{Results:}

Rhodopsins were long considered to exclusively act in light detection. Recent studies, however, showed that this might not necessarily be the case as various Drosophila rhodopsins were found to be involved in sensory modalities other than vision and light detection (Leung and Montell, 2017). Besides light-dependent functions Rh1, Rh5 and Rh6 were found to play light-independent roles in larval thermosensation (Shen et al., 2011; Sokabe et al., 2016); Rh5 and Rh6 in fly hearing (Senthilan et al., 2012) and Rh1,Rh6 in larval proprioception (Zanini et al., 2018). Thermosensory rhodopsin functions seem to involve the chromophore as eliminating the Santa-Maria receptor, or removing $\beta$-carotene from a diet, causes thermosensory defects as observed in rhodopsin mutants (Shen et al., 2011; Sokabe et al., 2016). Loss of Santa-Maria also impairs larval proprioception and fly hearing, and it was accordingly hypothesized that the chromophore would also be required for mechanosensory opsin functions (Senthilan et al., 2012; Sokabe et al., 2016).

The aim of this thesis was to systematically test this hypothesis using nutritional and genetic approaches. I started with re-analyzing hearing in mutant flies lacking Santa-Maria, which reportedly cause hearing defects (Senthilan et al., 2012).

\subsubsection{Scavenger receptor class B - SANTA-MARIA in Drosophila hearing}

\subsubsection{Auditory defects of santa-maria ${ }^{1}$ mutant flies}

First, free fluctuations of the fly's antennal sound receiver were monitored using laser Doppler vibrometry. Antennae of wild-type flies show self sustained oscillations in absence of external stimuli that arise from thermal motion and mechanical activity of Johnston's organ neurons (Göpfert and Robert, 2003). Fast Furier transforms (FFT) of the velocity traces were used to compute power spectra of the fluctuations. Motile JO neurons actively feed energy supporting antennal vibrations (Göpfert et al., 2005) that can be 
estimated by integrating the power spectral density (PSD) of the fluctuations for frequencies between 100 and $1500 \mathrm{~Hz}$. For control $w^{1118}$ flies, the respective fluctuation power was $1189 \pm 403 \mathrm{~nm}^{2} / \mathrm{Hz}$ (mean \pm 1 S.D., $\mathrm{N}=5$ ) (Figure $5 \mathrm{~A}$ ). The frequency at which velocity of fluctuations reaches its peak was considered as the individual mechanical best frequency (Ibf) of the antennal receiver, which for controls was $227 \pm 12 \mathrm{~Hz}$. As expected, santa maria ${ }^{1}$ mutant displayed ca. 10 times lower PSD $\left(136 \pm 13 \mathrm{~nm}^{2} / \mathrm{Hz}\right)$ and a higher Ibf $(595 \pm 81 \mathrm{~Hz})$ than the controls.

To further characterize mutant effects on hearing, the flies were exposed to pure tones of different intensities matching the antennal best frequency and the resulting receiver vibrations and compound action potentials were recorded (Figure 5B). For loud and faint sound stimuli, antennal displacements in controls linearly scaled with intensity, whereas a nonlinear scaling was found at intermediate intensities, boosting the vibrational response to faint sounds with an amplification gain of $10.5 \pm 1.7$. In santa-maria ${ }^{1}$ mutants, the antenna's displacement response was linearized, reducing the amplification gain to $1.65 \pm$ 0.4 .

The sound-evoked antennal nerve responses were measured as compound action potential (CAP). The measurements of maximum CAP responses showed high variability that comes from restrictions of the recording method. Main factors that influence measured values are the quality of the electrode and the distance of the inserted electrode from antennal nerve. Wild-type maximum CAP response was $16.1 \pm 10.8 \mu \mathrm{V}$, and in santamaria $^{l}$ mutants the amplitude was reduced $(5.7 \pm 3.9 \mu \mathrm{V})$ (Figure 5C).

The recorded nerve responses were normalized, plotted against the sound particle velocity, and then fitted with a Hill equation (Figure 5C). The sound particle velocity threshold (SPV threshold) defined as $10 \%$ of the maximum CAP amplitude, was $63 \pm 2$ $\mathrm{nm} / \mathrm{s}$ for control flies. Antennae of santa-maria ${ }^{l}$ flies were less sensitive to sound with thresholds of $0.12 \pm 0.06 \mathrm{~mm} / \mathrm{s}$. Another parameter tested was antennal displacement threshold, which refers to antennal displacement needed to elicit $10 \%$ of the maximum CAP response (Figure 5C). For wild-type flies, this displacement threshold was $78 \pm 5 \mathrm{~nm}$. Mutant santa-maria ${ }^{1}$ flies showed higher displacement thresholds of $62 \pm 7 \mathrm{~nm}$. 
The hearing deficits in satna-maria ${ }^{l}$ mutants are consistent with previous findings (Senthilan et al., 2012). Johnston's organ function is severely impaired, most prominent being a strong reduction in JO neuron motility as witnessed by the loss of mechanical amplification.
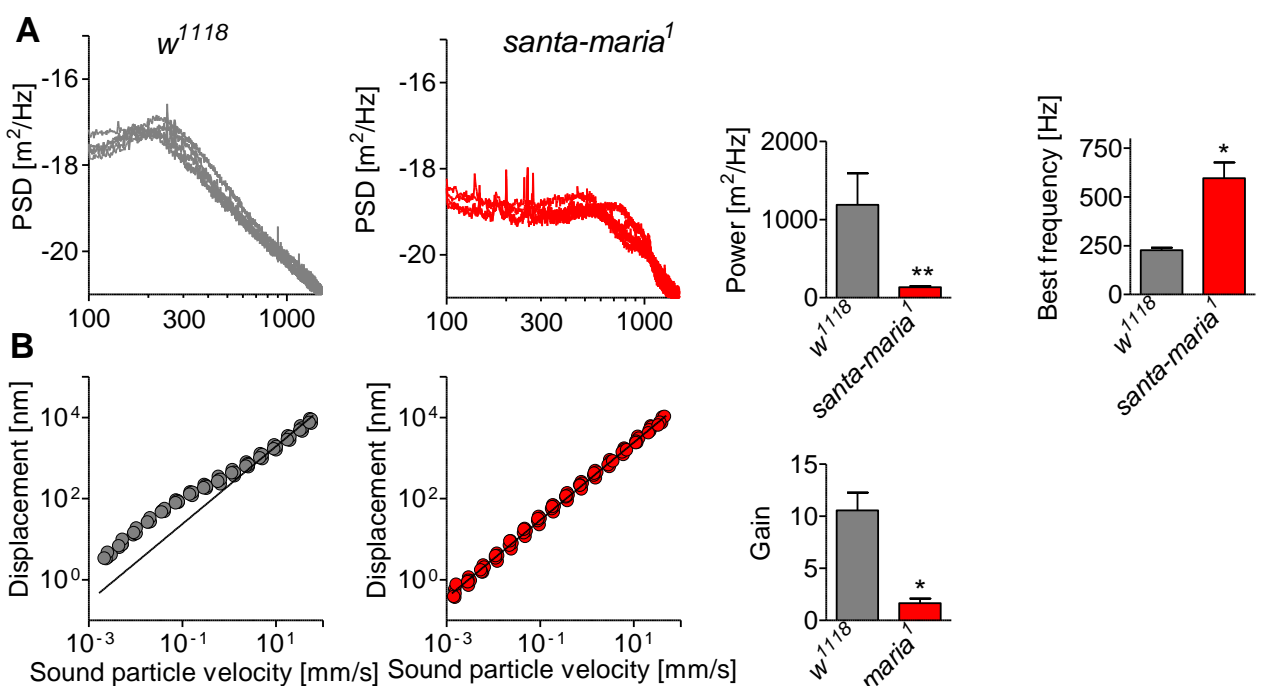

Sound particle velocity $[\mathrm{mm} / \mathrm{s}]$ Sound particle velocity $[\mathrm{mm} / \mathrm{s}]$
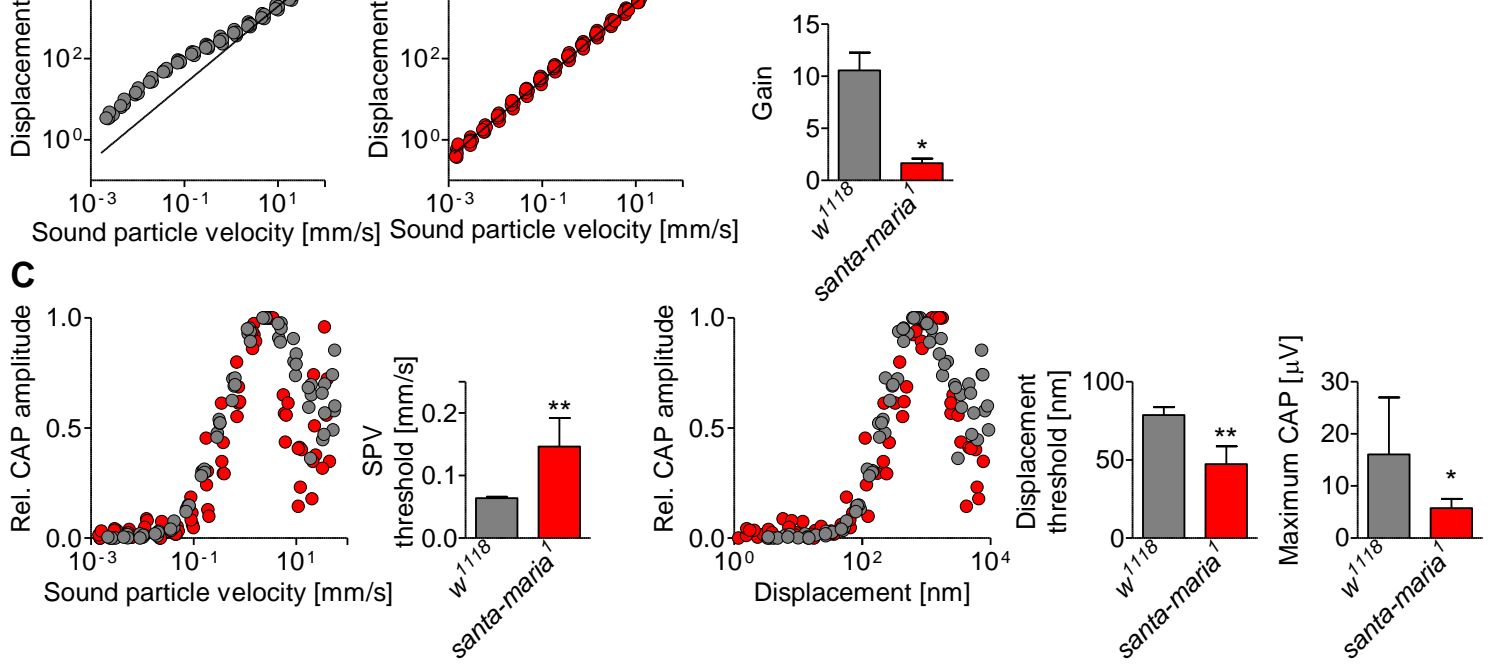

Figure 5. Biomechanical and sound evoked nerve responses analyses of wild-type and santa-maria ${ }^{I}$ mutant flies.

A) Left: power spectral density (PSD) of the free mechanical fluctuation of the antenna in the wildtype (gray) and santa-marial mutants (red) (N=5 per strain). Right: respective fluctuation powers and antennal best frequency.

B) Left: Tone-evoked antennal displacement as a function of the particle velocity of the tone. The black line indicates linearity. Right: respective mechanical amplification gain.

C) Left: Relative amplitude of toned-evoked CAPs as a function of the particle velocity of the tone and respective particle velocity threshold. Right: CAP amplitude plotted against the respective antennal displacement and corresponding displacement threshold. 
Data are presented as a mean values $\pm 1 \mathrm{SD}, \mathrm{N}=5, * \mathrm{P}<0.05, * * \mathrm{P}<0.01$ two-tailed Mann Whitney U-test.

\subsubsection{2 santa-maria expression pattern}

To assess the pattern of santa-maria expression, an existing santa-maria-Gal4 driver was used that was reported previously to target neurons and glia in the brain (Wang et al., 2007). After crossing this line to 20xUAS-6xGFP fluorescent reporter, no signal was detected in chordotonal organs of both larvae and adults. To enhance fluorescence signal I also generated flies carrying two copies of each transgene, but also here no expression in chordotonal organs could be seen (Figure 6). Thus, a recently developed method of generating Gal4 driver lines was employed that uses MiMIC-like Trojan exon constructs (T-GEM) that can be targeted via Crispr/Cas to the coding intron of the gene of interest enabling Gal4 expression in a pattern that mimics the native expression pattern (Diao et al., 2015). This approach enables to express GAL4 in the pattern that mimic the native site of gene expression (Diao et al., 2015). After crossing santa-maria ${ }^{T-G E M}$-Gal4 flies to flies carrying a 20xUAS-6xGFP reporter, the expression patter in larvae was examined. Already without anti-GFP staining, GFP fluorescence could be detected (Figure 7).
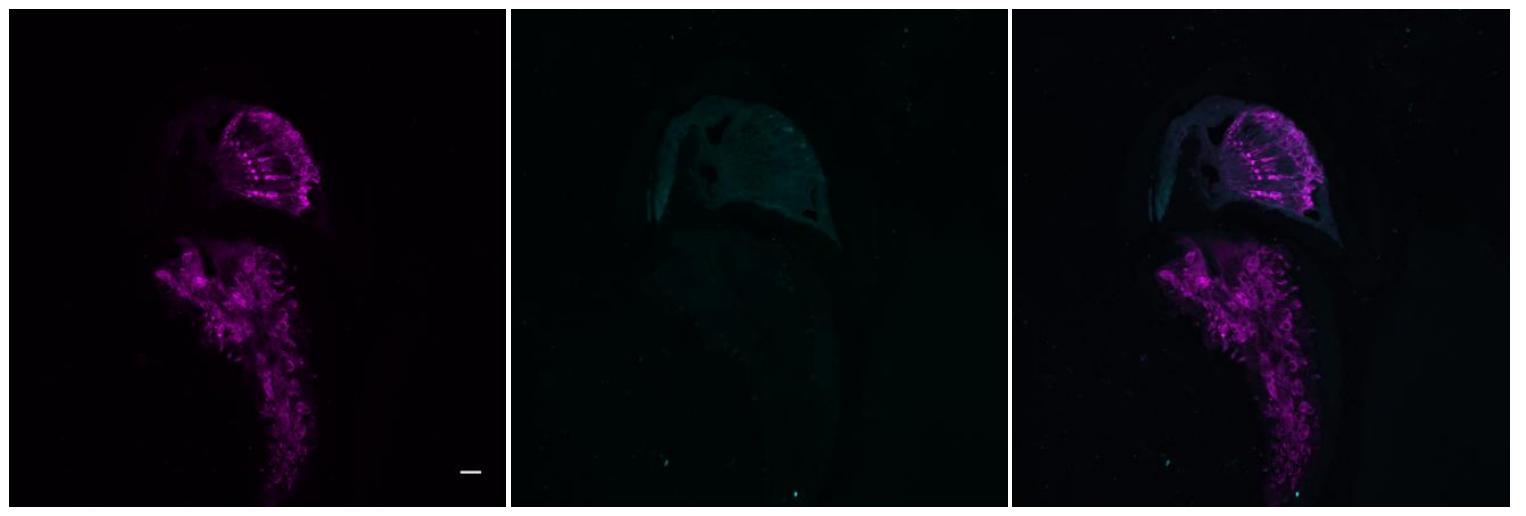

Figure 6. santa-maria-Gal4 expression pattern. Two copies of both santa-maria Gal-4 and 20xUAS-6xGFP were used. Anti-GFP staining of adult antennae did not yield any detectable signal (cyan) in the $2^{\text {nd }}$ or $3^{\text {rd }}$ antennal segments. Neurons are marked with anti-HRP (magenta). Scale bar $=10 \mu \mathrm{m}$. 


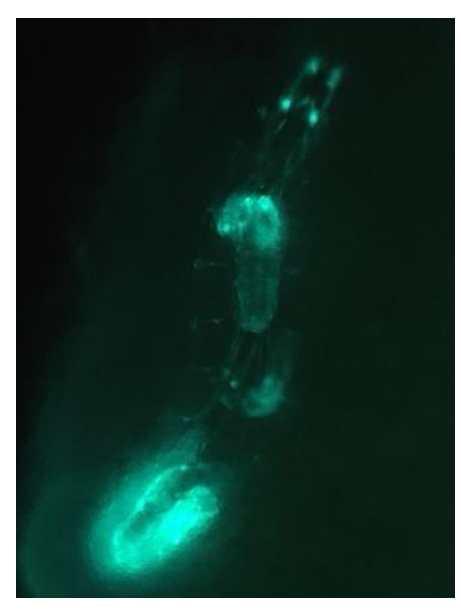

Figure 7. Epifluorescent image of the santa-maria ${ }^{T-G E M}$-Gal4 expression pattern in larva. GFP signals can be observed in Bolwig's organ, the brain, segmental nerves and the intestines.

To address whether Santa-Maria occurs in larval chordotonal neurons, immunochistohemistry staining on pentameric chordotonal organ (Ich5) was performed. The GFP signal seems to surround the cell bodies of lch5 neurons, their axon bundles, and other body wall sensory neurons (Figure 8). Counterstaining neurons with anti-HRP suggests that, within $1 \mathrm{ch} 5$, the peripheral glial cell that enwraps neuronal cell bodies and axons is Santa-Maria-positive.
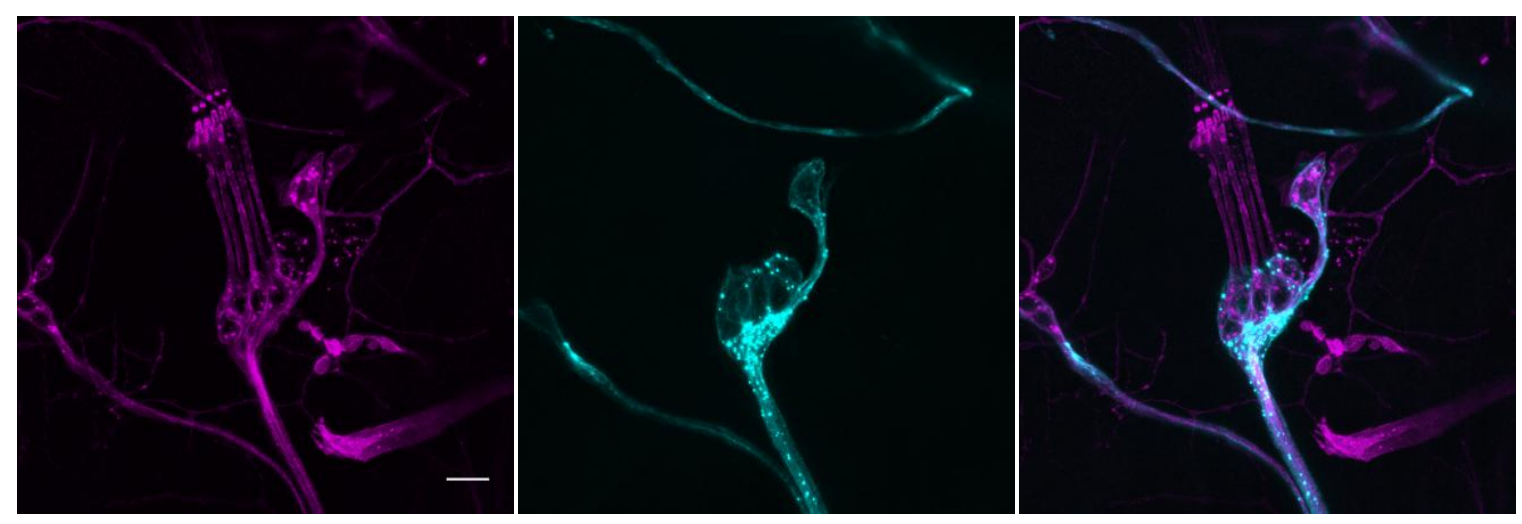

Figure 8. santa-maria ${ }^{T-G E M}$-Gal4 expression in larval lch5 chordotonal organ. Neurons of Ich5 organ marked with anti-HRP neuronal marker (magenta). GFP signal showed in cyan. On the right overlap picture. Scale bar $=10 \mu \mathrm{m}$. 
Immunohistochemical staining on sliced $2^{\text {nd }}$ antennal segment of adult flies also revealed broad santa-maria expression around somata and axons (Figure 9). Most probably stained structures are ligament cells and other glia cells.

The expression data suggests that santa-maria is expressed more broadly as suggested previously (Wang et al., 2007). Expression includes glia cells of chordotonal neurons and other sensory neurons in larvae as well as in adults (e.g. $3^{\text {rd }}$ antennal segment olfactory neurons, data not shown) and the larval gut, where expression was excluded based on the old driver (Wang et al., 2007).
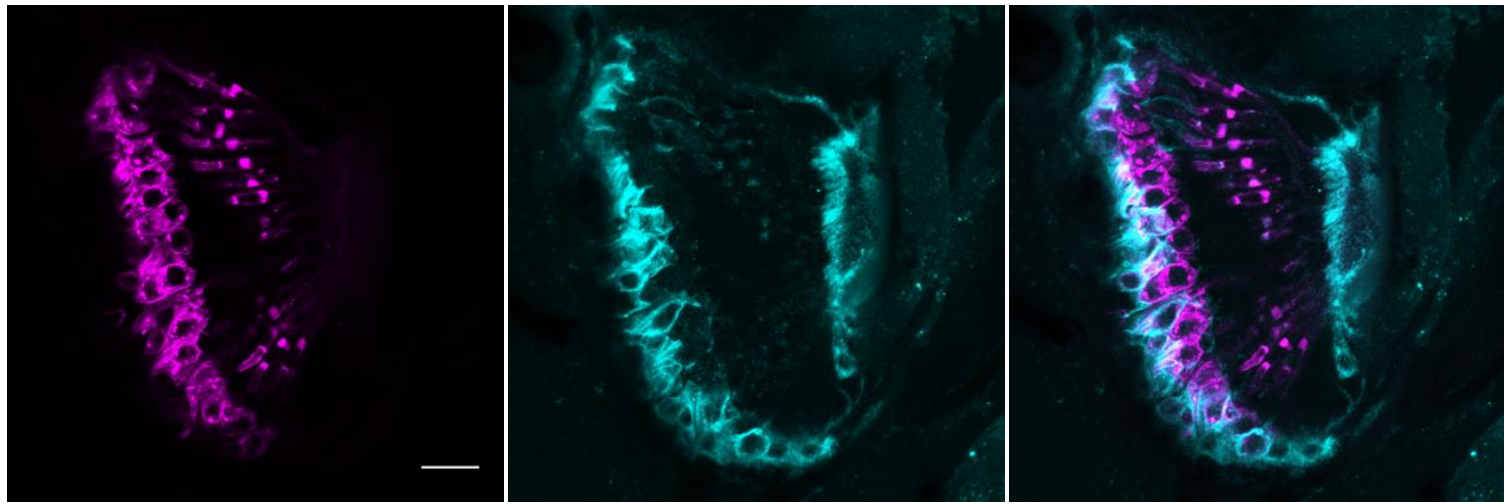

Figure 9. santa-maria ${ }^{T-G E M}$-Gal4 expression in Johnston's organ.

Anti-GFP staining of $2^{\text {nd }}$ antennal segment slices. Neurons are stained with HRP - magenta, GFP signal is shown in cyan. GFP signal was detected in glia cells enwrapping neuronal cell bodies and axons. Scale bar $=$ $10 \mu \mathrm{m}$.

\subsubsection{Localization of TRP channels in santa-maria ${ }^{1}$ mutants}

In Drosophila larvae, mutations in ninaE and Rh6 cause mislocalization of NOMPC and Nan-Iav TRP channels in lch5 cilia and impair cilium ultrastructure (Zanini et al., 2018). To test whether such phenotypes also arise from the loss of Santa-Maria, lch5 and JO of santa-maria ${ }^{1}$ mutants were stained with antibodies against NOMPC and Iav. HRP staining revealed no gross structural defects of the mechanosensory neurons, and the localization of TRP channels seemed normal with NOMPC being present in the tips of the 
cilia and Iav localizing more proximally to the basal cilium region (Figure 10, 11). Apparently, loss of opsins and santa-maria both affect hearing, but only the loss of opsins causes TRP channel mislocalization and ultrastructural cilium defects.

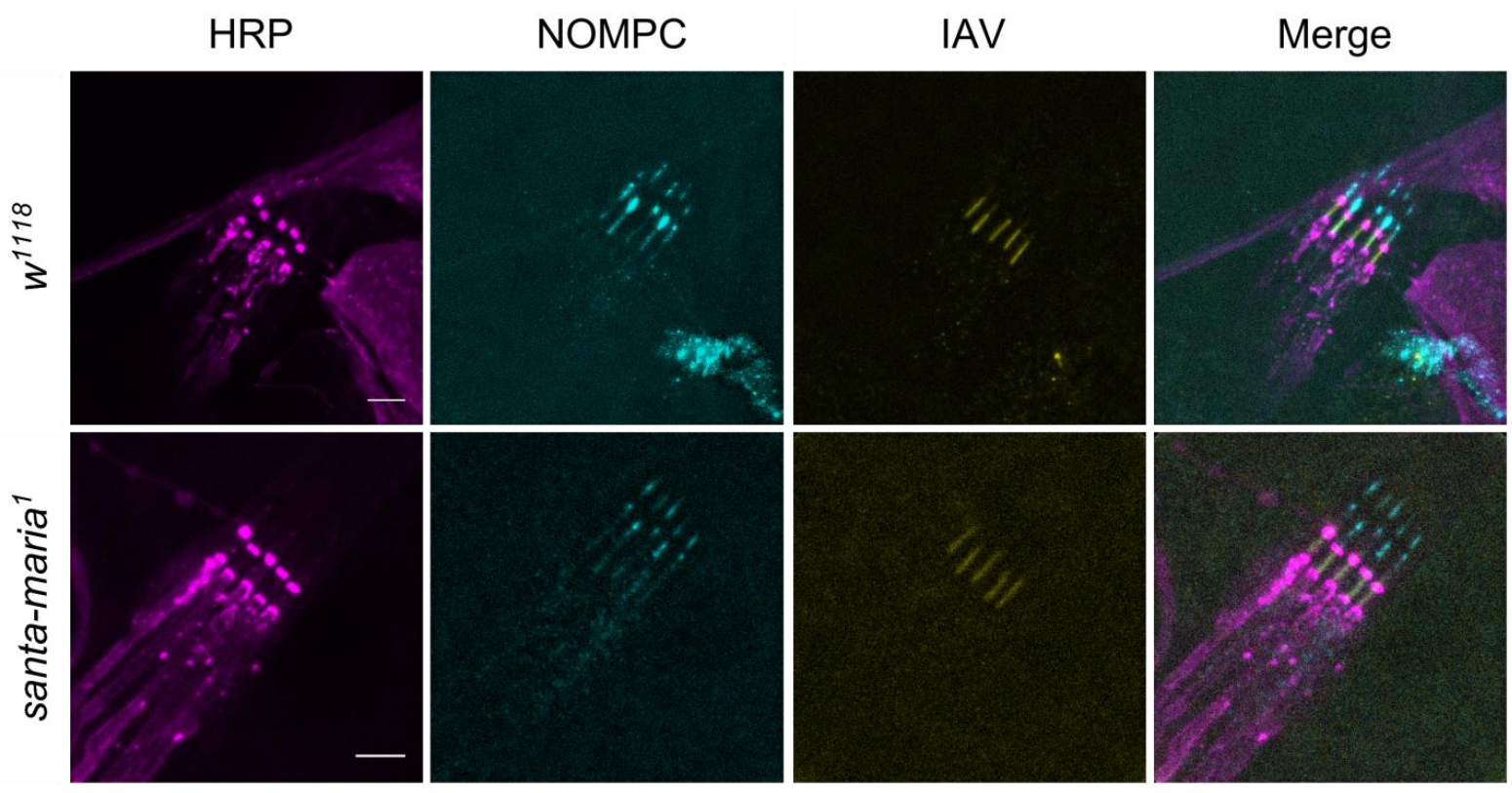

Figure 10. Localization of TRP channels in Ich5 organ in wild type and santa-maria ${ }^{I}$ mutant larvae.

Neurons are stained with HRP (magenta), anti-NOMPC staining is shown in cyan and anti-Iav staining in yellow. In the wild type, NOMPC is detected in the ciliary tip, whereas Iav resides more proximal between two HRP bands. No alterations of this pattern were detected in santa-maria ${ }^{l}$ mutants. Scale bars: $5 \mu \mathrm{m}$. 


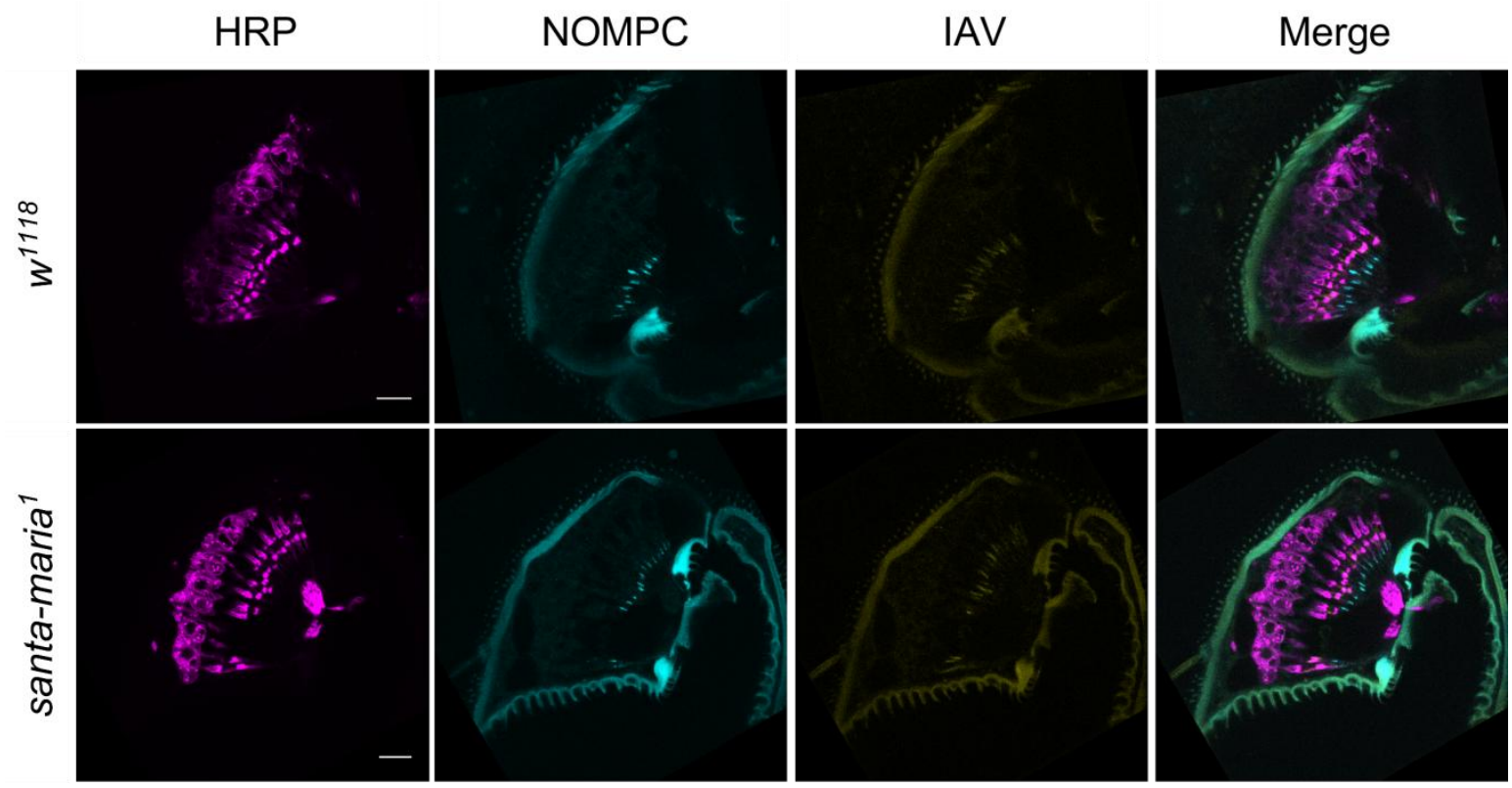

Figure 11. Localization of TRP channels in JO of wild type and santa-maria ${ }^{1}$ mutants.

Neurons are stained with HRP (magenta), anti-NOMPC staining is shown in cyan and anti-Iav staining in yellow. In the wild type, NOMPC is detected in the ciliary tip, whereas Iav resides more proximal between two HRP bands. No alterations of this pattern were detected in santa-maria ${ }^{l}$ mutants. Scale bars: $10 \mu \mathrm{m}$. 


\subsubsection{Tissue specific rescue of santa-maria mutants}

To test if genetic rescue of santa-maria restores normal hearing in santa-maria ${ }^{l}$ mutants, a rescue construct containing wild-type santa-maria was expressed in the santamaria $^{1}$ mutant background under the control of different Gal-4 drivers. First, I wanted to replicate the results of Senthilan et al (2012) and tested for rescue of hearing using a chordotonal neuron-specific driver. Instead of using JOI-Gal4, I decided to use the stronger driver Dnai2-Gal4 that was reported previously to specifically label chordotonal neurons (Karak et al., 2015). Second, because santa-maria ${ }^{\text {TGEM }}$-Gal4 showed staining in glia cells, I wanted to check whether expressing santa-maria under the control of the glial driver repo-Gal4 can restore hearing santa-maria ${ }^{l}$ mutants. Driving the expression of UASsanta-maria with either of these two Gal4 drivers partially rescued hearing. Compared to the mutants, antennal fluctuation powers and best frequencies were increased in the rescue flies (Figure 12A), and so was the mechanical amplification gain (Figure 12B). Also auditory sensitivity was partly restored, as witnessed by diminished particle velocity and displacement thresholds of sound-evoked CAPs (Figure 12C). 

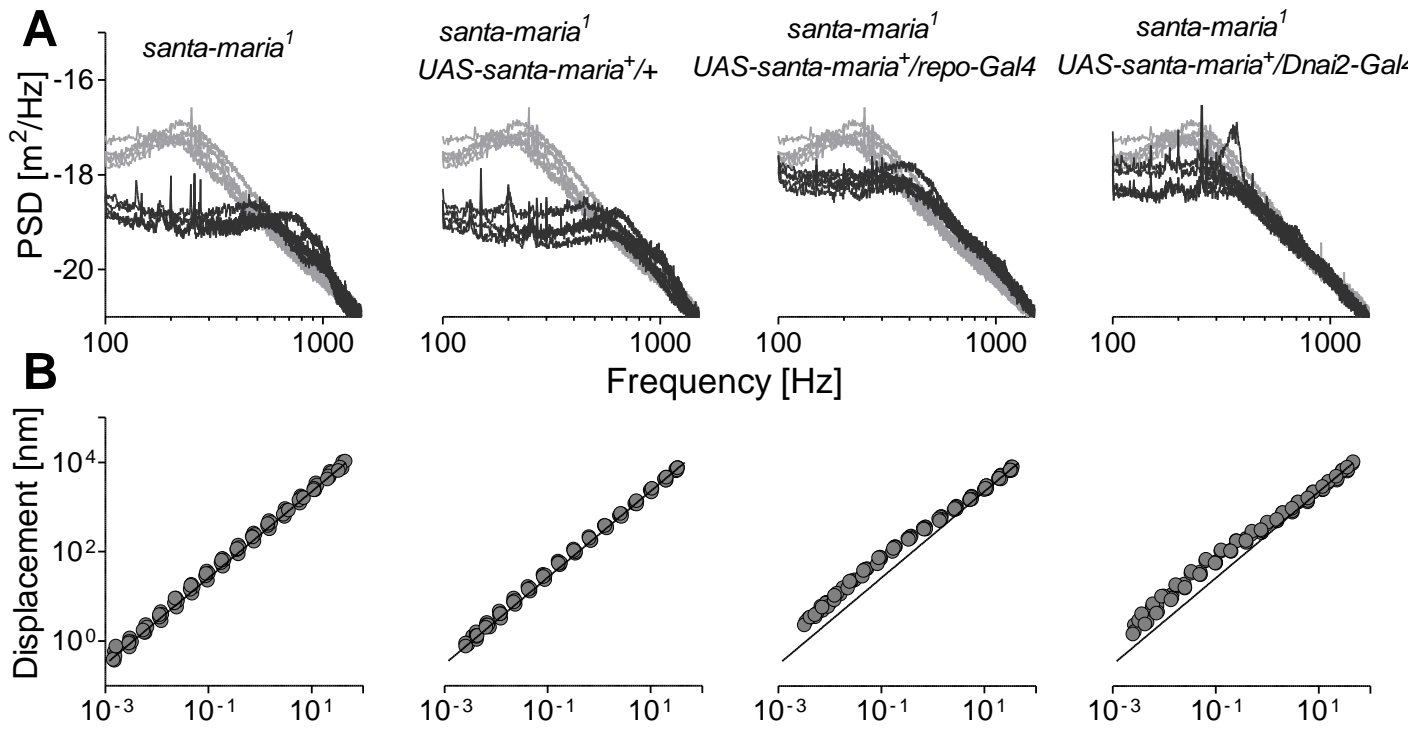

C

Sound particle velocity $[\mathrm{mm} / \mathrm{s}]$
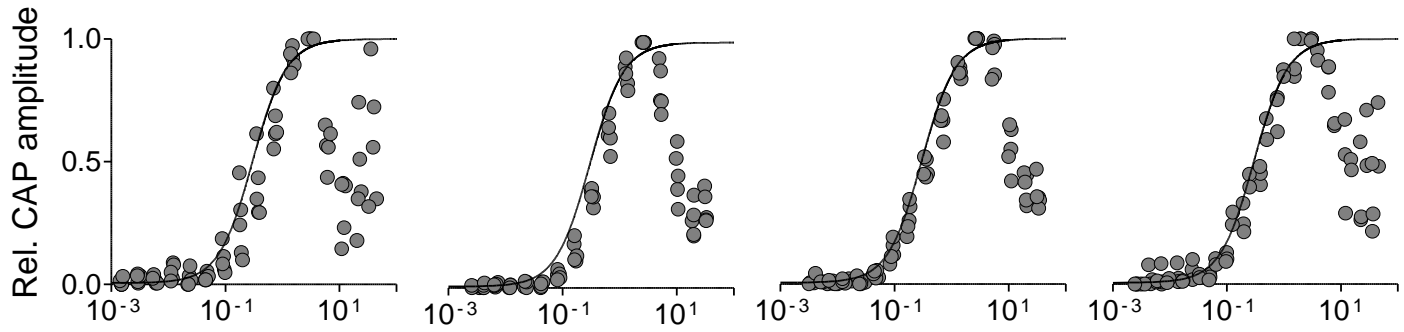

D

Sound particle velocity $[\mathrm{mm} / \mathrm{s}]$

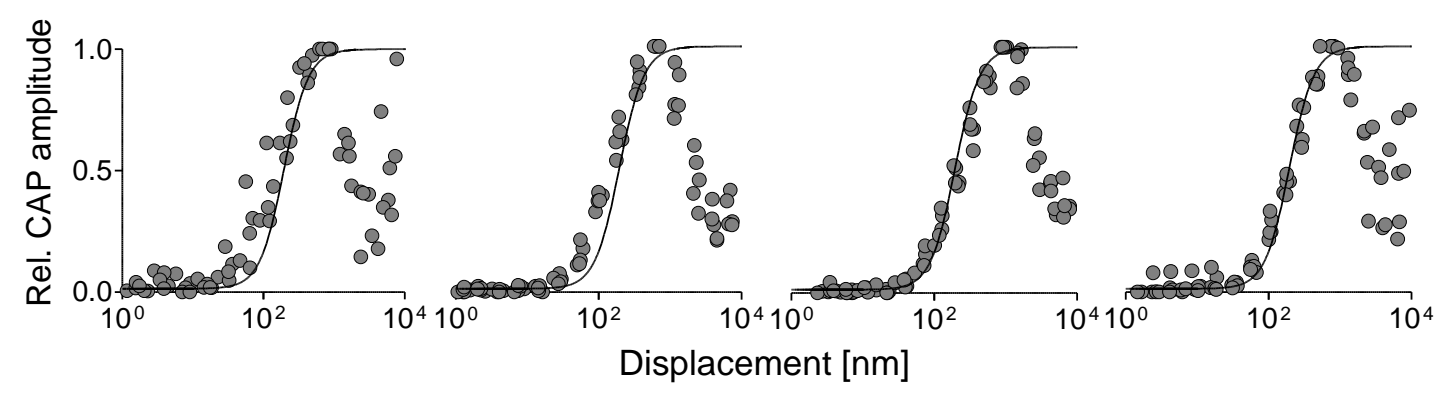

E
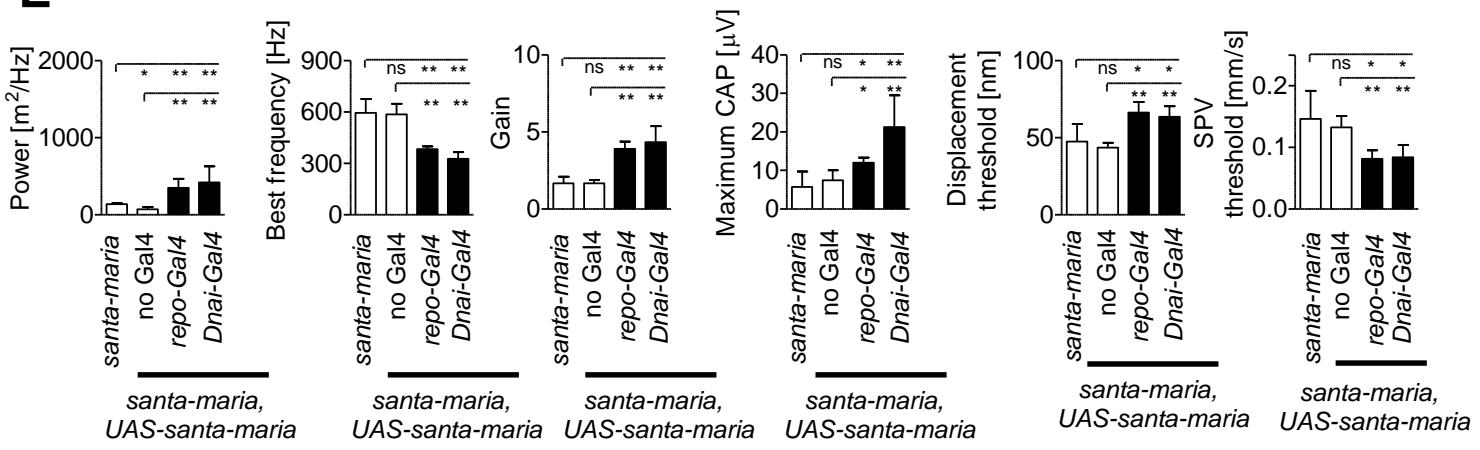

Figure 12. Laser Doppler analysis of santa-maria GAL4-UAS rescue. 
A) Power spectral density (PSD) of the free mechanical fluctuation of the antenna in santa-maria ${ }^{l}$ mutants; santa-maria ${ }^{l}, U A S$-santa-maria mutants, santa-maria repo-GAL4 rescue and santa-maria Dnai2-GAL4 rescue flies (N=5 per strain). Control $w^{1118}$ traces in grey.

B) Tone-evoked antennal displacement as a function of the particle velocity of the tone. The black line indicates linearity.

C) Relative amplitude of toned-evoked CAPs as a function of the particle velocity of the tone.

D) Relative CAPs amplitudes plotted against the respective antennal displacement.

E) Respective: fluctuation powers, antennal best frequencies, mechanical amplification gains, maximum CAP amplitudes, sound particle velocity thresholds and displacement thresholds.

Data are presented as a mean values $\pm 1 \mathrm{SD}, \mathrm{N}=5, * \mathrm{P}<0.05, * * \mathrm{P}<0.01$, ns $=$ not significant, two-tailed Mann Whitney U-test.

\subsubsection{Relevance of the chromophore generation pathway for fly audition}

The first step in the de novo synthesis of the chromophore is the uptake of dietary beta-carotenoids in the gut. This uptake requires the scavenger receptor NinaD (Kiefer et al., 2002). Subsequently, beta-carotinoids are taken up in a Santa-Maria-dependent manner into neurons and glia in the brain, where they are cleaved into retinal by the beta,betacarotene-15,15'-oxygenase (BCO) NINAB (Kiefer et al., 2001). Eliminating NINAD or NINAB proteins abolishes chromophore synthesis, leading to blindness and retinal degeneration (Voolstra et al., 2010).

If the chromophore were needed for fly audition, nina $D^{l}$ and $\operatorname{nina} B^{360}$ null mutants should show similar hearing impairments as observed in santa-maria ${ }^{l}$ mutants. Compared to controls, however, antennal free fluctuation measurements revealed no significant changes in both fluctuation power and antennal best frequency in ninaD ${ }^{l}(\mathrm{PSD}=1130 \pm 329$ $\left.\mathrm{nm}^{2} / \mathrm{Hz}, \mathrm{Ibf}=185 \pm 6 \mathrm{~Hz}\right)$ and ninaB ${ }^{360}\left(\mathrm{PSD}=1604 \pm 385 \mathrm{~nm}^{2} / \mathrm{Hz}, \mathrm{Ibf}=183 \pm 6 \mathrm{~Hz}\right)$ mutants (Figure 13A). Also amplification gains resembled those of controls, with gains of ca. 10.5 and 8.4 for $n i n a D^{l}$ and $n i n a B^{360}$ mutants, respectively (Figure 13B). Recorded antennal nerve responses were similar to the once observed for $w^{1118}$ controls (Figure 13C and D). Maximum CAP responses (ninaD $D^{l} 23.1 \pm 6.2 \mu \mathrm{V}$ and ninaB ${ }^{360} 26.7 \pm 10.5 \mu \mathrm{V}$ ), sound particle velocity thresholds (ninaD ${ }^{l} 0.058 \pm 0.01 \mathrm{~mm} / \mathrm{s}$ and ninaB ${ }^{360 d} 0.054 \pm 0.005 \mathrm{~mm} / \mathrm{s}$ ) and displacement thresholds (ninaD $D^{1} 68.89 \pm 10.14 \mathrm{~nm}$ and ninaB ${ }^{360 d} 77.85 \pm 9.35 \mathrm{~nm}$ ) 
were in normal range. Hence, disrupting chromophore synthesis leaves fly hearing unaffected.

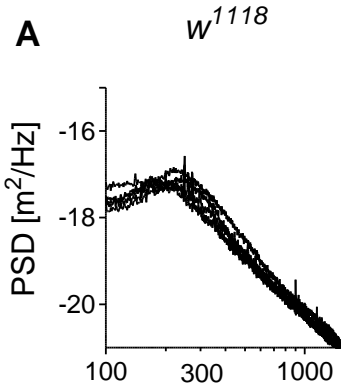

B
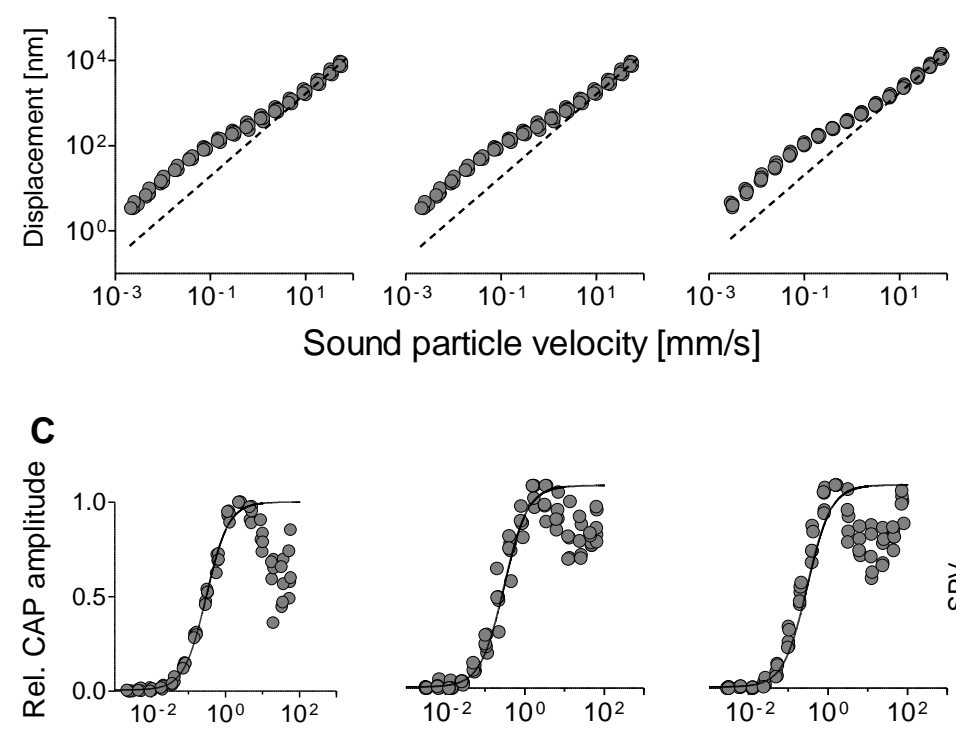

Sound particle velocity $[\mathrm{mm} / \mathrm{s}]$
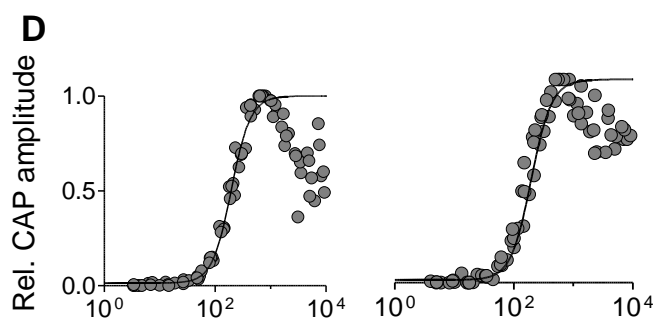

Displacement [nm]

nina $B^{360 d}$
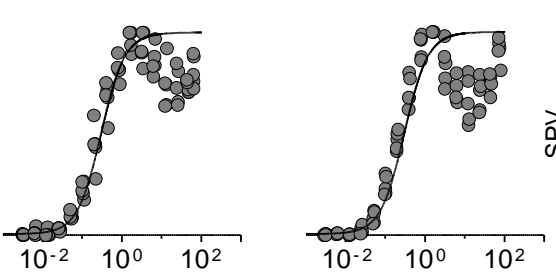
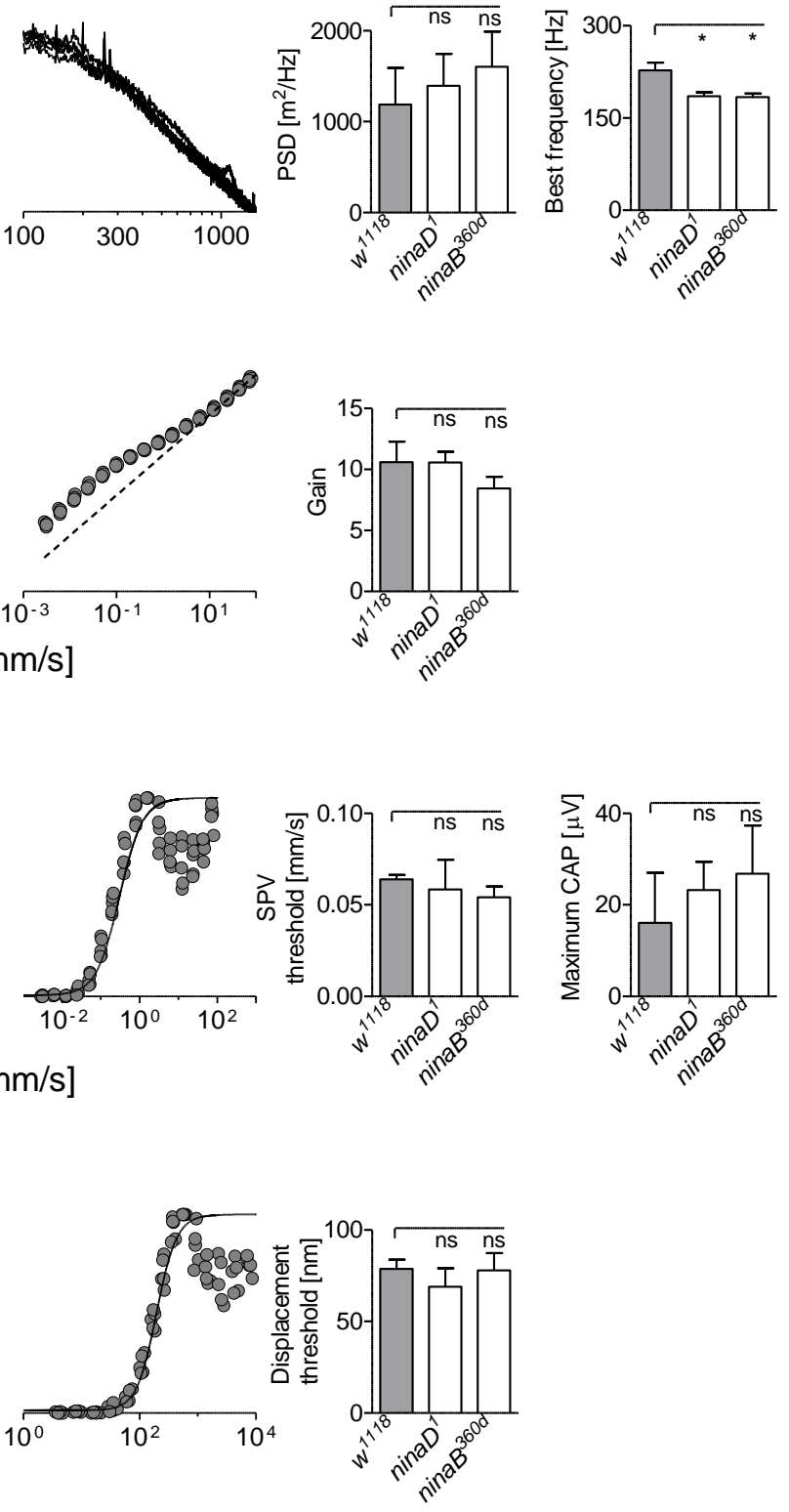

Figure 13. Auditory performance of $\operatorname{ninaD}^{I}$ and ninaB $^{360 d}$ mutant flies.

A) Left: power spectral density (PSD) of the free mechanical fluctuation of the antenna in the wild-type, ninaD $D^{I}$ and ninaB ${ }^{360 d}$ flies ( $\mathrm{N}=5$ per strain). Right: respective fluctuation powers and antennal best frequencies. 
B) Left: Tone-evoked antennal displacement as a function of the particle velocity of the tone. The black dashed line indicates linearity. Right: respective mechanical amplification gains.

C) Left: Relative amplitude of toned-evoked CAPs as a function of the particle velocity of the tone. Right: respective particle velocity threshold and maximum CAP amplitudes.

D) Left: Relative CAP amplitude plotted against the respective antennal displacement. Right: corresponding displacement thresholds.

Data are presented as a mean values $\pm 1 \mathrm{SD}, \mathrm{N}=5, * \mathrm{P}<0.05$, ns $=$ not significant, two-tailed Mann Whitney U-test.

\subsubsection{Vitamin A depletion}

To further test the relevance of the chromophore for Drosophila audition, $w^{1118}$ flies were kept for six generations on medium depleted of vitamin A. As mentioned previously, eliminating vitamin A from a diet will disrupt the de novo synthesis of the chromophore and, in electroretinogram recordings (ERGs), eliminate the prolonged depolarizing afterpotencial (PDA) (Dolph et al., 1993; Pak et al., 2012). PDA arises from the bi-stable nature of rhodopsin where blue light photoconverts rhodopsin to its active form called metharhodopsin $\left(\mathrm{M}^{*}\right)$ generating a depolarizing receptor potential (PDA) that persist even in the dark (Figure 14 left). Metharhodopsin can be photoconverted back to its inactive state by exposure to orange light. ERG measurements confirmed that the vitamin Adepleted flies, but not control flies raised on standard medium, lacked PDA (Figure 14 right). 


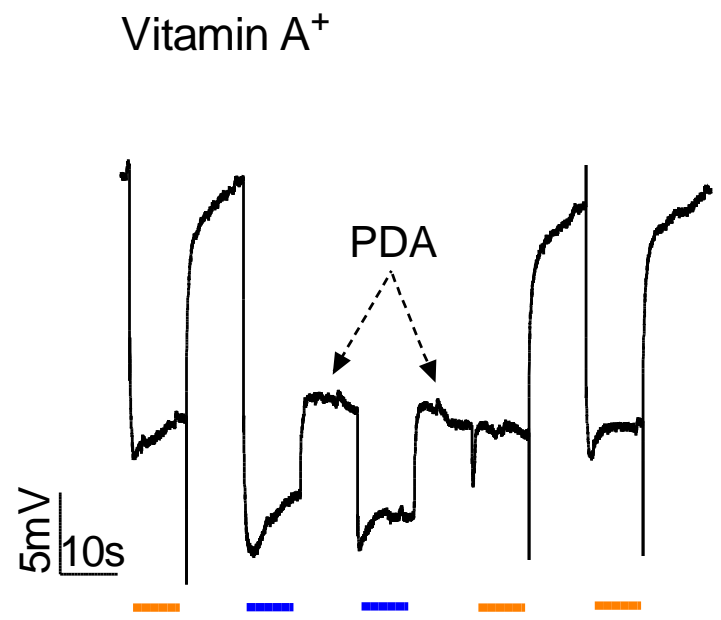

\section{Vitamin $\mathrm{A}^{-}$}

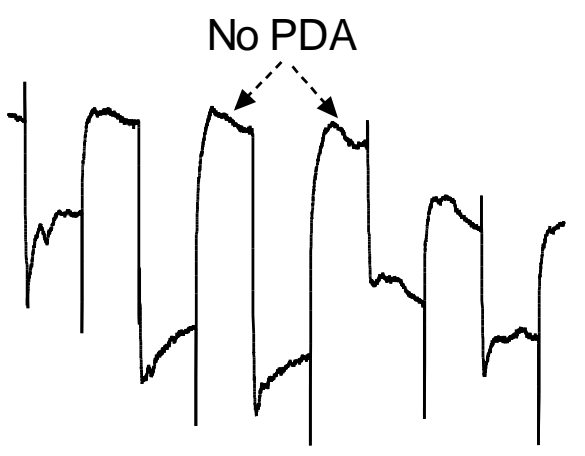

Figure 14. ERG recording from wild type and vitamin A depleted flies.

Left: responses to an orange and a blue stimulus of control flies raised on the normal medium $\left(\mathrm{Vit}^{+}\right)$. The first blue light pulse generates a large response during the stimulus, photoconverting rhodopsin to metarhodopsin. When light is switched off, PDA (Prolonged depolarizing afterpotential) is generated, with photoreceptor cells R1-6 staying depolarized and being inactivated. The next blue light pulse elicits only small response that comes from photoreceptors R7-8. Orange light terminates PDA, metarhodopsin is photoconverted back to rhodopsin and the response goes back to the resting potential. Right: PDA is lost in flies raised for 6 generations on vitamin A-depleted food (Vit $\mathrm{A}^{-}$). There is no rhodopsin that can be photoconverted, so PDA cannot be generated.

To test whether vitamin-deprivation affects hearing, antennal mechanics were examined. Antennal fluctuation powers and best frequencies of vitamin A-depleted flies were indistinguishable from those of controls, and the same applied to the mechanical amplification gain and hearing thresholds (Figure 15). Hence, unlike vision, hearing seems independent of vitamin A and, accordingly, the choromophore. 

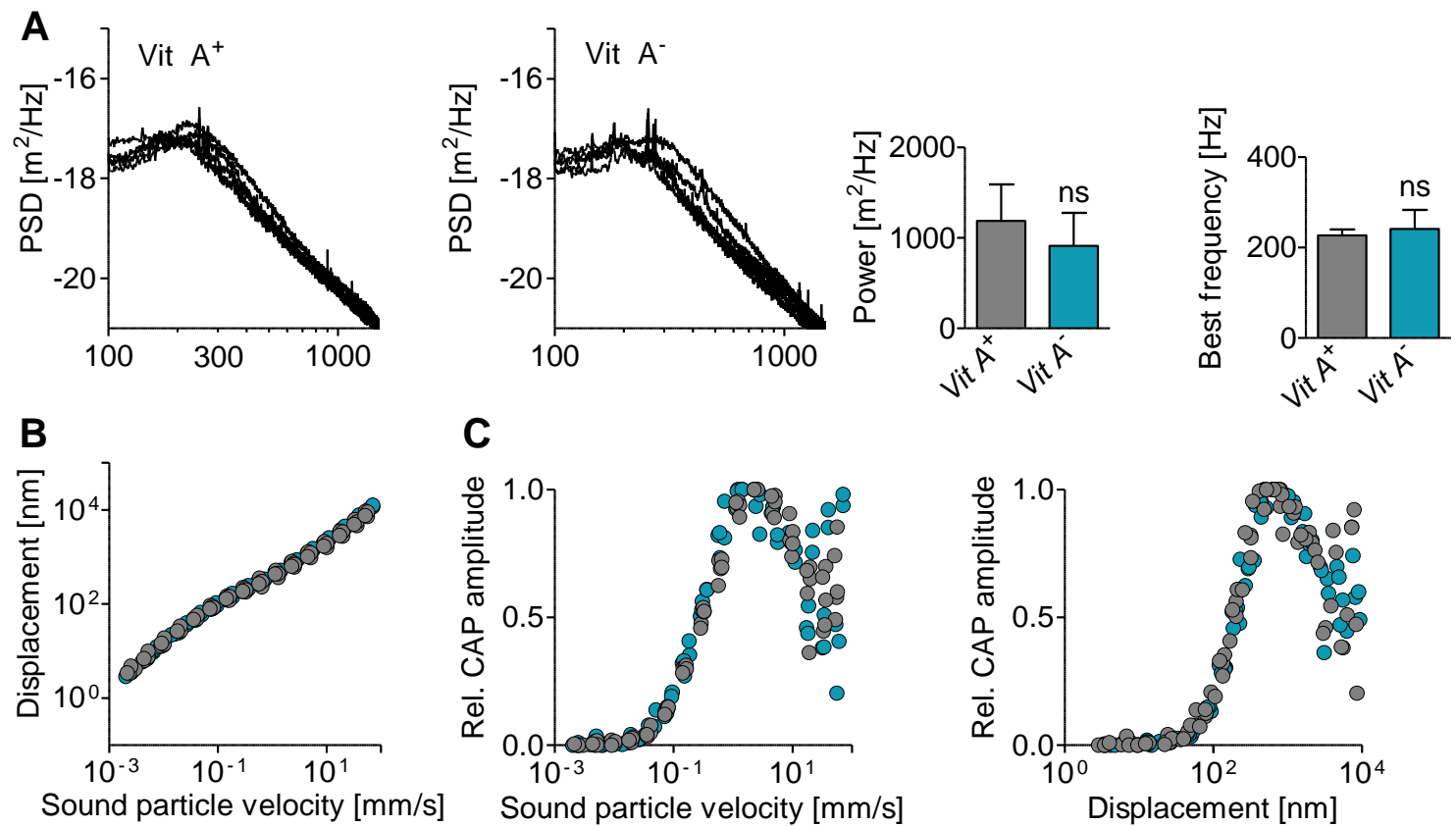

\section{C}
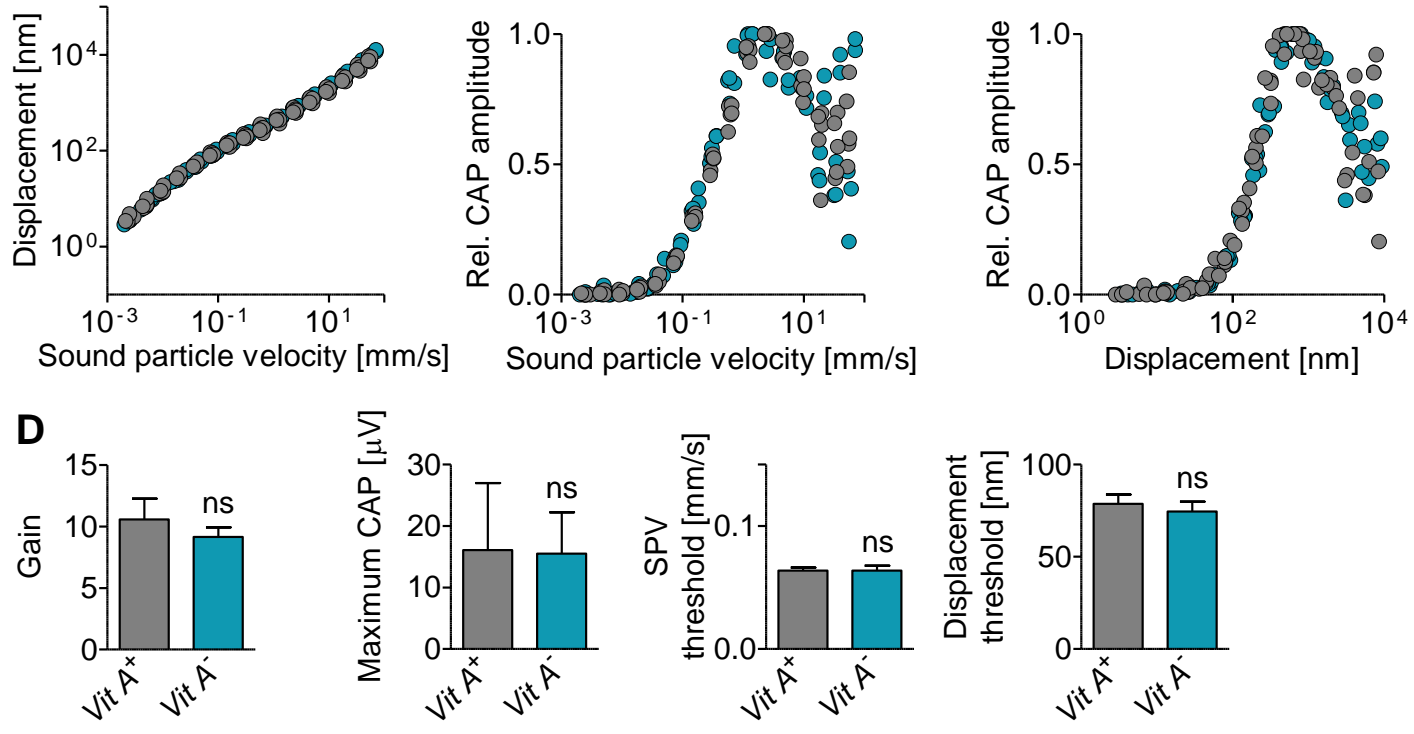

Figure 15. LDV measurements of Vitamin A depleted flies.

A) Left: power spectral density (PSD) of the free mechanical fluctuation of the antenna in the Vitamin A depleted (Vit $\left.A^{-}\right)$and flies raised on normal food (Vit $\left.A^{+}\right)(\mathrm{N}=5$ per strain). Right: respective fluctuation powers and antennal best frequencies.

B) Sound receiver displacement in response to sound stimuli. Superimposed data, VitA ${ }^{+}$(gray) and VitA blue

C) Left: Relative amplitude of toned-evoked CAPs as a function of the particle velocity of the tone. Right: CAP amplitude plotted against the respective antennal displacements.

D) Respective mechanical amplification gains, maximum CAP amplitudes, sound particle velocity thresholds and antennal displacement thresholds.

Data are presented as a mean values $\pm 1 \mathrm{SD}, \mathrm{N}=5, * \mathrm{P}<0.05, \mathrm{~ns}=$ not significant, two-tailed Mann Whitney U-test. 


\subsubsection{Auditory importance of the genes implicated in chromophore processing and recycle}

In the last chapter I showed that blocking chromophore synthesis by eliminating its dietary substrate $\beta$-carotene, or disrupting genes involved in de novo chromophore generation pathway (ninaD and ninaB) does not affect Drosophila hearing. Therefore, auditory rhodopsin functions seem chromophore-independent. Interestingly, the scavenger receptor Santa-Maria operating in the chromophore synthesis pathway between NINAD and NINAB turned out to be crucial for JO function. Following this path it was intriguing to probe auditory performance and expression patterns of other genes involved in visual chromophore synthesis and the chromophore recycling pathway.

\subsubsection{PINTA is functionally involved in auditory process}

The next protein operating in de novo visual chromophore synthesis is PINTA. It is a member of CRAL-TRIO family of proteins that is involved in all-trans-retinal binding in retinal pigment cells within the eye (Wang, 2005).

pinta $^{l}$ null mutant flies were subjected to LDV analysis. Surprisingly, auditory phenotypes were observed that resembled those of santa-maria mutants. The most prominent effect was a drop in fluctuation power to $164 \pm 59 \mathrm{~nm}^{2} / \mathrm{Hz}$ and an increase of the antennal best frequency to $354 \pm 22 \mathrm{~Hz}$ (Figure 16A). Along with the impaired antennal fluctuations, amplification gains were reduced to $2.9 \pm 0.3$ (Figure 16B). Electrophysiological recordings from the antennal nerve showed no significant differences of maximum CAP amplitudes and sound particle velocity thresholds (Figure 16C). Larger antennal displacements, however, were required to elicit nerve responses in pinta ${ }^{l}$ mutant flies, signaling that sound transduction is impaired (Figure 16D). Normal hearing was restored when a genomic pinta rescue construct, $P\left\{\right.$ pinta $\left.^{+}\right\}$was expressed in the pinta ${ }^{l}$ mutant background. 

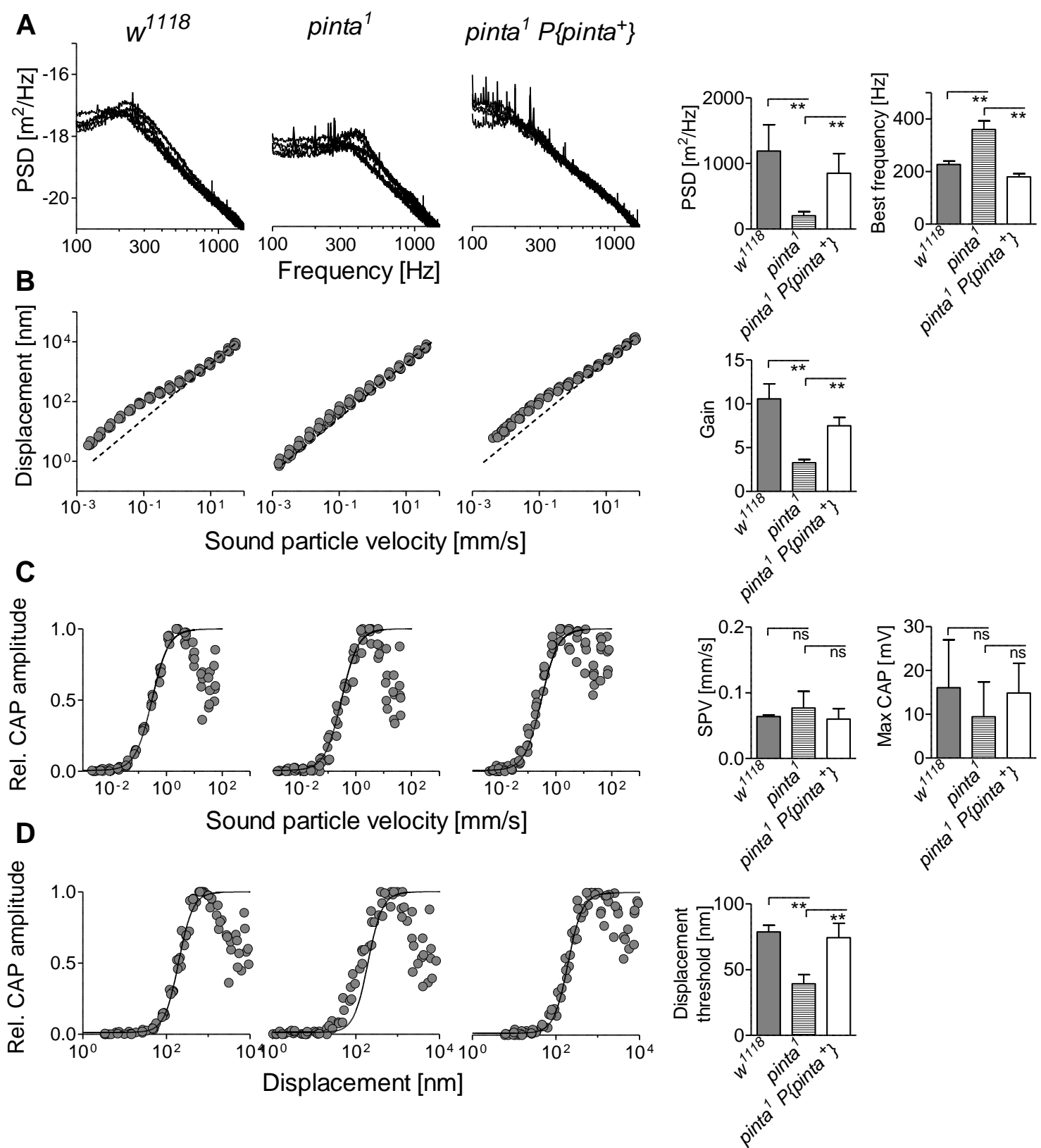

Figure 16. JO function in $\operatorname{pinta}^{l}$ mutants and rescue flies.

A) Left: power spectral density (PSD) of the free mechanical fluctuation of the antenna in the wild-type, pinta $^{l}$ and pinta genomic rescue flies ( $\mathrm{N}=5$ per strain). Right: respective fluctuation powers and antennal best frequencies.

B) Left: Tone-evoked antennal displacement as a function of the particle velocity of the tone. The black dashed line indicates linearity. Right: respective mechanical amplification gains.

C) Left: Relative amplitude of toned-evoked CAPs as a function of the particle velocity of the tone. Right: respective particle velocity thresholds and maximum CAP amplitudes.

D) Left: CAP amplitude plotted against the respective antennal displacement. Right: corresponding displacement thresholds. 
Data are presented as a mean values $\pm 1 \mathrm{SD}, \mathrm{N}=5, * \mathrm{P}<0.05, * * \mathrm{P}<0.01$ two-tailed Mann Whitney U-test.

To asses cell types where pinta is expressed, a Gal4 promoter fusion construct was generated (pinta-Gal4). pinta-Gal4 flies were used to drive expression of 20xUAS-6xGFP in larva and adult Drosophila. In larvae, GFP signals were detected in cap cells of lch5 organs and other chordotonal neurons (lch1, vchA, vchB) (Figure 17 top). These elongated cells create tendon-like structures that apically support the cilium of chordotonal neurons (Hartenstein, 1988). Additionally, very faint signals were observed in the scolopale cells that surround the distal part of the neurons. To further test whether pinta-Gal4 also labels scolopale cells, another fluorescent reporter expressing RFP with nuclear localization was used. Nuclear RFP signals in cells surrounding the distal parts of the cilia confirmed that pinta, besides being expressed in cap cells, is also present in scolopale cells (Figure 17 bottom). 


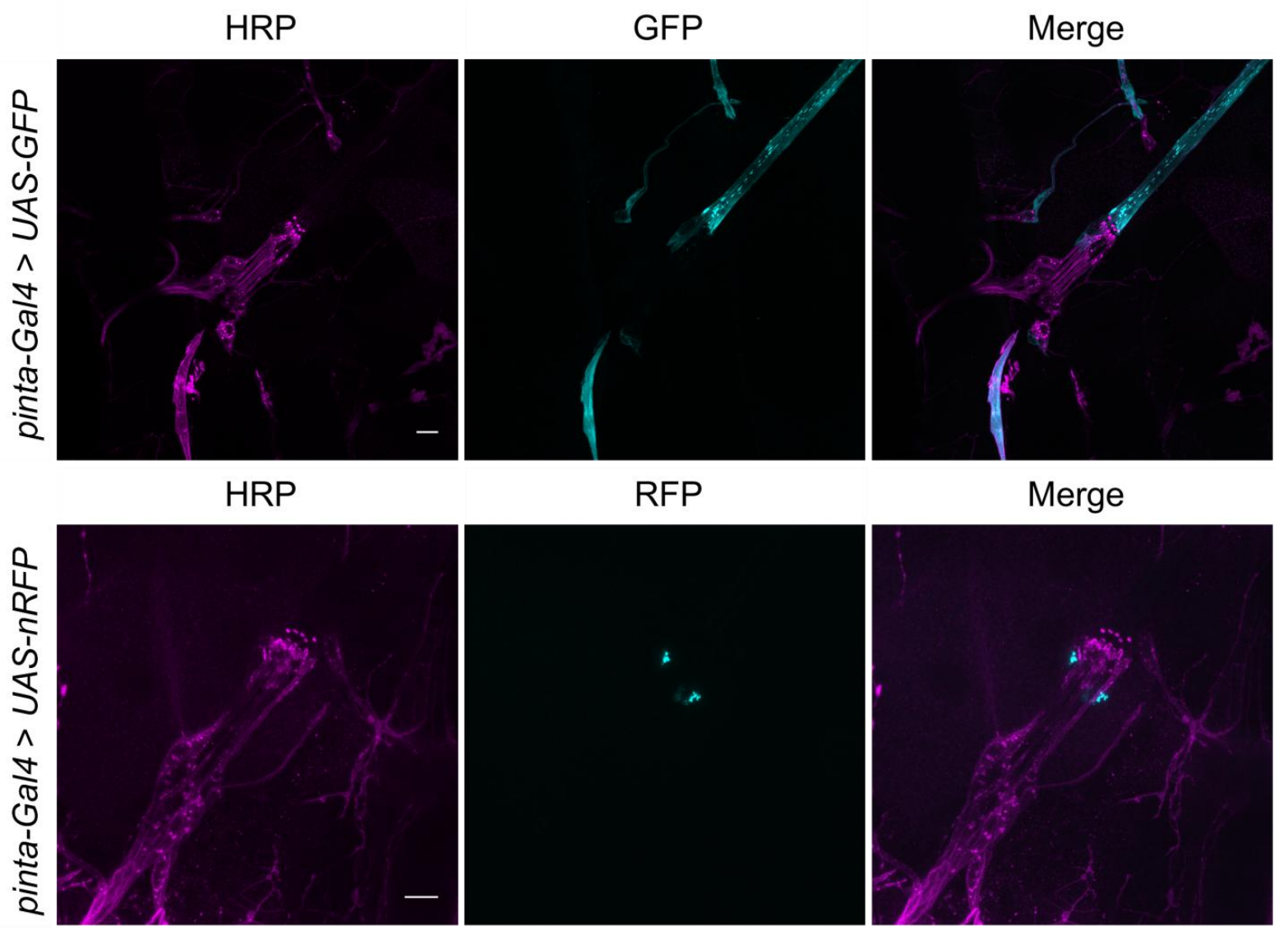

Figure 17. pinta expression in larval Ich5 organ.

Top panel: pinta-Gal4 > 20xUAS-6xGFP, neurons of Ich5 organ marked with anti-HRP neuronal marker showed in magenta. GFP signal showed in cyan. Overlap picture on the right. Scale bar $=10 \mu \mathrm{m}$.

Bottom panel: pinta-Gal4 > UAS-nRFP, neurons of Ich5 organ marked with anti-HRP neuronal marker showed in magenta. RFP signal showed in cyan. Overlap picture on the right. Scale bar $=10 \mu \mathrm{m}$

Next, the expression pattern of pinta-Gal4 in the adult $2^{\text {nd }}$ antennal segment was investigated. GFP signals were spotted as stripes on the both sides of the scolopidium (Figure 18 top). Like in lch5, these structures are most probably cap cells of JO neurons. To test this impression, pinta-Gal4 was crossed to flies expressing UAS-nuclearRFP and additionally counterstained with DAPI to mark all nuclei on the slice. The RFP signals colocalized with DAPI positive nuclei next to the proximal ciliary region, where also the GFP signals had been observed, identifying the respective cells as supporting cap cells (Figure 18 bottom). Nuclear RFP additionally labeled cell nuclei of scolopale cells, some JO neurons and hypodermal cells beneath the cuticle. 


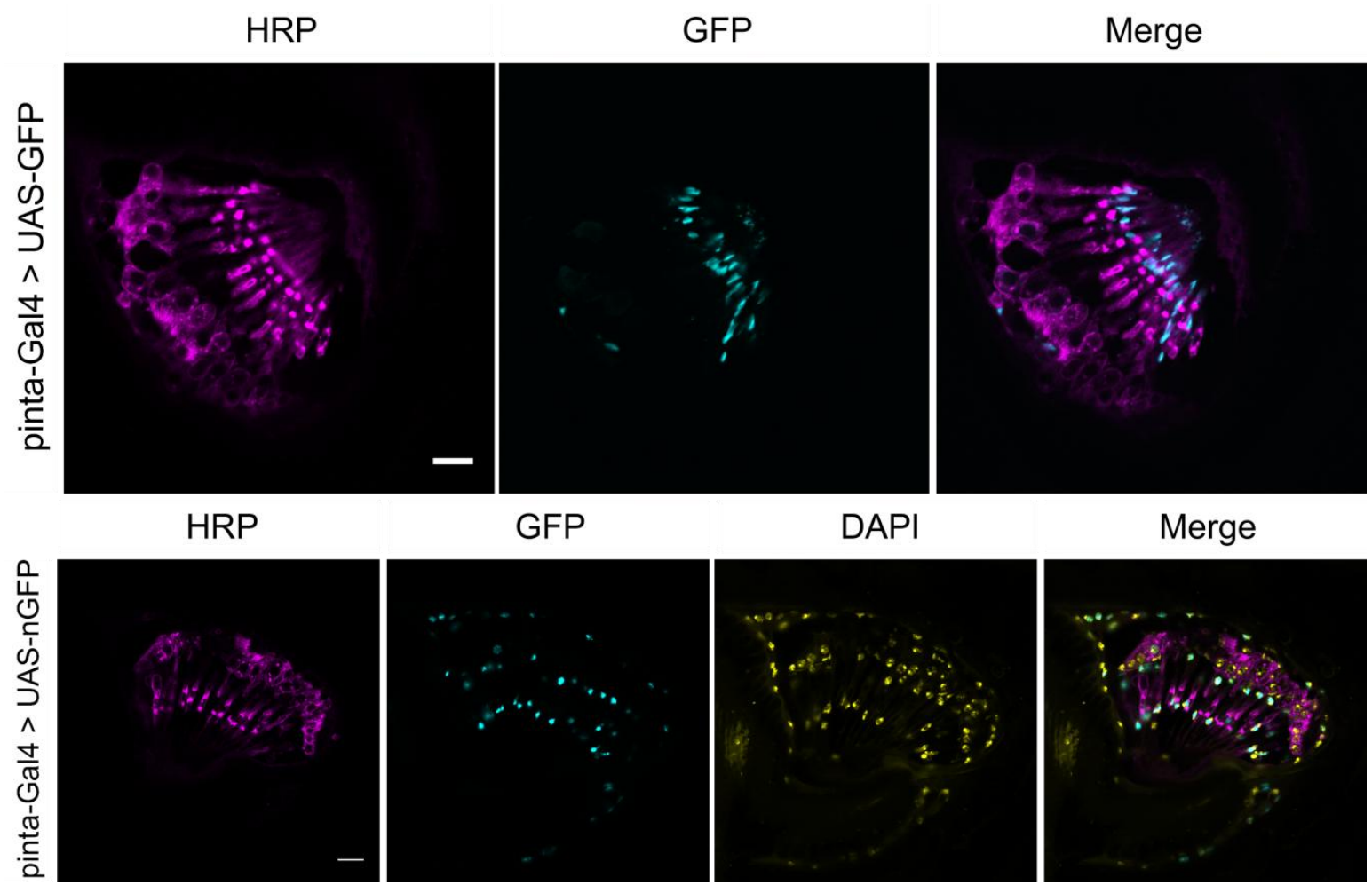

Figure 18. pinta expression pattern in Johnston's organ.

Top panel: Immumohistochemical staining of $2^{\text {nd }}$ antennal segment slices. Neurons are stained with HRP magenta, GFP signal is shown in cyan. An overlay is shown on the right. Scale bar $=10 \mu \mathrm{m}$.

Bottom panel: pinta-Gal4 > UAS-nRFP, neurons of Ich5 organ marked with anti-HRP neuronal marker showed in magenta. RFP signal showed in cyan. DAPI shown in yellow. Overlap picture on the right. Scale bar $=10 \mu \mathrm{m}$

\subsubsection{2 ninaG function and expression in chordotonal organs}

The next protein participating is visual chromophore synthesis is NINAG, an enzyme that belongs to the glucose-methanol-choline oxidoreductase family that mediates oxidation and hydroxylation of small organic molecules (Sarfare et al., 2005). In flies, NINAG acts in the conversion of (3R)-3-hydroxyretinol to the $3 \mathrm{~S}$ enantiomer in the last step of chromophore production. However, in ninaG mutant flies only Rh1 synthesis is abolished because only Rh1 uses 3S retinal enantiomer (Ahmad et al., 2006). 
nina $G$ null mutant flies (nina $G^{P 330}$ ) were analyzed in free fluctuation measurements and subsequently exposed to pure tones to assess the amplification gain and the antennal nerve response. Disrupting ninaG gene led to strong auditory defects in both antennal mechanics and sound evoked antennal nerve responses. Compared to controls, the free fluctuations of the antennal sound receiver showed a severe reduction in power $(60 \pm 19$ $\mathrm{nm} 2 / \mathrm{Hz})$ and a shift of best frequency towards higher values $(542 \pm 10 \mathrm{~Hz})$ (Figure 19A). These auditory defects were associated with almost complete loss of amplification (gain = $1.8 \pm 0.4$ ) (Figure 19B). Moreover, sound-evoked antennal nerve responses were highly affected as maximum CAP amplitudes only reached $3.4 \mathrm{mV}$, suggesting severe defects in sound detecting JO neurons (Figure 19D). Compared to controls, higher sound particle velocities were necessary to evoke antennal nerve responses (SPV threshold $=0.15 \mathrm{~mm} / \mathrm{s} \pm$ $0.039 \mathrm{~mm} / \mathrm{s})($ Figure 19C). However, smaller antennal displacements were needed to elicit a nerve response (displacement threshold $=43 \pm 6 \mathrm{~nm}$ ) (Figure 19C). 


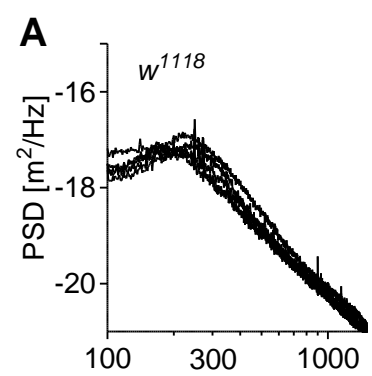

\section{B}

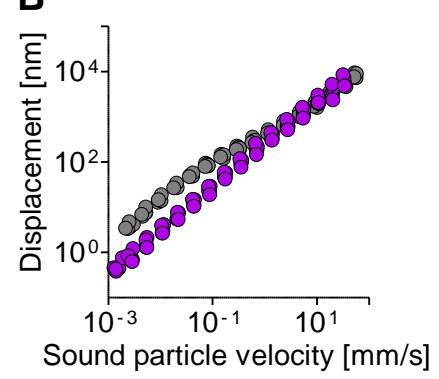

D

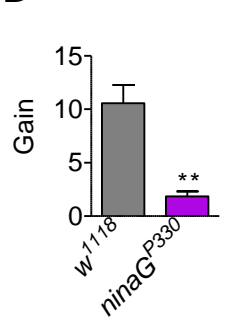

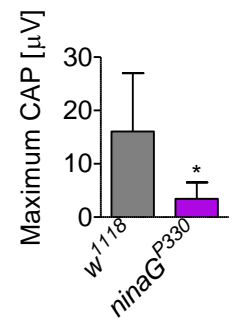

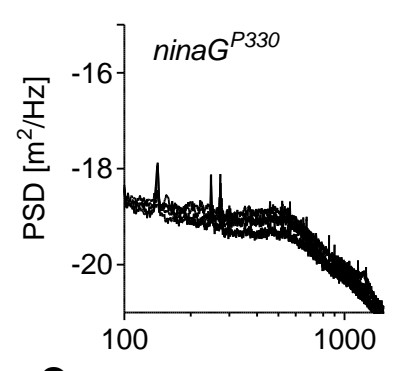

C

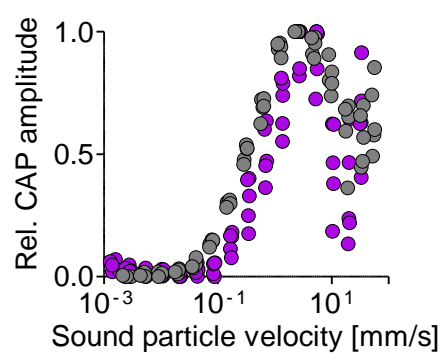

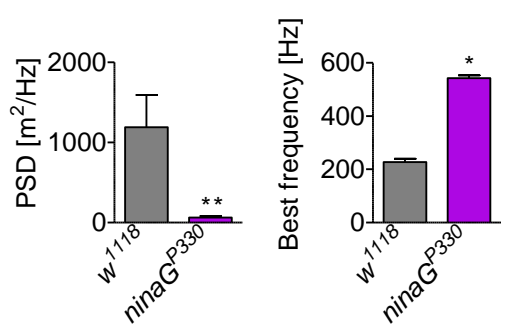

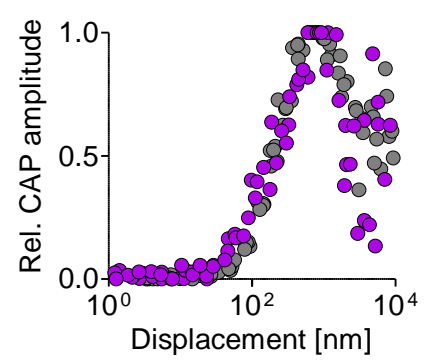

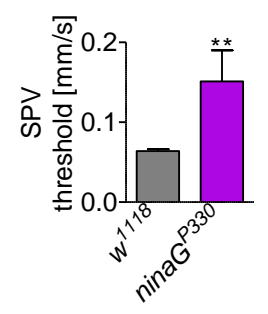

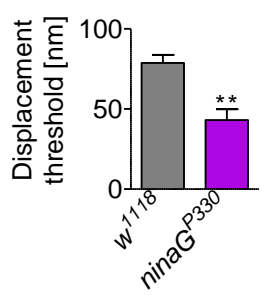

\section{Figure 19. Auditory phenotype of ninaG mutant flies}

A) Left: power spectral density (PSD) of the free mechanical fluctuation of the antenna in control and $\operatorname{ninaG}^{P 330}$ (N=5 per strain). Right: respective fluctuation powers and antennal best frequencies.

B) Sound receiver displacement in response to sound stimuli. Superimposed data, control (gray) and nina $G^{P 330}$ magenta.

C) Left: Relative amplitude of toned-evoked CAPs as a function of the particle velocity of the tone. Right: CAP amplitude plotted against the respective antennal displacement.

D) Respective gains, maximum CAPs amplitudes, sound particle velocity thresholds and antennal displacement thresholds.

Data are presented as a mean values $\pm 1 \mathrm{SD}, \mathrm{N}=5, * \mathrm{P}<0.05 * * \mathrm{P}<0.01$, two-tailed Mann Whitney U-test. 
To test whether chordotonal organs might express ninaG, a promoter fusion construct expressing GAL4 (ninaG-Gal4) was generated and subsequently used to drive a hexameric 20UAS-6xGFP fluorescent reporter. In larvae, strong GFP signals were observed outside of lch5 neuronal cell bodies at their axonal side, most likely in supporting ligament cells (Figure 20 bottom). To test this notion, the wild type larvae were stained with an antibody against $\alpha$ Tub85E, which is known to exclusively label accessory and attachment cells of chordotonal organs (Halachmi et al., 2016). As expected, ligament cell labeled by anti- $\alpha$ Tub85E antibody strongly resembled the structure observed in ninaG-Gal4 UAS-GFP larvae, further suggesting that the ligament cells of lch5 express ninaG (Figure 20 top).

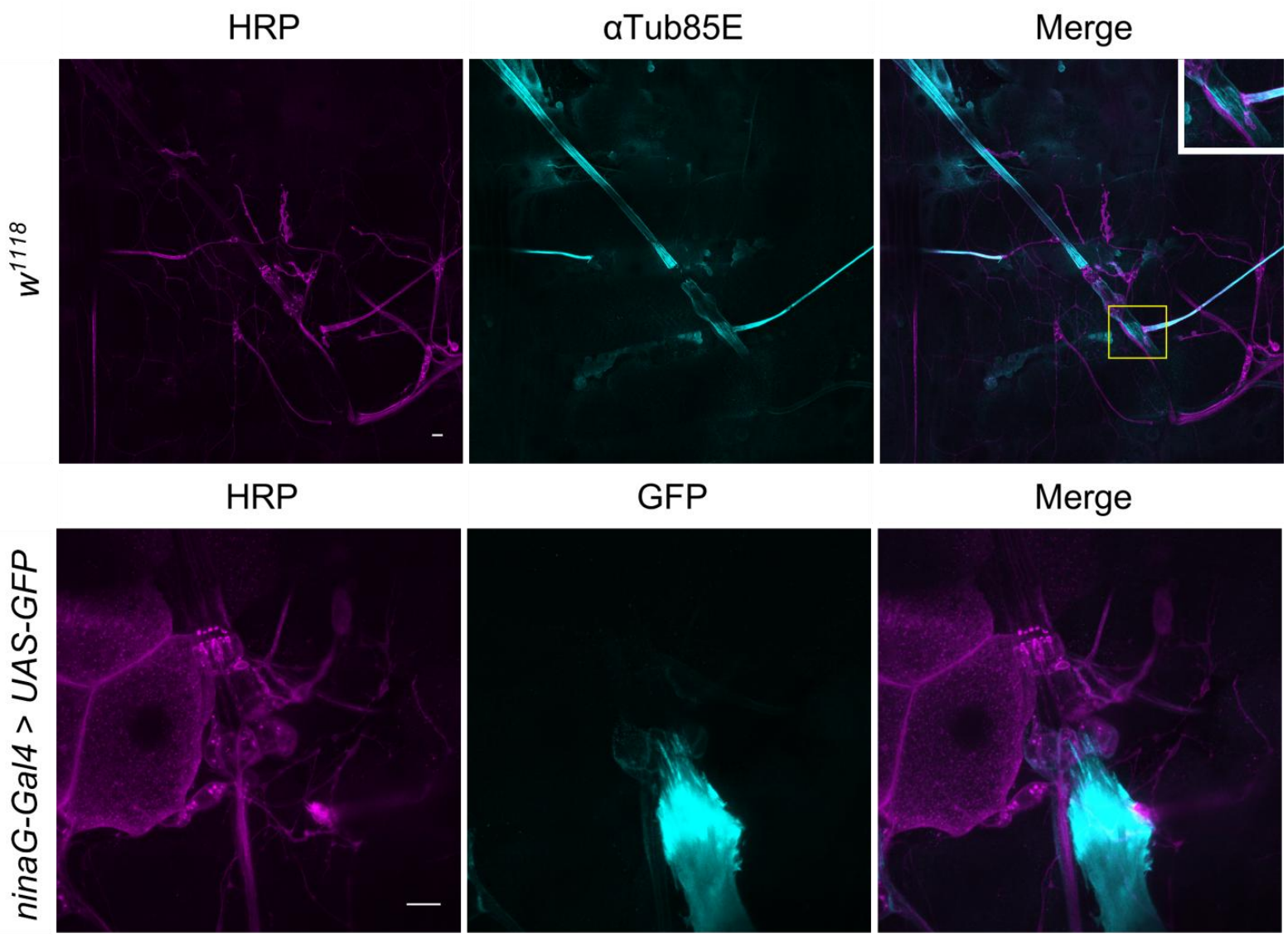

Figure 20. $\alpha$ Tub85E and ninaG expression pattern in larval Ich5 chordotonal organ.

Top: Antibody staining against chordotonal organ specific protein $\alpha$ Tub85E (cyan), neurons marked by HRP (magenta). Bottom: anti GFP staining on ninaG-Gal4 > UAS-GFP larvae lch5 organ (cyan), neurons marked by HRP (magenta). Scale bar $=10 \mu \mathrm{m}$. 
The same approach was used to study the ninaG expression pattern in Johnston's organ. In ninaG-Gal4 > UAS-GFP flies, signal was detected around neuronal cell bodies, recapitulating the staining pattern of the antibody $\alpha \mathrm{Tub85E}$ (Figure 21). ninaG is thus expressed in ligament cells, in both lch5 and JO.

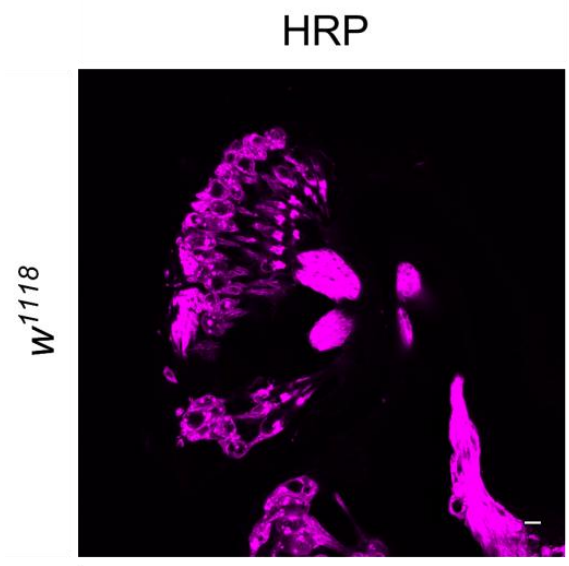

HRP

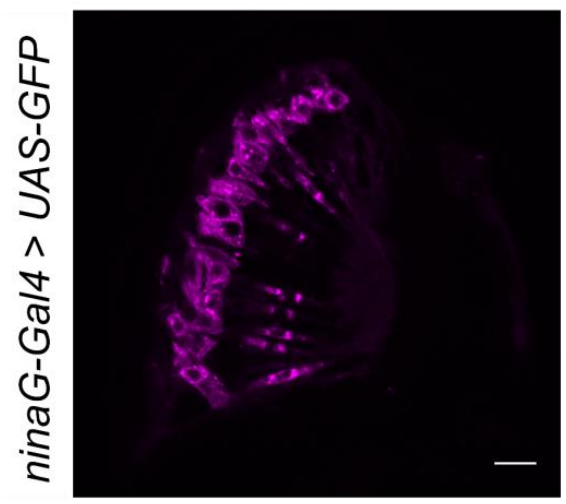

aTub85E

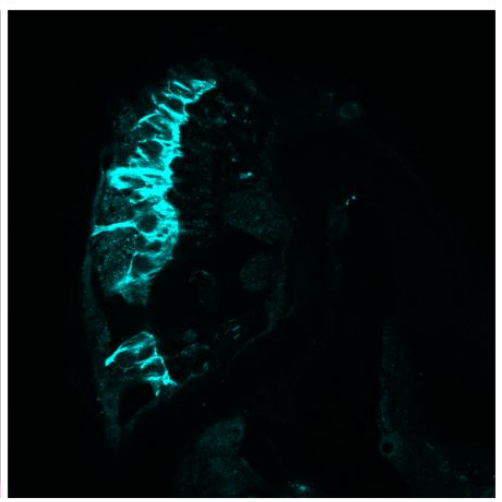

GFP

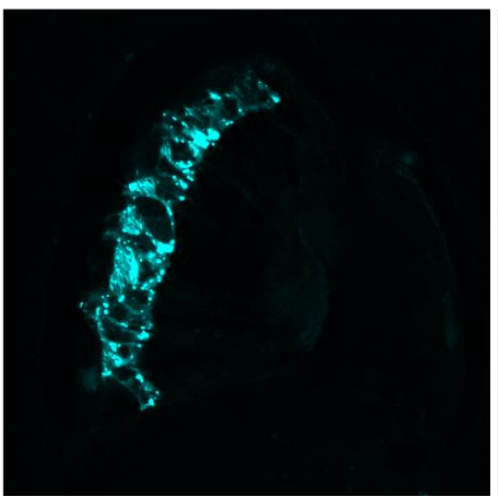

Merge

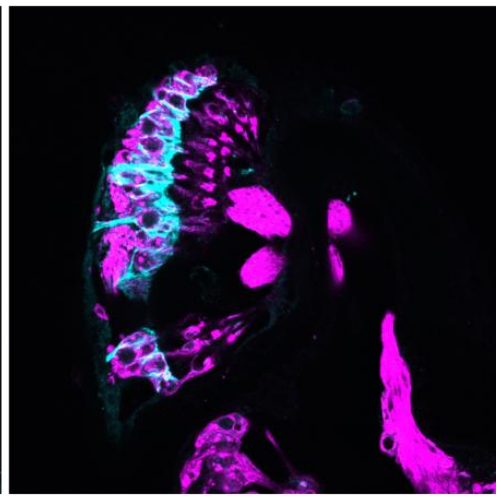

Merge

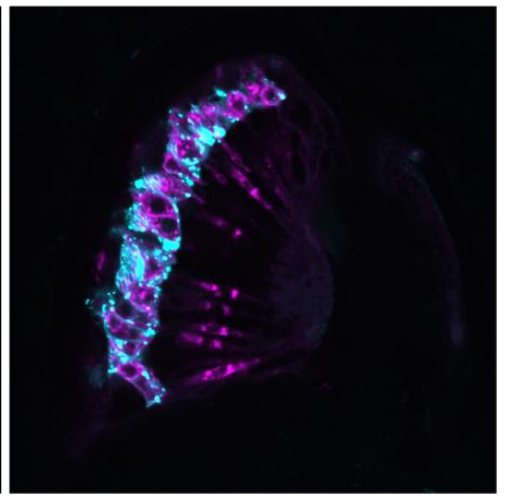

Figure 21. ninaG expression pattern in adult JO.

Top: Antibody staining against chordotonal organ specific protein $\alpha$ Tub85E (cyan), neurons marked by HRP (magenta). Bottom: anti-GFP staining on ninaG-Gal4 > UAS-GFP flies (cyan), neurons marked by HRP (magenta). Scale bar $=10 \mu \mathrm{m}$. 


\subsubsection{Genes of chromophore recycling pathway in fly hearing}

So far, I investigated all of the known proteins participating in "de novo" chromophore synthesis. However, lately it has been shown that Drosophila photoreceptors are also able to regenerate photoisomerized 3-OH-all-trans retinal back to its cis configuration through a visual cycle as known from the mammalian retina (Wang et al., 2010). In Drosophila, this visual cycle involves enzymatic activity of pigment cell dehydrogenase (Pdh) (Wang et al., 2010) and retinal dehydrogenase B (RDHB) (Wang et al., 2012) that are expressed in retinal pigment cells (RPC). To determine whether these proteins are necessary for proper JO function, respective mutant flies $\left(P d h^{l}\right.$ and $\left.r d h B^{l}\right)$ were analyzed.

Antennal free fluctuation measurements revealed massive defects in JO neurons motility in both mutants tested. The fluctuation power of $P d h^{1}$ and $r d h B^{l}$ mutants was reduced to $323 \pm 147$ and $69 \pm 37 \mathrm{~nm}^{2} / \mathrm{Hz}$ respectively (Figure $22 \mathrm{~A}$, E). Together with this low power, also the antennal best frequency was shifted to higher values: $386 \pm 15 \mathrm{~Hz}$ for $P d h^{l}$ and $581 \pm 58 \mathrm{~Hz}$ for $r d h B^{l}$ mutants (Figure 22A, E). Low fluctuation powers indicate reduced mechanical amplification, and sound receiver responses to pure tones showed almost linear scaling (Figure 22B, E). The amplification gains reached $3.6 \pm 0.7$ for $P d h$ mutants and $1.5 \pm 0.1$ for $r d h B^{l}$ mutants (Figure 22E). Maximum CAP amplitudes measured from antennal nerve were greatly diminished in $r h d B^{l}$ mutants $(2.3 \pm 0.1 \mu \mathrm{V})$ (Figure 22E), indicating that besides defects in amplification also current responses are greatly affected. Furthermore, considerably higher sound particle velocities were needed to exceed the response threshold $(0.23 \pm 0.11 \mathrm{~mm} / \mathrm{s})$ (Figure 22C, E). $P d h^{1}$ mutant flies showed slightly larger CAP amplitudes compared to $r d h B^{l}$, but they were still noticeable smaller than in controls. Maximum CAP amplitudes reached only $6.3 \pm 2.2 \mu \mathrm{V}$, and the antennal displacement threshold $(49 \pm 11 \mathrm{~nm})$ was increased (Figure 22D, E).

The auditory defects seen in $P d h^{l}$ mutant flies were reversed to wild-type levels when a genomic $P d h$ recue construct, $P\left\{P d h^{+}\right\}$, was introduced into the $P d h^{l}$ mutant background. 

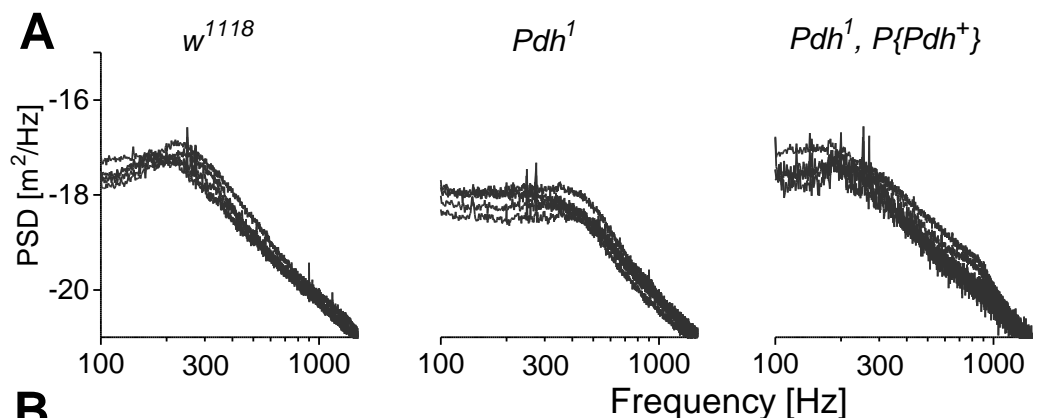

$r d h B^{1}$
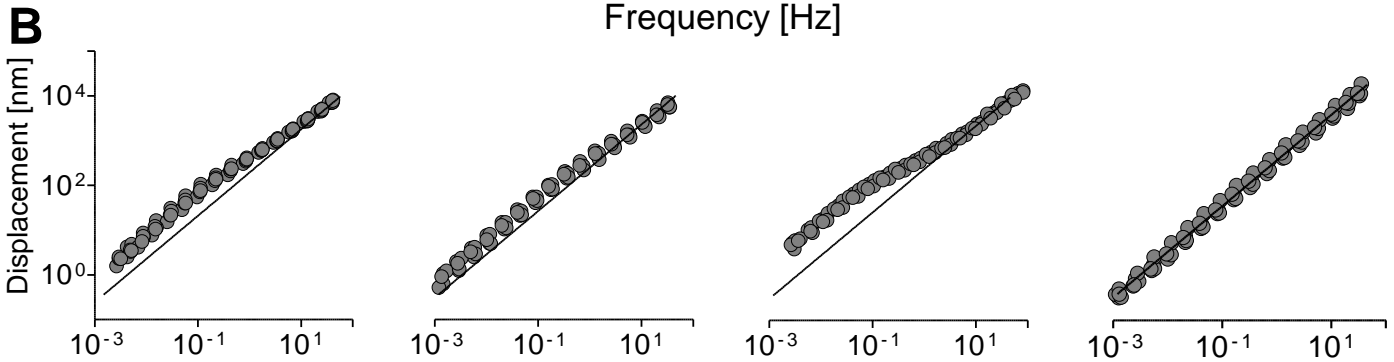

C
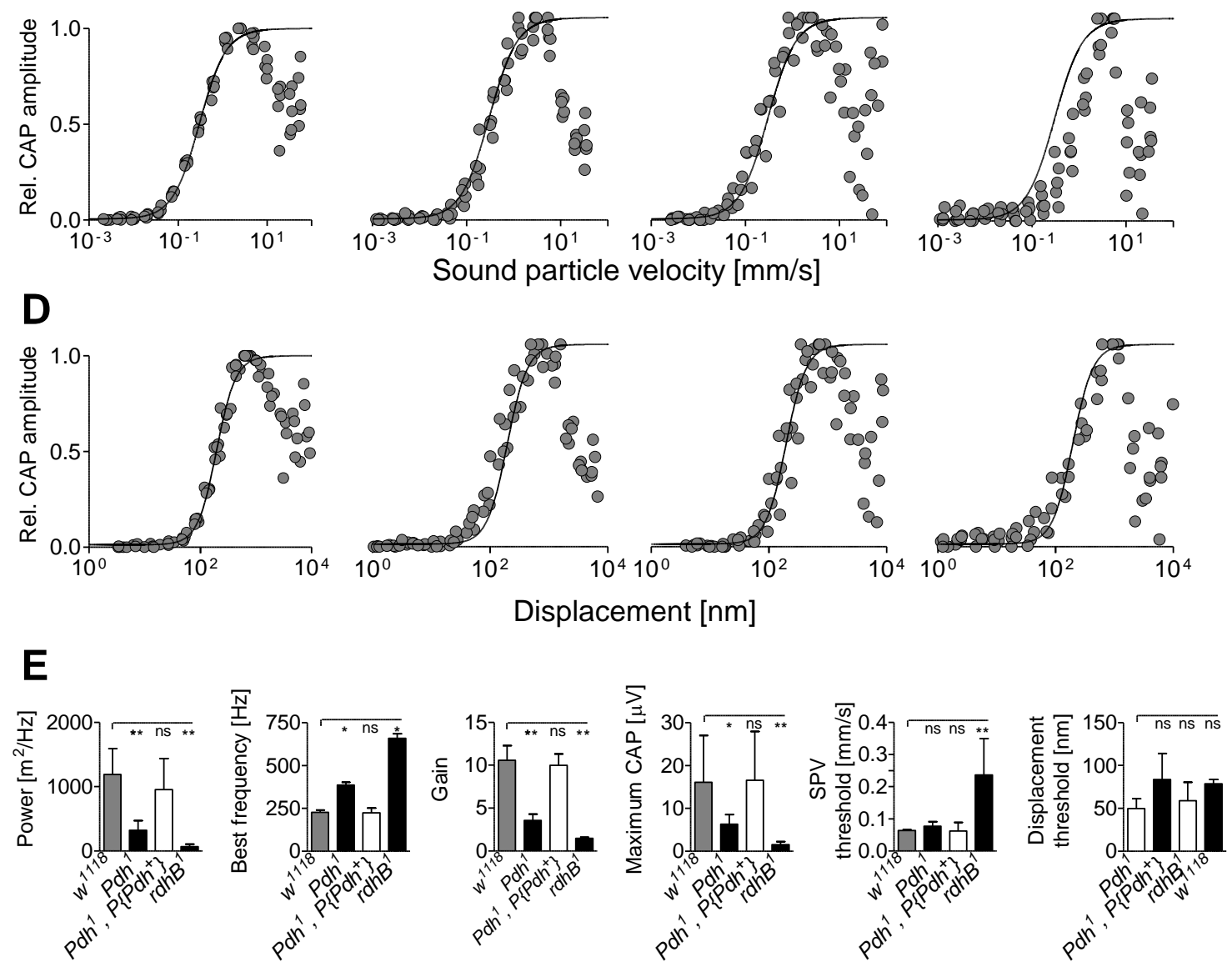

Figure 22. Auditory performance of the mutant flies implicated in chromophore recycle.

A) Power spectral density (PSD) of the free mechanical fluctuation of the antenna in $w^{1118}$ control flies; $p d h^{l}$ mutants; $p d h^{l}, P\left\{p d h^{l}\right\}^{+}$genomic rescue and $r d h B^{l}$ mutants flies (N=5 per strain). 
B) Tone-evoked antennal displacement as a function of the particle velocity of the tone. The black line indicates linearity.

C) Relative amplitude of toned-evoked CAPs as a function of the particle velocity of the tone.

D) Relative CAPs amplitudes plotted against the respective antennal displacement.

E) Respective: fluctuation powers, antennal best frequencies, mechanical amplification gains, maximum CAP amplitudes, sound particle velocity thresholds and displacement thresholds.

Data are presented as a mean values $\pm 1 \mathrm{SD}, \mathrm{N}=5, * \mathrm{P}<0.05, * * \mathrm{P}<0.01$, ns $=$ not significant, two-tailed Mann Whitney U-test.

The promoter fusion construct $P d h$-Gal4 was generated to reveal the cell types where $P d h$ is expressed, however, no signal was detected in Ich5 chordotonal organ and in adult JO. The only visible GFP signals came from the adult eye and ocelli (Figure 23), where $P d h$ is reportedly expressed in retinal pigment cells (Wang et al., 2010).

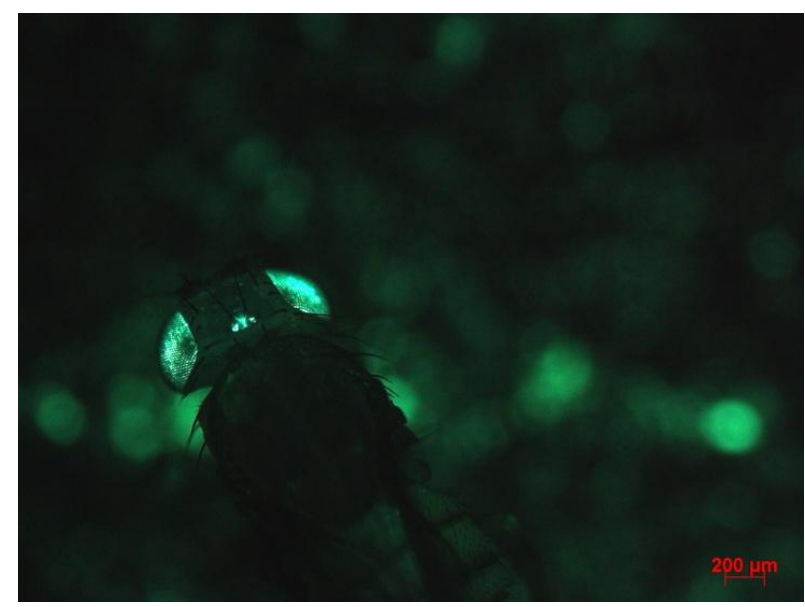

Figure 23. Pdh-GAL4 expression in the eye of Drosophila.

Overview of adult fly expressing $U A S-G F P$ in the pattern of Pdh-Gal4. Picture was taken from epifluorescent microscope with GFP filter.

To find out whether $r d h B$ is expressed in chordotonal nurons, previously published rdhB-Gal4 (Wang et al., 2012) was used to drive expression of UAS-GFP reporter. After 
immunohistochemical staining a weak GFP signals were detected in JO neurons cell bodies (Figure 24).

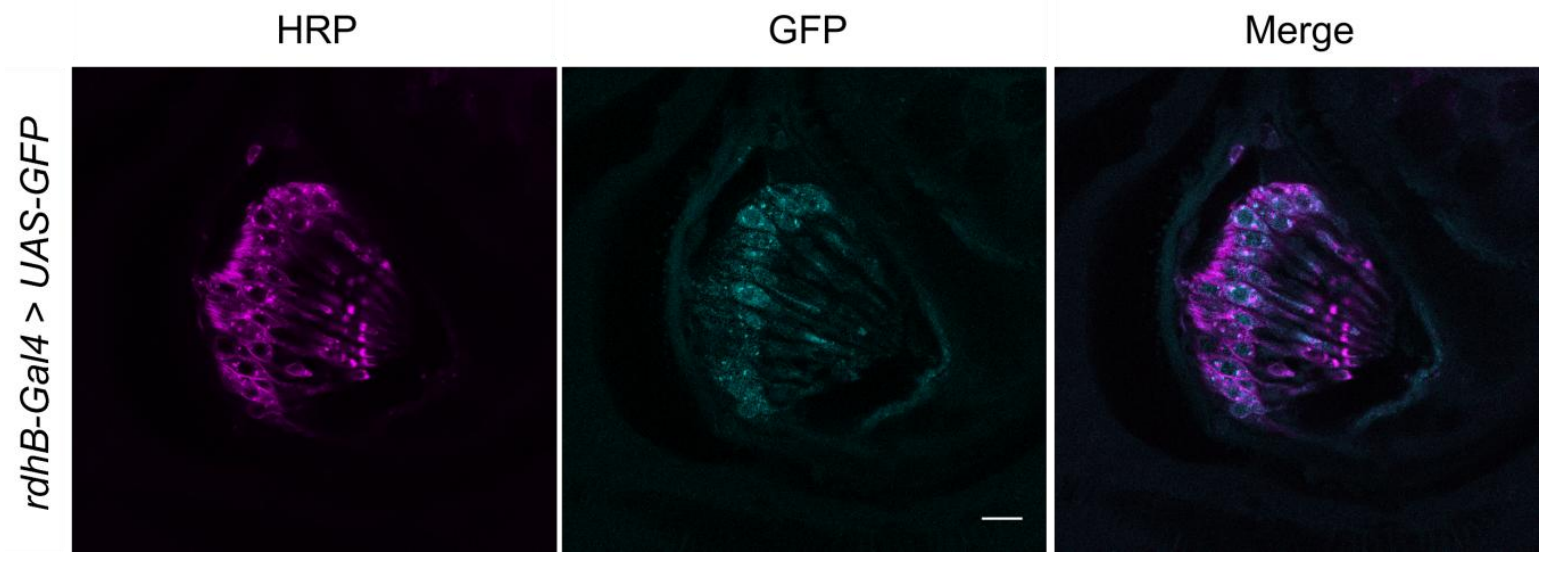

Figure 24. rdhB-Gal4 expression pattern in adult JO

Anti-GFP staining on ninaG-Gal4 > UAS-GFP flies (cyan), neurons marked by HRP (magenta). Scale bar $=$ $10 \mu \mathrm{m}$. 


\subsubsection{Possible roles of Rhodopsin1 in Drosophila hearing}

The main visual rhodopsin Rh1 is encoded by ninaE gene and is found in 6 out of the 8 photoreceptor cell types in the fly eye. Rh1 is crucial for vision and the maintenance of proper photoreceptor architecture. In the past years nonvisual Rh1 functions have been reported in the context of thermosensation (Shen et al., 2011) and proprioreception (Zanini et al., 2018). These studies, however, focused exclusively on Rh1 functions in $3^{\text {rd }}$ instar larvae, no research was done on adult Drosophila. Giving that larval proprioreceptive lch5 chordotonal organ requires Rh1 for controlling locomotion (Zanini et al., 2018), and adult hearing uses morphologically similar neurons, I checked whether $R h 1$ is expressed in JO and, if so, if it has any function there. Initially, Rh1 was not detected in the screen of the genes expressed in adult JO (Senthilan et al., 2012). However, I decided to reassess this result using the reverse transcription polymerase reaction (RT-PCR) on cDNA obtained from the $2^{\text {nd }}$ antennal segment. $R h l$ mRNA transcripts were detected in Johnston's organ (Figure 25).

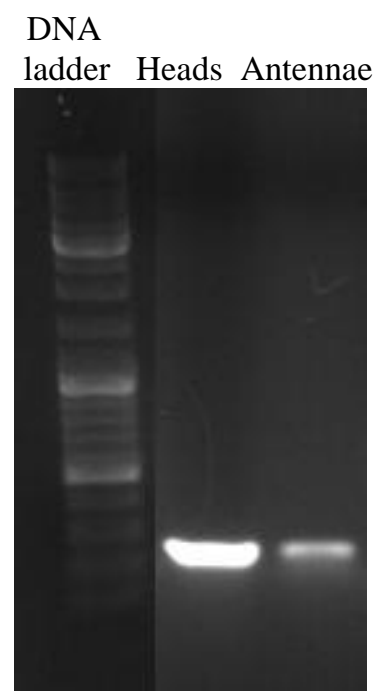

Figure 25. Rhodopsin1 RT-PCR analysis.

mRNA expression of rh1 was checked by performing PCR on cDNA from heads $\left(2^{\text {nd }}\right.$ row) and antenna $\left(3^{\text {rd }}\right.$ row) of wild-type flies. 


\subsubsection{Probing Johnston's organ function in nina $^{17}$ mutants}

Assuming that $r h 1$ is expressed in Drosophila antennae the intriguing question was whether it contributes to auditory functions like $r h 5$ and $r h 6$. To evaluate this, I analyzed hearing in nina $E^{17}$ null mutants lacking the Rh1 opsin (O'Tousa et al., 1985). Antennal free fluctuation measurements revealed a substantial drop in power $(368 \pm 270 \mathrm{~nm} 2 / \mathrm{Hz})$ and a slight increase in the antennal best frequency $(295 \pm 26 \mathrm{~Hz})$ when compared to its genetic background CantonS (Power $=1272 \pm 569 \mathrm{~nm}^{2} / \mathrm{Hz}$ and $\mathrm{Ibf}=210 \pm 29 \mathrm{~Hz}$ ) (Figure 26A and E). When exposed to pure tones, the antennal sound receiver of $R h 1$ mutants showed reduced amplification gain $(4.3 \pm 0.9)$ compared to control flies $(10.8 \pm 2.7)$ (Figure 26B and E). Maximum CAP amplitudes of the mutants resembled those of controls $(21.4 \pm 12.1$ and $14.4 \pm 4.9 \mu \mathrm{V}$ respectively) (Figure 26E). Difference between mutants and controls, however, were also found with respect to sound particle velocity thresholds $0.1 \pm 0.01$ and $0.05 \pm 0.01$ respectively (Figure 26C and E). Displacement thresholds, however, seemed to be unaffected by nina $E^{17}$ mutation (Figure 26D and E).

Notwithstanding these apparent phenotypes, no hearing defects were seen when the nina $E^{17}$ mutation was uncovered with the ninaE deficiency $D f(3 R)$ Exel6174. Moreover, no auditory defects were also detectable when the genetic background was changed to $y w$. These results strongly indicate that auditory defects seen in $c s$; nina $E^{17}$ mutant flies were not caused by the Rh1 mutation itself, but rather site mutations within CantonS genetic background. Thus, in contrast to $R h 5$ and $R h 6$ mutant flies where strong auditory defects that could be rescued have been documented (Senthilan et al., 2012), the main visual opsin Rh1 seems dispensable for fly hearing. 
A

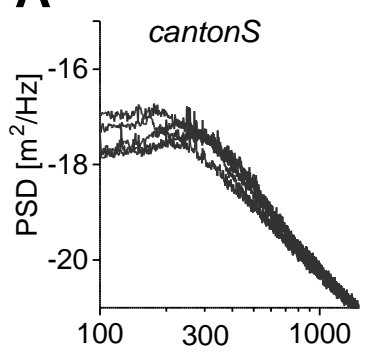

cs; $\operatorname{nina}^{17}$

cs; $\operatorname{nina} E^{17} / D f$

$y w ; \operatorname{nina}^{17}$

B
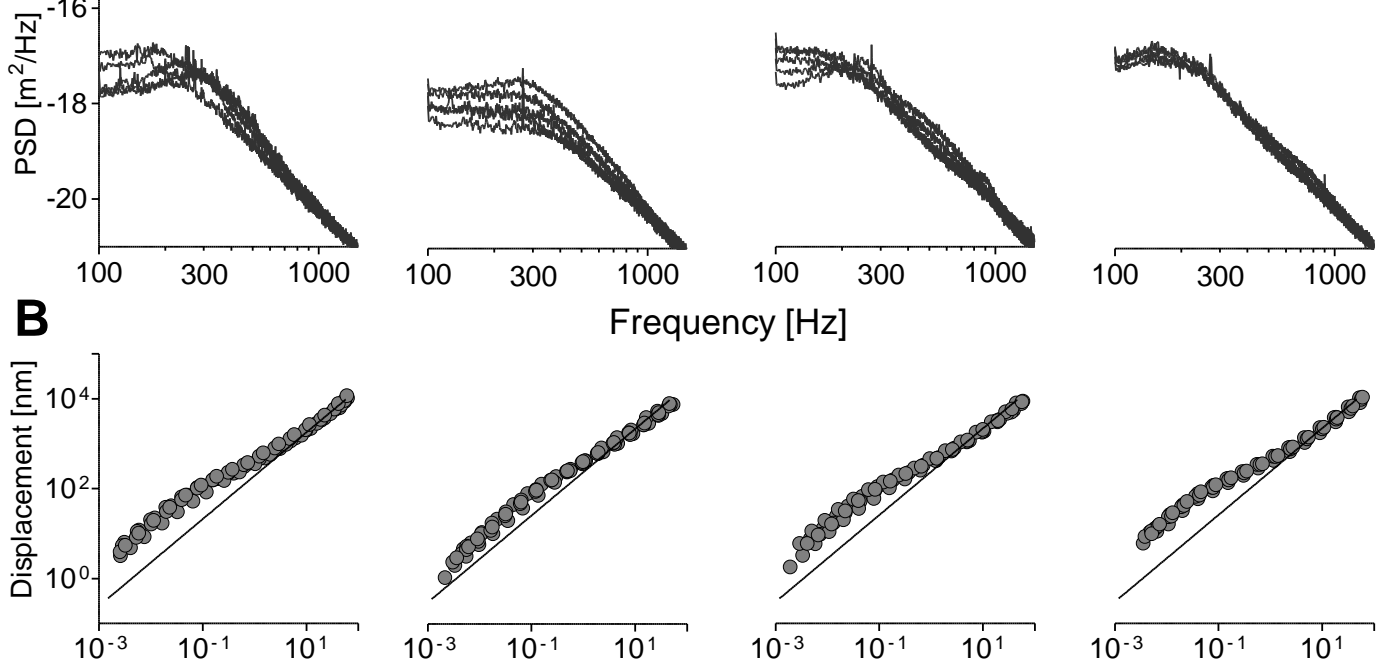

C

Sound particle velocity $[\mathrm{mm} / \mathrm{s}]$
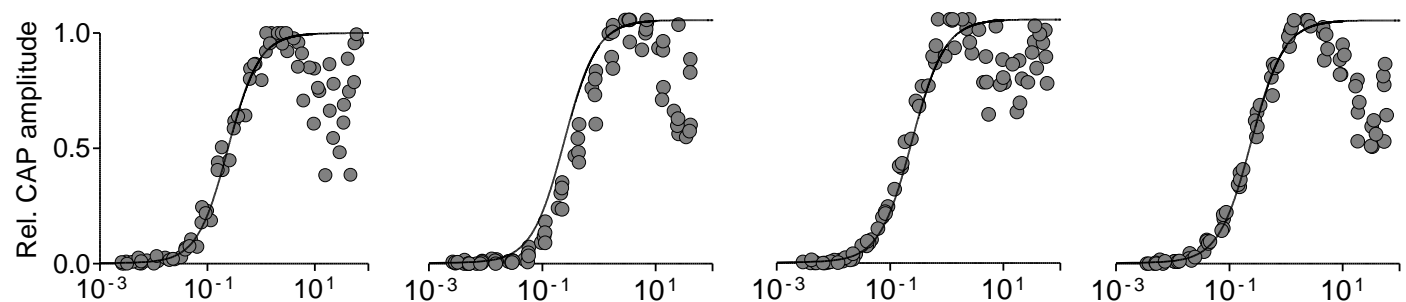

D

Sound particle velocity $[\mathrm{mm} / \mathrm{s}$ ]
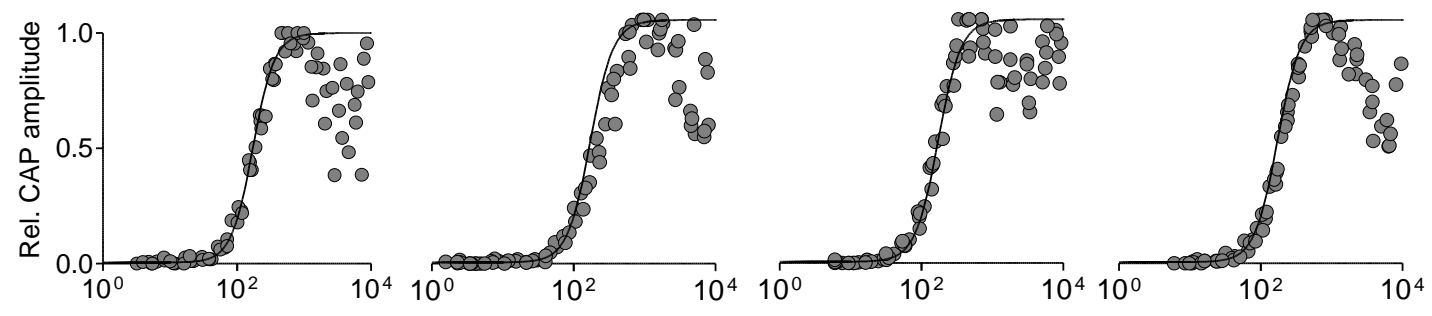

Displacement [nm]

E

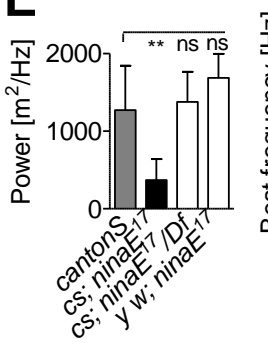

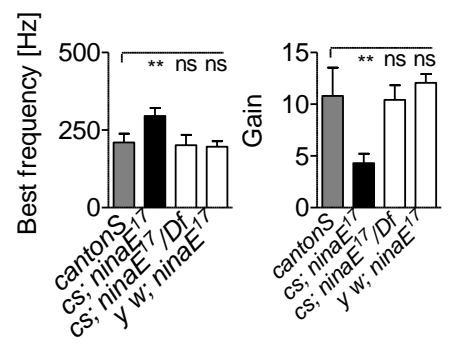
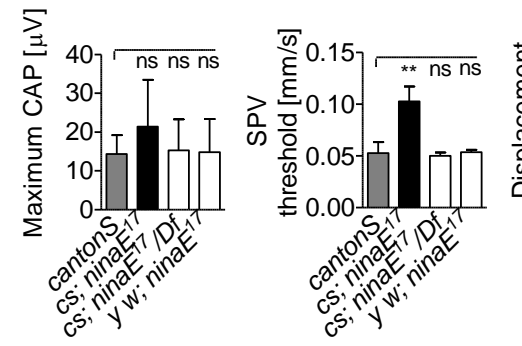

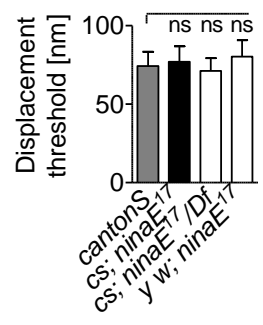

Figure 26. Auditory performance of various $\operatorname{ninaE}^{17}$ mutant strains 
A) Power spectral density (PSD) of the free mechanical fluctuation of the antenna in cantonS control flies, nina $E^{17}$ in cantonS genetic background ( $c s ;$ nina $\left.E^{17}\right)$, nina $E^{17}$ uncovered by deficiency cs; nina $E^{17} / D f$ and nina $E^{17}$ with genetic background changed to $y w$ ( $y w$; nina $\left.E^{17}\right)$ flies $(\mathrm{N}=5$ per strain).

B) Tone-evoked antennal displacement as a function of the particle velocity of the tone. The black line indicates linearity.

C) Relative amplitude of toned-evoked CAPs as a function of the particle velocity of the tone.

D) Relative CAPs amplitudes plotted against the respective antennal displacement.

E) Respective: fluctuation powers, antennal best frequencies, mechanical amplification gains, maximum CAP amplitudes, sound particle velocity thresholds and displacement thresholds.

Data are presented as a mean values $\pm 1 \mathrm{SD}, \mathrm{N}=5, * \mathrm{P}<0.05, * * \mathrm{P}<0.01$, ns $=$ not significant, two-tailed Mann Whitney U-test. 


\subsection{Discussion}

Drosophila opsins, besides being light sensors, also have non-visual roles in larval thermosensation, proprioception and adult hearing (Senthilan et al., 2012; Shen et al., 2011; Sokabe et al., 2016). Without Rh5 or Rh6 Johnston's organ function is severly impaired, as witnessed by abolished mechanical amplification as well as defects in signal transduction (Senthilan et al., 2012). Initial studies suggested that all these non-visual opsins functions are chromophore-dependent as disrupting chrmopohore synthesis by elminating the SantaMaria scavenger receptor cause similar sensory defects as seen in opsin mutants alone.

In this thesis I tested the hyphothesis that the chromophore is required for nonvisual opsin functions. I studied all genes known to participate in chromophore synthesis, checking their functional contribution to Drosophila hearing. Additionally, I investigated the impact of the santa-maria ${ }^{1}$ mutation on JO function and morphology. I also tested wheter proteins involved in chromophore recycling are necessary for fly audition. Finally, I checked if the main visual opsin of adult flies, Rh1, is needed for hearing.

\subsubsection{Eliminating key genes of chromophore synthesis left hearing unaffected}

Dietary uptake of $\beta$-carotene is crucial for the de novo synthesis of the chromophore. In flies, the first step in chromophore synthesis, the uptake of $\beta$-carotene into gut cells, depends on NINAD, a class B scavanger receptor (Giovannucci and Stephenson, 1999). In nina $D^{l}$ null mutant flies, this chromophore uptake is disrupted, yet hearing was normal, resembling that of controls. Upon uptake in the gut, $\beta$-carotene is cleaved into retinal by NINAB (Oberhauser et al., 2008), which also is dispensable for fly audition. Hence, disrupting $\beta$-carotene uptake and cleavage leaves hearing unaffected, suggesting that auditory opsin functions are independent of the chromophore. Support for this chromophore-independence comes from nutritional approaches, in which the animals were raised for several generations on a medium depleted of provitamin $\mathrm{A}$ ( $\beta$-carotene). 
Removing the chromophore substrate greatly reduces rhodopsin levels as evidenced by loss of PDA phenotype in photoreceptor cells (Pak et al., 2012). However, hearing remained unaffected, further suggesting that hearing requires opsin apoproteins without chromophore.

In flies, this is the first evidence for a chromophore-independent opsin function. In photoreceptor cells, the chromophore is crucial for opsin maturation and trafficking in the ER (Colley et al., 1991). Thus, it was concluded that even though non-visual opsins functions are independent of light, they still need the chromophore for opsin synthesis (Voolstra et al., 2010) . Based on my results, it seems that in hearing, opsins can be metabolized without chromophore, or there is another molecule that can play a similar role as retinal in photoreceptor cells. In either case, more research will be needed to check whether the retinal binding pocket of different opsins is free or occupied by another cofactor.

\subsubsection{Santa-Maria scavenger receptor is cructial for JO function}

Previous studies had been shown that the santa-maria ${ }^{l}$ mutation severely impacts audition in adult flies and locomotion in larvae (Senthilan et al., 2012; Zanini et al., 2018), as well as larval thermosensation (Shen et al., 2011; Sokabe et al., 2016). Consistent with these studies, hearing in santa-maria mutant flies was found to be defective, with SANTAMARIA being required for JO neuron motility and, thus, mechanical signal amplification. Also transduction seems affected as louder sounds and larger antennal displacements are required to evoke CAP responses in the antennal nerve, and also maximum CAP amplitudes are slightly lower than in controls.

Using a santa-maria T-GEM line, the native pattern of santa-maria expression was revealed. This driver showed stronger and broader expression than previously reported santa-maria-Gal4 (Wang et al., 2007), labelling accessory glia cells of chordotonal organs and other sensory neurons in both larvae and the adult stage. Also hindgut seem to express 
santa-maria - an expression that might have implications on chromophore synthesis and that had been excluded based on the old driver line (Wang et al., 2007).

The strong auditory phenotype of santa-maria ${ }^{l}$ mutants is partially rescued when $U A S$-santa-maria is driven by repo-Gal4 that targets all glia except for midline glia (Stork et al., 2012). Also the chordotonal neuron-specific driver Dnai2-Gal4 (Karak et al., 2015) is able to partially rescue hearing, suggesting that also these receptors express santa-maria at low levels, or that ectopic expression of santa-maria in the chordotonal receptors can compensate for its loss in chordotonal organ glial cells.

Mutations in opsins reportedly cause mislocalization of NOMPC and IAV TRP channels in the cilia of larval proprioceptor cells (Zanini et al., 2018). In the JO of santamaria $^{l}$ mutants, no such mislocalization was detected, neither in larval proprioceptors nor in JO receptor cells. This suggests that, in mechanoreceptors, SANTA-MARIA and opsins have unrelated functions, yet what these functions are still remains unclear. It is known that in vertebrates class B scavenger receptors type I (SR-BI) are able to recognize a broad array of ligands like oxidized low density lipoprotein (LDL), high density lipoprotein (HDL), native lipoproteins, and fatty acids (Steinbrecher, 1999). Giving that, one might speculate that Santa-Maria mediates for example cholesterol transport in chordotonal neurons, helping to maintain a proper plasma membrane composition and membrane tension necessary for mechanotransduction channel gating. This could explain why, even though TRP channels are correctly localized in santa-maria ${ }^{l}$ mutants, JO function is impaired.

\subsubsection{Auditory organ function is dependent on the proteins previously implicated is chromophore processing}

In my study, I also showed that proteins previously implicated in all-trans retinal binding and processing, PINTA and NINAG, are involved in hearing. In absence of these proteins, JO neurons lack motility witnessed by the loss of mechanical amplification. Whereas electrical JO responses of pinta ${ }^{l}$ mutants are affected only slightly, nina $^{P 330}$ flies show strong defects with respect to CAP amplitudes and thresholds. Like santa-maria, both 
genes are expressed in accessory cells of chordotonal organs. Pinta was detected in cap cells and scolopale cells, and ninaG is affiliated with ligament cells in chordotonal organs of both larvae and adult flies. In vision, the precise role of PINTA is largely unclear, besides the fact that it preferentially binds all-trans retinol in retinal pigment cells and is necessary for chromophore synthesis (Pak et al., 2012). The presence of a CRAL-TRIO domain suggests that PINTA might bind small lipophilic molecules other than retinol. Judging from the pinta ${ }^{l}$ hearing phenotype and expression pattern it may be involved in trafficking small molecules between the cap and scolopale cells.

The NINAG enzyme is also required JO neurons motility, active antennal amplification and proper electrical sound responses. NINAG belongs to a glucosemethanol-choline oxidoreductase (GMC) class of oxidoreductases (Ahmad et al., 2006). These proteins are known to act on $\mathrm{CH}-\mathrm{OH}$ group of donors performing redox reactions on a wide range of organic metabolites, however most of these metabolites still remain unknown (Sarfare et al., 2005). The exact function of NING in ligament cells likewise remains unclear. It might act in the oxidation of membrane lipids, which has a major impact on membrane physiochemical properties, both in neurons and in glial cells (Fantini et al., 2015). Possibly, NINAG participates in metabolic reactions that supply JO neurons with necessary nutrients, and further studies will be required to unravel it's mechanosensory role.

\subsubsection{Genes of chromophore recycling pathway are functionally involved in hearing}

Analogous to vertebrates, Drosophila is endowed with an enzymatic visual cycle that recycles the chromophore after its release from light-activated rhodopsin. The two enzymes participating in this pathway, PDH and RDHB, are also needed for hearing. Defects in JO performance in $P d h^{1}$ mutants resemble those seen in pinta ${ }^{l}$ mutants, with both mutant lines showing moderately reduced mechanical amplification gains. Soundevoked CAPs were only partially affected by the loss of PDH, and normal auditory function was restored by a genomic $P d h$ rescue. $r d h B^{l}$ mutants showed similarly strong auditory 
defects as seen in nina $G^{P 330}$ mutants, including strongly reduced mechanical amplification, CAP amplitudes, and auditory sensitivity.

Unfortunately, I was not able to detect $P d h$ expression in chordotonal organs. The only detectable GFP signals driven by promoter fusion construct Phd-Gla4 occurred in the retinal pigment cells. One explanation for the lack of signals in the mechanosensory organs can be that a respective part of the promoter/enhancer of $P d h$ is located further away in the genome than the $2 \mathrm{~kb}$ upstream of first ATG used to generate the Gal4 line. Another issue is that $P d h$ gene has 4 isoforms and it is possible that they are expressed via different promoters. Thus, a new Gal4 line should be generated to fully mimic $P d h$ expression pattern. RDHB, in turn, seems to occur in adult JO neurons, where faint GFP signals were detected using a previously published $r d h B$-Gal4 line (Wang et al., 2012).

$\mathrm{PDH}$ is a member of Short-chain dehydrogenase/reductase (SDR) proteins that exhibit retinol dehydrogenase and alcohol dehydrogenase (NAD) activity (Kallberg et al., 2002). PDH also shows considerable protein sequence homology (34\% identity and 54\% similarity (Gramates et al., 2017)) to mammalian Hydroxyprostaglandin dehydrogenase 15-(NAD) (HPGD) enzyme that participates in prostaglandins (PGs) metabolism (Clish et al., 2000). In flies, these highly conserved lipid signaling molecules were implicated in actin cytoskeletal remodeling in follicle cells (Groen et al., 2012). Moreover, recently HPGD was found to be expressed in mouse hair cells (Scheffer et al., 2015). There is a possibility that PDH also participates in PG metabolism, however nothing is known about PGs signaling in chordotonal organs.

Similarly to PDH, RDHB belongs to SDR class of enzymes and its only known function is the dehydrogenation of 11-cis-hydroxyretinol. When checked for orthologs, RDHB shares 57\% similarity and 37\% identity with mammalian DHRS11 (Gramates et al., 2017). This latter protein is widely expressed in human tissues, including: testis, small intestine, colon, and kidney where its catalyzes a broad range of reactions, mainly on steroids (Endo et al., 2016). In flies, RDHB might not only participate in chromophore synthesis but in some other enzymatic reactions, most probably on membrane lipids changing their composition and properties. 


\subsubsection{Rhodopsin1 has no function in JO}

The main visual rhodopsin of adult flies, Rh1, was previously shown to be involved in larval thermosensation and proprioception (Shen et al., 2011; Zanini et al., 2018). Accordingly, it seemed likely that it also plays functions in JO, in particular because larval and adult chordotonal organs are very similar in terms of both genetics and morphology. RT-PCR analysis confirmed that $r h 1$ mRNA occurs in the adult $\mathrm{JO}$, and $c s$; nina $E^{17}$ mutant flies displayed moderately impaired JO function. When nina $E^{17}$ mutation was uncovered by ninaE deficiency or put into other genetic background $(y w)$, however, hearing remained normal, indicating that that there is a site mutation in $c s ; n i n a E^{17}$ that is affecting hearing. Thus, even though Rh1 is crucial for larval chordotonal receptor function, it seems rather dispensable for the function of JO. That $r h 1$ mRNA can be detected in JO clearly does not mean that Rh1 functions in hearing, and I also cannot fully exclude contamination from the eye when separating second antennal segments by sieving. 


\section{Chapter 2: Identifying novel genes in Drosophila hearing.}

\subsection{Introduction:}

The first genetic screen for genes that are expressed in Johnston's organ was performed by Senthilan and colleagues 2012. Among the 274 identified genes the authors focused on 42 of them, describing their functional contribution to fly hearing. David Piepenbrock in his doctoral dissertation (Piepenbrock, 2013) characterized auditory phenotype of 92 more mutant fly strains. He found most of them to have defective JO functions manifested in the wide range of hearing phenotypes. Following this direction I decided to deeply characterize a couple of genes that appeared to be interesting.

My approach was to carefully study the screening list and pick the genes to study their expression pattern and hearing phenotypes based on following criteria:

- The genes that are highly abundant in Johnston's organ

- The genes that were not characterized previously or the knowledge about them is very limited

- $\quad$ The genes that contain suitable MiMIC insertions

\subsubsection{MiMIC as a powerful tool in Drosophila genetics}

\subsubsection{MiMIC features}

The Minos-Mediated Integration Cassette (MiMIC) is a specifically engineered transposable element that provides a very powerful tool in Drosophila genetics (Venken et al., 2011). One of the main features of MiMIC elements is the presence of two inverted $\Phi C 31$ attP sites that flank the whole cassette, allowing for site-specific recombination 
through recombinase-mediated cassette exchange (RMCE) (Baer and Bode, 2001). Another feature is the presence of a mutagenic gene-trap cassette that consists of a splice acceptor (SA), stop codons in all three reading frames, and a strong SV40 polyadenylation signal sequence (Venken et al., 2011). Thus, a MiMIC insertion in a coding intron and in proper orientation is highly mutagenic, leading to the truncation of transcripts.

\subsubsection{RMCE}

Exploiting the RMCE it is possible to replace MiMIC cassette with any other DNA fragment flanked by $a t t B$ sites. One of these specifically engineered DNA cassette is "Trojan exon" that consists of splice acceptor, T2A self cleaving peptide and Gal4 effector followed by pA signal (Diao and White, 2012; Diao et al., 2015c). Exchanging correctly positioned MiMIC transposon with Trojan-Gal4 allows for expressing Gal4 in pattern of a native gene. The other possibility is to swap MiMIC with cassette containing green fluorescent protein. In this approach the protein product is tagged with GFP allowing for subcellular localization analysis. 


\subsection{Results}

\subsubsection{Selection of candidate genes}

The candidate "hearing genes" were picked based on Senthilan genetic screen (Senthilan et al., 2012), RNA-seq data from Natasha Zhang (unpublished data) and criteria that were mentioned above. The two candidate genes were CG13636 (sosie) and CG14085 (Figure 27).

\begin{tabular}{|c|c|c|c|c|c|c|c|}
\hline Affymetrix ID & Public ID & Gene symbol & Gene name & Average p-value & $\mathrm{p}$-value contr $1 / \mathrm{mut}$ & p-value contr $2 / m u t$ & JO/Brain expression \\
\hline $1637514_{1} 2 t$ & CG14142 & \multirow{5}{*}{$\begin{array}{l}\text { CG14142 } \\
\text { CG13133 } \\
\text { CG14445 } \\
\text { Obp58b } \\
\text { a10 }\end{array}$} & \multirow{5}{*}{ 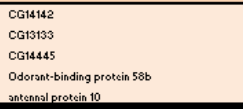 } & $2.88 E-07$ & $7.64 \mathrm{E}-08$ & 4.99E-07 & \multirow{5}{*}{\begin{tabular}{|c|}
3.069266639 \\
.808554816 \\
3.195957601 \\
1.858256466 \\
2.225833121 \\
\end{tabular}} \\
\hline 1636818_-2t & CG13133 & & & $1.50 E-06$ & $8.94 \mathrm{E}-07$ & $2.10 \mathrm{E}-06$ & \\
\hline $1631403-2 x$ & CG14445 & & & $1.978-06$ & $5.84 \mathrm{E}-07$ & $3.366-06$ & \\
\hline 1626953_xt & CG15518 & & & 3.46E-06 & 4.99E- -06 & $1.922-06$ & \\
\hline 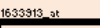 & $\cos 6642$ & & & G G2EE-A6 & $3425-07$ & $1255-0.55$ & \\
\hline 641733-2-2x & CG13636 & CG13636 & CG13636 & 6.96E -06 & $1135=-05$ & $2625 \mathrm{E}-06$ & 1078666753 \\
\hline 1835519-2t & CG13950 & CG13950 & CG13950 & $7.31 E-06$ & $2.31 E-06$ & $1.23 E-05$ & 3.652136926 \\
\hline \multirow{6}{*}{ 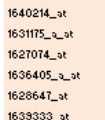 } & CGS1216 & \multirow{3}{*}{$\begin{array}{l}\text { Noom } \\
\text { CG10283 } \\
\text { CG10185 }\end{array}$} & $\begin{array}{l}\text { CG139550 } \\
\text { Nicotinmmide smidases }\end{array}$ & 9.19E-06 & $6.97 \mathrm{EE}-06$ & $1.14 E-05$ & 2.263828729 \\
\hline & CG10283 & & CG10283 & 1.11E- -05 & $4.16--06$ & $1.80 \mathrm{E}-05$ & 0.868569019 \\
\hline & CG10185 & & & $1.711 E-05$ & $2.89 E-05$ & $5.200-06$ & 3.464006559 \\
\hline & CG4329 & CG4329 & CG4329 & $1.89 E-05$ & $1.98 E-05$ & $1.80 \mathrm{E}-05$ & 2.280071502 \\
\hline & $\cos 5430$ & .5 & antenal protetin 5 & $2.73 E-05$ & $5.22 E-06$ & 4.94E-05 & 2.688555972 \\
\hline & cG3935 & \multirow{2}{*}{ cG10062 } & \multirow{2}{*}{$\begin{array}{l}\text { orizatesese } \\
\text { cG10062 }\end{array}$} & 3.07E-05 & $5.60 \mathrm{E}-05$ & $5.46 E-06$ & 1.493276264 \\
\hline \multirow{2}{*}{ 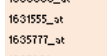 } & CG10062 & & & 3.90E-05 & $5.45 E-06$ & 7.25E-05 & 1.367668045 \\
\hline & CG11041 & CG11041 & CG11041 & $4.21 E-05$ & $6.53 E-05$ & $1.89 \mathrm{E}-05$ & 3.51589191 \\
\hline \multirow{3}{*}{$\begin{array}{l}\text { 1635956_-2x } \\
\text { 1623923_2_xt } \\
\text { 1639022_xt }\end{array}$} & CG33472 & \multirow{2}{*}{$\begin{array}{l}q u r \\
g l\end{array}$} & & $4.52 E-05$ & $6.56 \mathrm{E}-05$ & $2.47 E-05$ & 0.832136795 \\
\hline & CG7672 & & \multirow{2}{*}{$\begin{array}{l}\text { gloss } \\
\text { CG128336 }\end{array}$} & 4.54E-05 & $3.48 E-07$ & $9.05 E-05$ & 1.00497998 \\
\hline & CG12836 & CG12836 & & $5.08 E-05$ & $6.34 \mathrm{E}-05$ & $3.81 \mathrm{E}-05$ & 2.193153851 \\
\hline \multirow{2}{*}{$\begin{array}{l}1640774 \text {-2 } 2 x t \\
1640649-2 x\end{array}$} & CG17111 & \multirow{2}{*}{$\begin{array}{l}\text { Mob2 } \\
\text { CG15878 }\end{array}$} & \multirow{2}{*}{$\begin{array}{l}\text { Mob2 } \\
\text { cG15878 }\end{array}$} & $5.24 E-05$ & $6.07 \mathrm{TE}-05$ & $4.41 E-05$ & 0.940757877 \\
\hline & CG15878 & & & $5.55 E-05$ & $4.82 \mathrm{E}-05$ & 6.27E-05 & 2.309750328 \\
\hline \multirow{2}{*}{ 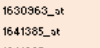 } & CG1176 & \multirow{2}{*}{$\begin{array}{l}\text { Pbprp4 } \\
\text { CG14342 }\end{array}$} & \multirow{2}{*}{$\begin{array}{l}\text { Pheromone-binding protetin-related protetin } 4 \\
\text { CG14342 }\end{array}$} & 6.22E-05 & 4.25E-05 & $8.18 \mathrm{E}-05$ & 3.594795243 \\
\hline & CG14342 & & & $6.28 E-05$ & $2.98 E-05$ & $9.58 E-05$ & 2.163360751 \\
\hline \multirow{2}{*}{$\begin{array}{l}1641605 \text { - } 2 t \\
1641427 \text { - } t\end{array}$} & CG11219 & \multirow{2}{*}{$\begin{array}{l}\text { Plp82 } \\
\text { foi }\end{array}$} & \multirow{2}{*}{$\begin{array}{l}\text { PIP82 } \\
\text { fest of intimocy }\end{array}$} & 6.52E-05 & $9.33 \mathrm{E}-06$ & $1.211-04$ & 0.964515777 \\
\hline & CG6817 & & & $6.66 \mathrm{E}-05$ & $9.30 \mathrm{E}-05$ & $4.018-05$ & 1.238565596 \\
\hline 1636556___ot & CG3620 & norpA & no rececptor potential A & $7.72 E-05$ & $1.40 \mathrm{E}-04$ & $1.45 E-05$ & 0.888302597 \\
\hline 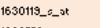 & CG3620 & norpA & no recepptor potential A & $7.78 E-05$ & $4.00 E-05$ & $1.16 E-04$ & 0.97041297 \\
\hline 1638756_at & CGIT2T9 & cGirzis & cG17279 & $8.70 E-05$ & $3.111-0.05$ & $1.43 E-04$ & 4.236065203 \\
\hline $1634752-2 x$ & CG & CG14085 & CG14085 & $908 E=-05$ & $118 \mathrm{E}=04$ & $6.378-05$ & 2.149436535 \\
\hline 1625729-3t & CG31019 & CG31019 & CG51019 & $9.43 E-05$ & $1.177-04$ & $7.21 \mathrm{E}-05$ & 2.127864812 \\
\hline 1640192_xt & $\cos 5842$ & nan & nanchung & $1.08 E-04$ & $1.17 \mathrm{TE}-05$ & $2.04 \mathrm{E}-04$ & 1.995344931 \\
\hline 1630304_-2t & CG3723 & Dhe93AB & Dyncin hesery chain ot $93, A B$ & L.09E-04 & $1.86 \mathrm{E}-04$ & $3.21 \mathrm{E}-05$ & 2.077110575 \\
\hline 1637870_-2x & $\cos 308$ & dpr5 & dpr5 & $1.10 E-04$ & $1.41 E-04$ & $7.978-05$ & 0.818300174 \\
\hline 1640970_xt & cG9313 & cG9513 & cG9313 & $1.12 E-04$ & $1.37 \mathrm{EE}-04$ & $8.695-05$ & 1.450950162 \\
\hline 1626722_.t & CG14087 & CG14087 & CG14087 & $1.13 \mathrm{E}-04$ & $1.62 \mathrm{E}-04$ & $6.31 E-05$ & 0.894411867 \\
\hline 1631168 -2t & $\cos 6887$ & CG5687 & $\operatorname{cG5} 6887$ & $1.14 \mathrm{E}-04$ & $1.73 \mathrm{E}-04$ & $5.44 E-05$ & 1.345839368 \\
\hline 163809Lat & CG15143 & CG15143 & $\operatorname{cG15143}$ & $1.18 \mathrm{E}-04$ & $1.89 \mathrm{~F}-04$ & $4.77 \mathrm{E}-05$ & 1.594023939 \\
\hline 1638110_xt & CG40467 & CG40467 & CG40467 & $1.20 E-04$ & 4.72E-05 & $1.93 \mathrm{E}-04$ & 0.930087436 \\
\hline 1624383_x & HDCo5946 & & & $1.25 E-04$ & $1.61 \mathrm{E}-04$ & $8.87 \mathrm{E}-05$ & 1.922929249 \\
\hline 1633313_-2t & CG18768 & Ank2 & Ankyrin 2 & $1.35 E-04$ & $1.88 \mathrm{E}-04$ & $8.177-05$ & 0.971298961 \\
\hline 1632968 _t & $\operatorname{cG6} 6053$ & CG6053 & CG6053 & 1.40E-04 & $1.42 E-04$ & 0.000138488 & 2.489562475 \\
\hline $1630118-e_{-2 x}$ & CG8529 & Dyb & Dyearobresin-like & $1.54 E-04$ & $1.07 E-04$ & 0.000200437 & 0.797543729 \\
\hline $1636288 \_x$ & CGM132 & yuri & yuri gogorin & $1.595-04$ & $2.25 E-04$ & $9.36 \mathrm{E}-05$ & 1.688681723 \\
\hline 1636865_2t & CG3250 & 000 & $00 . \mathrm{c}$ & $1.67 \mathrm{E}-04$ & $1.58 E-04$ & 0.000174962 & 2.269494063 \\
\hline 1634272_xt & CG18516 & CG18516 & CG18516 & $1.68 \mathrm{E}-04$ & $5.64 E-05$ & 0.000278846 & 4.344801648 \\
\hline 1626574_2t & CG9935 & cG9935 & CG9935 & $2.10 E-04$ & $3.85 E-05$ & 0.0003807 & 0.95474114 \\
\hline 1628369_xt & $\operatorname{cG8285}$ & boss & bride of acenenleses & $2.17 \mathrm{E}-04$ & $1.35 E-05$ & 0.000420452 & 0.913389059 \\
\hline
\end{tabular}

Figure 27. Screenshot showing list of the genes detected in Drosophila JO from Senthilian et al., 2012.

Highlighted are the two genes that met chosen criteria: CG13636 (sosie) and CG14085. Modified from Senthilian et al,. 2012. 


\subsubsection{Sosie}

sosie gene has 3 annotated transcripts that encode 3 protein variants. The biggest, sosie-PA has a predicted molecular mass of $20 \mathrm{kDa}$ and consists of 186 amino acids. The other two isoforms are $8.2 \mathrm{kDa}$ proteins consisting of 74 amino acids. The protein is insectspecific and no orthologs can be found in non-insect species. Previously, Sosie was reported to localize to membranes in the germ line and follicle cells where it is responsible for epithelial integrity and cell migration (Urwyler et al., 2012). Moreover, Sosie was shown to be crucial for maintaining the normal localization of the cortical F-actin cytoskeleton, most probably by organizing or supporting $\beta_{\mathrm{H}^{-}}$Spectrin localization and interactions with the actin organizing genes cheerio and chic (Urwyler et al., 2012).

Within the sosie gene there is one MiMIC insertion, $\left(M i\{M I C\} \operatorname{sosie} e^{M I 1265}\right)$, which is inserted into a coding intron in the same orientation as the gene. Thus, this MiMIC transposon should act as a mutator gene trap that truncates the sosie-PA transcript variant.

\subsubsection{Hearing in sosie mutant flies is severely impaired}

Homozygous sosie $e^{\text {MiMIC }}$ flies are viable and do not display any obvious mutant phenotype e.g. walking or coordination problems. However, the free fluctuations of their sound receiver are severely impaired. Compared to controls, the fluctuation power was reduced to $220 \pm 197 \mathrm{~nm}^{2} / \mathrm{Hz}$, with the fluctuations displaying a very pronounced peak at $772 \pm 149 \mathrm{~Hz}$ (Figure 28A). In line with the altered fluctuations, mechanical amplification was virtually lost, with amplification gains of $1.5 \pm 0.2$ (Figure 28B). Electrophysiological recordings from the antennal nerve revealed virtually no sound-evoked CAPs responses (Figure 28C). The maximum CAPs amplitude was as low as $1 \pm 0.1 \mu \mathrm{V}$, and when relative response amplitudes were plotted against the sound particle velocity or the antennal displacement, data scattered and no clear response could be seen (Figure 28C). 

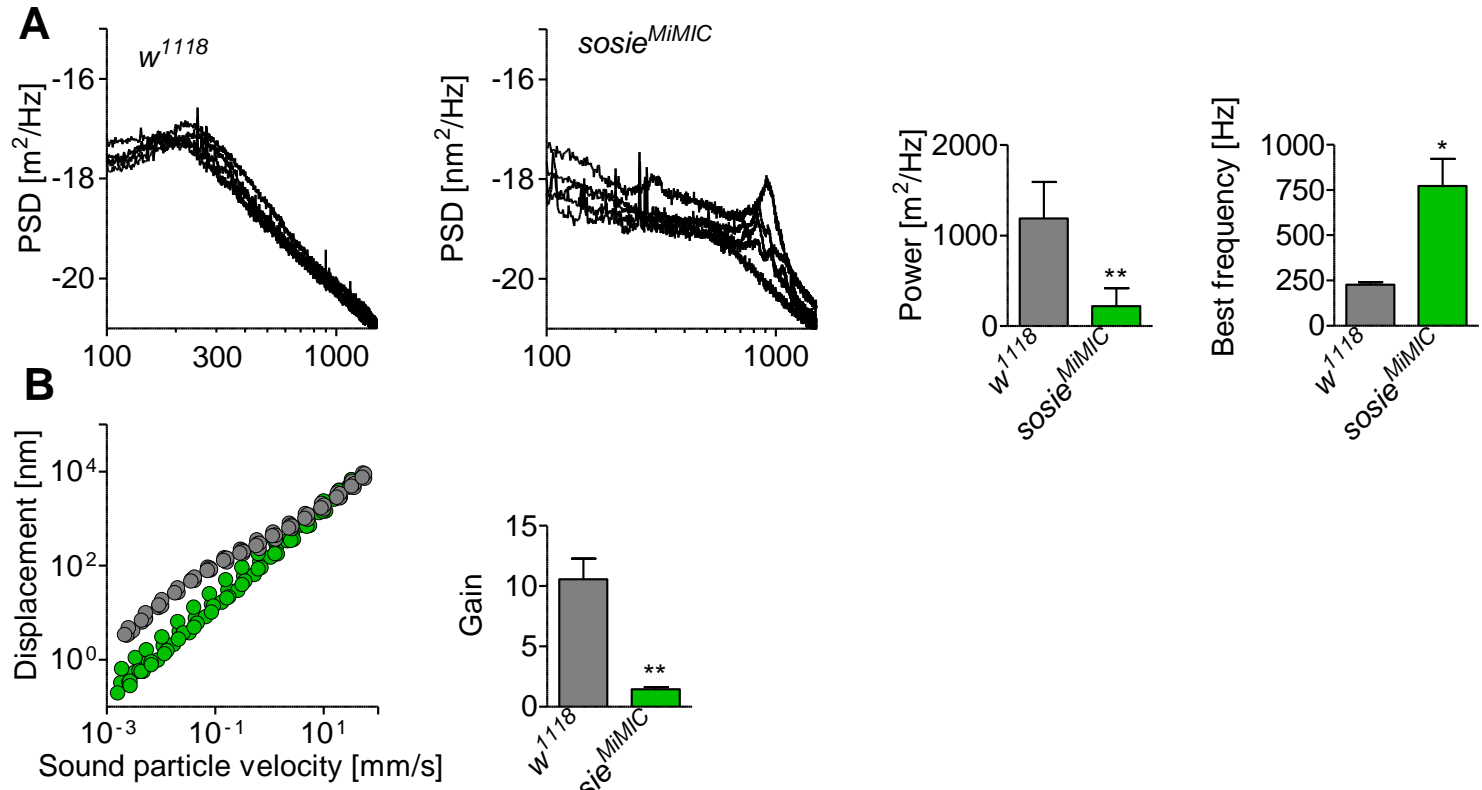

\section{C}
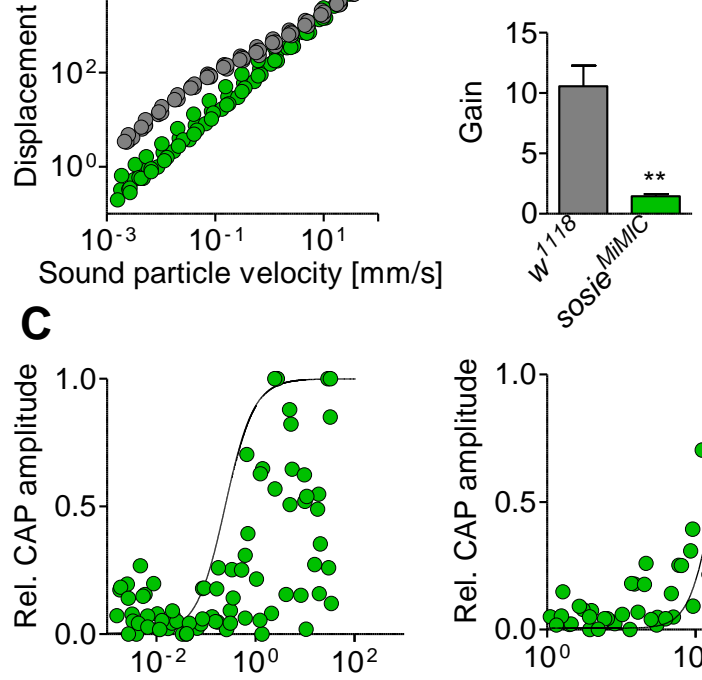

Sound particle velocity $[\mathrm{mm} / \mathrm{s}]$
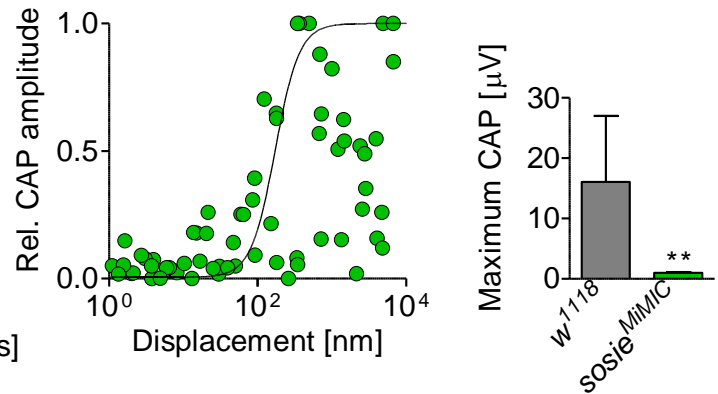

Figure 28. Laser Dopppler Vibrometer analysis of auditory defects in sosie mutant flies.

A) Left: power spectral density (PSD) of the free mechanical fluctuation of the antenna in the $w^{1118}$ controls and sosie $e^{M I M I C}$ mutants $(\mathrm{N}=5$ per strain). Right: respective fluctuation powers and antennal best frequencies.

B) Left: Tone-evoked antennal displacement as a function of the particle velocity of the tone. In grey controls and in green sosie ${ }^{M I M I C}$ mutants. Right: respective mechanical amplification gains.

C) Left: Relative amplitude of toned-evoked CAPs as a function of the particle velocity of the tone and respective particle velocity thresholds. Middle: CAP amplitude plotted against the respective antennal displacement and corresponding displacement thresholds. Left: Maximum CAP responses.

Data are presented as a mean values $\pm 1 \mathrm{SD}, \mathrm{N}=5, * \mathrm{P}<0.05, * * \mathrm{P}<0.01$ two-tailed Mann Whitney U-test. 


\subsubsection{Sosie is present in auditory neurons}

To assess the cell types that express sosie, a sosie ${ }^{\text {Trojan }}-$ Gal4 was generated. Therefore, RMCE between $M i\{M I C\} \operatorname{sosie}^{M I 1265}$ and the Trojan-exon was performed using a "triplet donor" in vivo approach (Diao et al., 2015c). Then, sosie ${ }^{\text {Trojan }}$-Gal4 was crossed to $U A S-Y F P$ flies to check for expression in larval and adult chordotonal organs. In larvae, GFP signals were clearly visible even without immunhistochemical staining. sosie ${ }^{\text {Trojan }}$ Gal4 showed a broad expression pattern in the nervous system, including lch5 chordotonal organ neurons (Figure 29 top). In adults, GFP signals were found in $2^{\text {nd }}$ antennal segment neurons (Figure 29 bottom). Interestingly, not all neurons seem to be expressing sosie as indicated by arrows (Figure 29 bottom left).

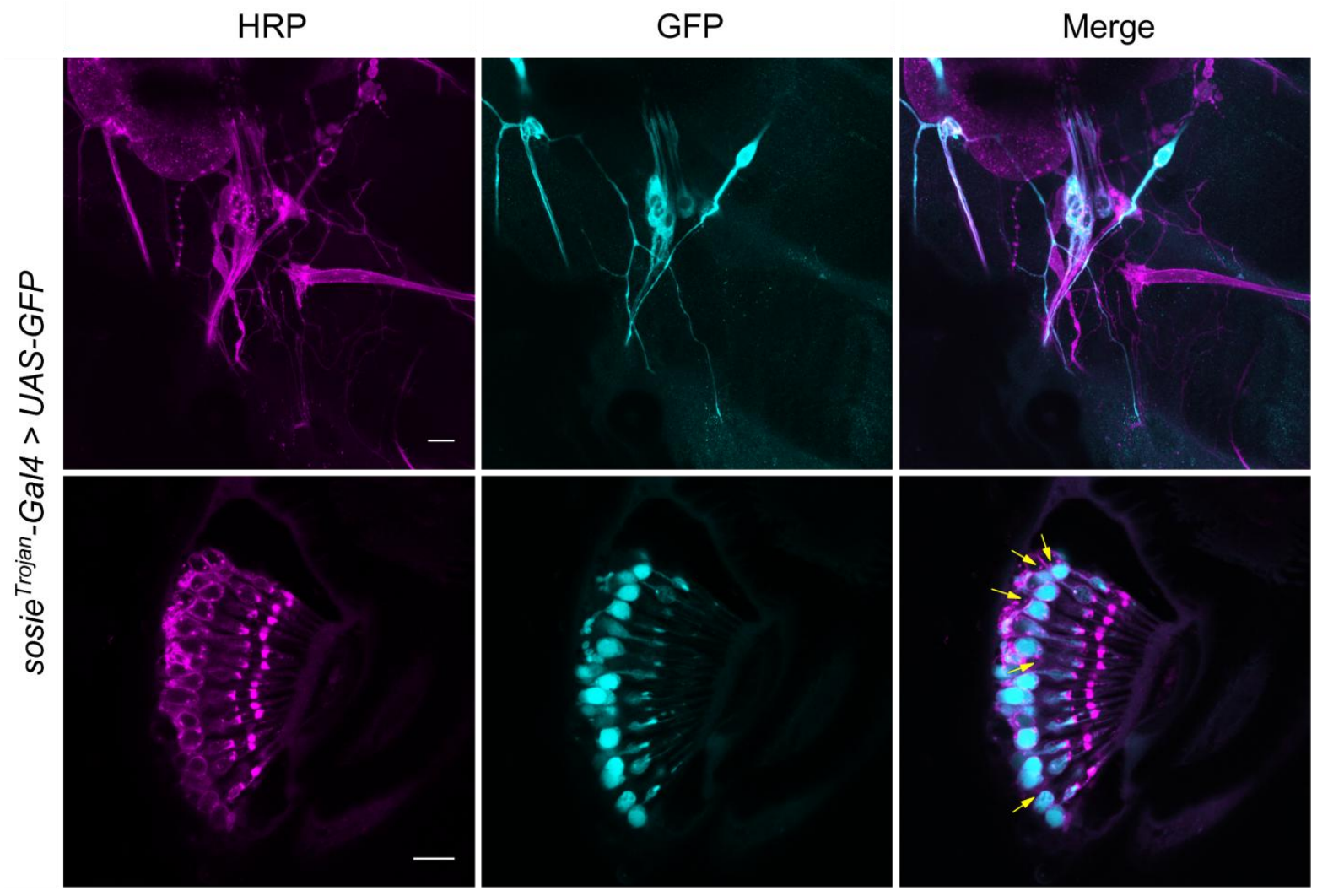

Figure 29. sosie $^{\text {Trojan }}$-Gal4 expression pattern in larval and adult chordotonal organs

Top: Immumohistochemical staining of larval lch5 chordotonal organ. Neurons are stained with HRP magenta, GFP signal is shown in cyan. Overlap picture on the right. Scale bar $=10 \mu \mathrm{m}$.

Bottom: Adult $2^{\text {nd }}$ antennal segment staining. Neurons are stained with HRP - magenta, GFP signal is shown in cyan. Overlap picture on the right (arrowheads indicate neurons that are not stained). Scale bar $=10 \mu \mathrm{m}$. 


\subsubsection{Morphology of JO neurons in sosie mutants}

Auditory impairments in sosie $e^{M i M I C}$ mutants might reflect defects in F-actin organization, similary to what previously observed in oocytes. To check this possibility, sliced $2^{\text {nd }}$ antennal segments of sosie $e^{M i M I C}$ mutant flies were stained with the neuronal marker anti-HRP and phalloidin, which stains F-actin. However, no structural defects of the neurons or the adjacent actin- rich scolopale rods could be detected (Figure 30).

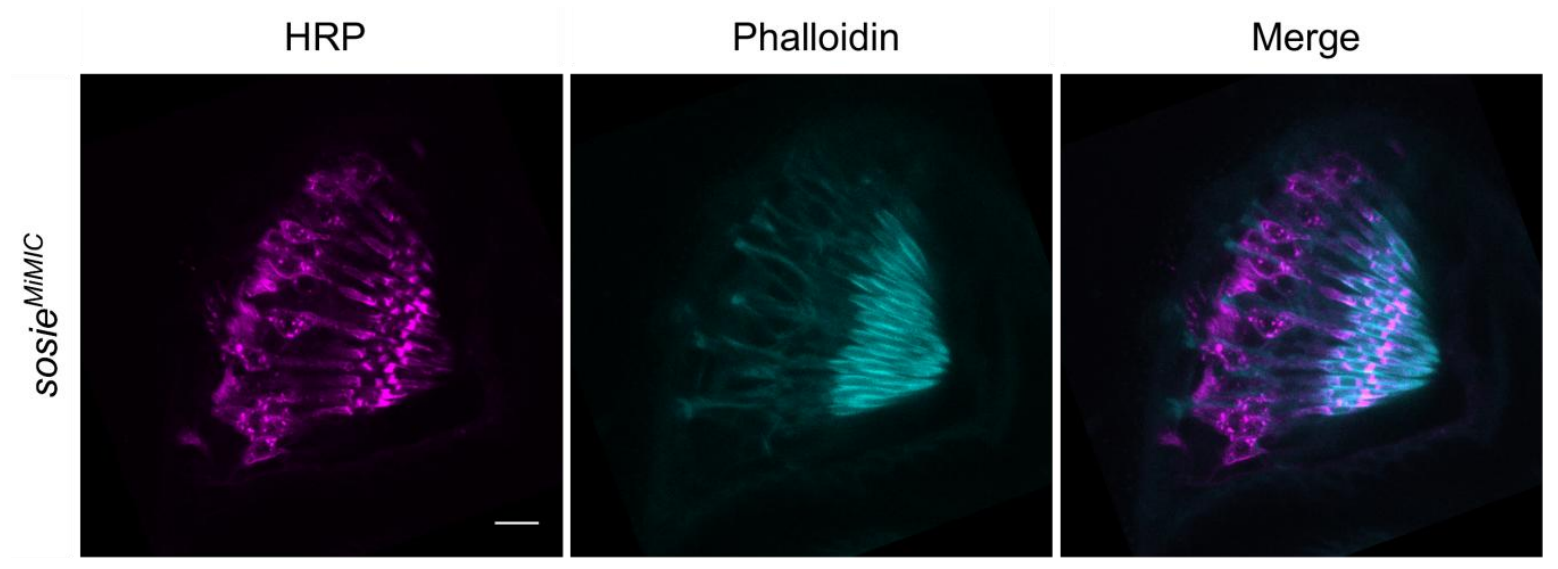

Figure 30. Johnston's organ staining of sosie ${ }^{M i M I C}$ mutants

Adult $2^{\text {nd }}$ antennal segment staining. Neurons are stained with HRP - magenta, phalloidin is shown in cyan. Overlap picture on the right. Scale bar $=10 \mu \mathrm{m}$. 


\subsubsection{CG14085 - the unknown Drosophila gene}

CG14085 gene encodes one protein variant of a predicted mass of $98 \mathrm{kD}$ that previously was not characterized. The protein is categorized as "Protein of unknown function DUF4495" family which shares two conservative motifs: QMW and DLW that can be found in eukaryotes. In order to make a prediction of CG14085 protein model the phyre2 online software was used (Kelly et al., 2015). Based on its analysis, predicted secondary structure of CG14085 protein is still mysterious due to relatively low alligment coverage and identity procentage with other known protein domains as sumarized in Table 1.

\begin{tabular}{|c|c|c|l|}
\hline $\begin{array}{l}\text { Alligment } \\
\text { coverage }\end{array}$ & Confidence & $\%$ identity & Protein data base (PDB) molecule \\
\hline $6 \%$ & 44.6 & 11 & Putative phospholipase b-like 2 \\
\hline $9 \%$ & 37.3 & 11 & $\begin{array}{l}\text { Tutd, benzylsuccinate alpha-gamma } \\
\text { complex }\end{array}$ \\
\hline $6 \%$ & 34.2 & 11 & Putative phospholipase b-like 2 \\
\hline $5 \%$ & 33.7 & 23 & RNA-binding domain \\
\hline
\end{tabular}

Table 1. Summarized analysis of CG14085 protein domains obtained from phyre2 software

\subsubsection{Hearing deficits in CG14085 mutant flies}

To test whether CG14085 has a function in fly auditory system a MiMIC line CG14085 ${ }^{\text {MI11086 }}$ was used. In this strain MiMIC transposon is placed in coding intron between $2^{\text {nd }}$ and $3^{\text {rd }}$ exon in correct orientation, which should result in truncated transcript. Homozygous animals and viable and do not show any noticeable impairments. When it comes to auditory performance, mutants show considerably higher fluctuation power (6333 $\left.\pm 1730 \mathrm{~nm}^{2} / \mathrm{Hz}\right)$ together with reduced antennal best frequency $(132 \pm 20 \mathrm{~Hz})$ (Figure $\left.31 \mathrm{~A}\right)$. As a consequence of excessive JO neurons motility, amplification gain increased to $26 \pm 5$ (Figure 31B). Maximum sound-evoked action potentials recorded from antennal nerve were significantly lower reaching $7.4 \pm 0.9 \mathrm{mV}$. The CG14085 ${ }^{M i M I C}$ mutation strongly impaired sensitive hearing as both sound particle velocity threshold and displacement threshold increased to $0.118 \pm 0.044 \mathrm{~mm} / \mathrm{s}$ and $179 \pm 43 \mathrm{~nm}$ respectively (Figure $31 \mathrm{C}$ ). 

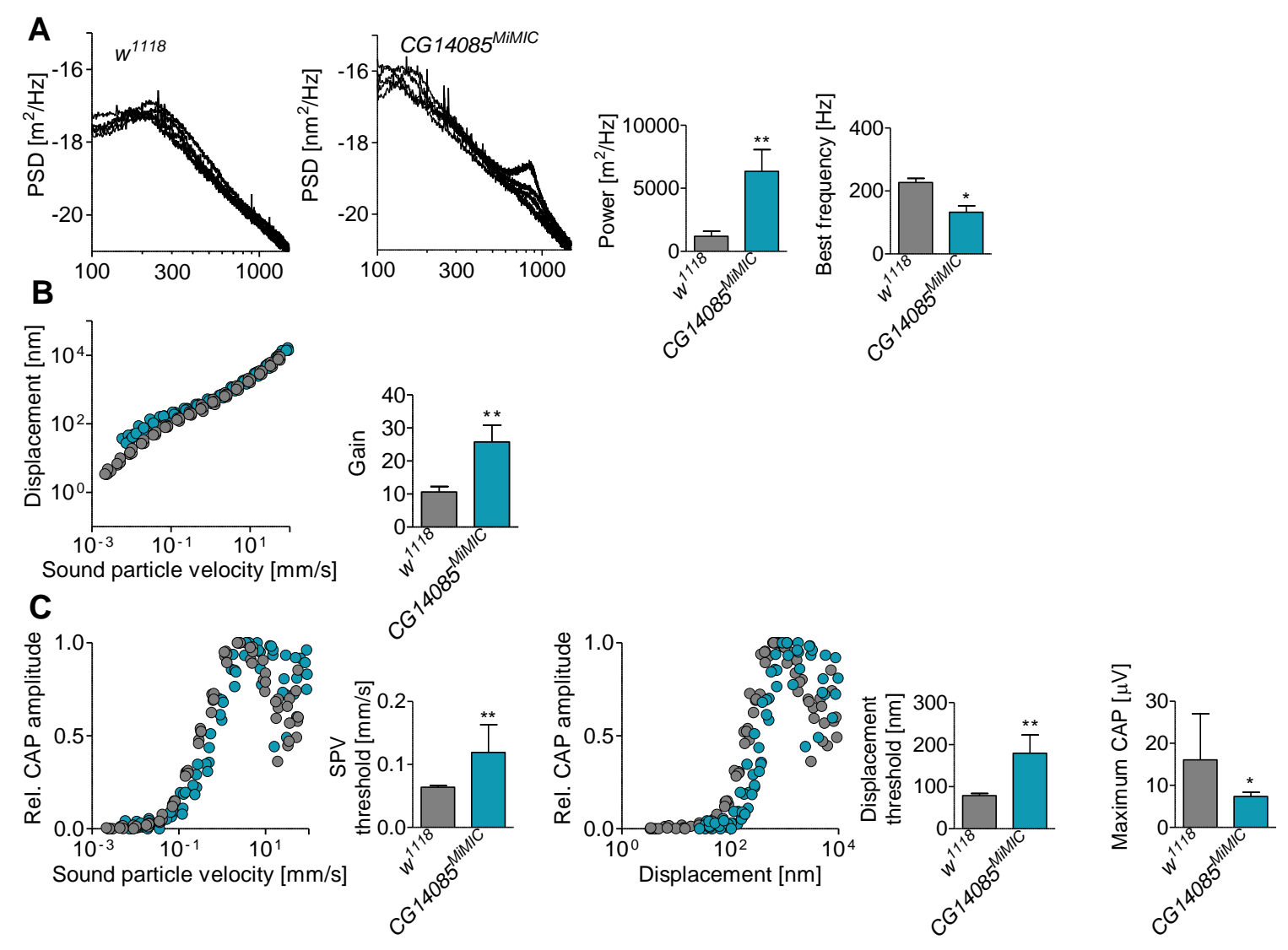

Figure 31. Auditory phenotype of CG14085 ${ }^{M i M I C}$ mutant flies.

A) Left: power spectral density (PSD) of the free mechanical fluctuation of the antenna in the $w^{1118}$ controls and $C G 14085^{M I M I C}$ mutants ( $\mathrm{N}=5$ per strain). Right: respective fluctuation powers and antennal best frequency.

B) Left: Tone-evoked antennal displacement as a function of the particle velocity of the tone. $C G 14085^{M I M I C}$ mutants in blue and controls in gray. Right: respective mechanical amplification gains.

C) Left: Relative amplitude of toned-evoked CAPs as a function of the particle velocity of the tone and respective particle velocity thresholds. Right: CAPs amplitude plotted against the respective antennal displacement and corresponding displacement thresholds together with maximum CAPs.

Data are presented as a mean values $\pm 1 \mathrm{SD}, \mathrm{N}=5, * \mathrm{P}<0.05$, ** $\mathrm{P}<0.01$ two-tailed Mann Whitney U-tests against $w^{1118}$ controls and CG14085 $5^{\text {MIMIC }}$ mutants. 


\subsubsection{CG14085 is expressed in chordotonal organs}

To investigate whether CG14085 is expressed in Drosophila chordotonal organs MiMIC cassette was replaced with Trojan-Gal4 through in vivo RMCE. When crossed to UAS-GFP reporter fluorescent signals can be observed both in larval lch5 chordotonal organ neurons and in adult JO neurons (Figure 32). It is worth to mention that CG14085 expression pattern seem to be chordotonal neurons specific, as I could not detect GFP signals in other neurons or cells.

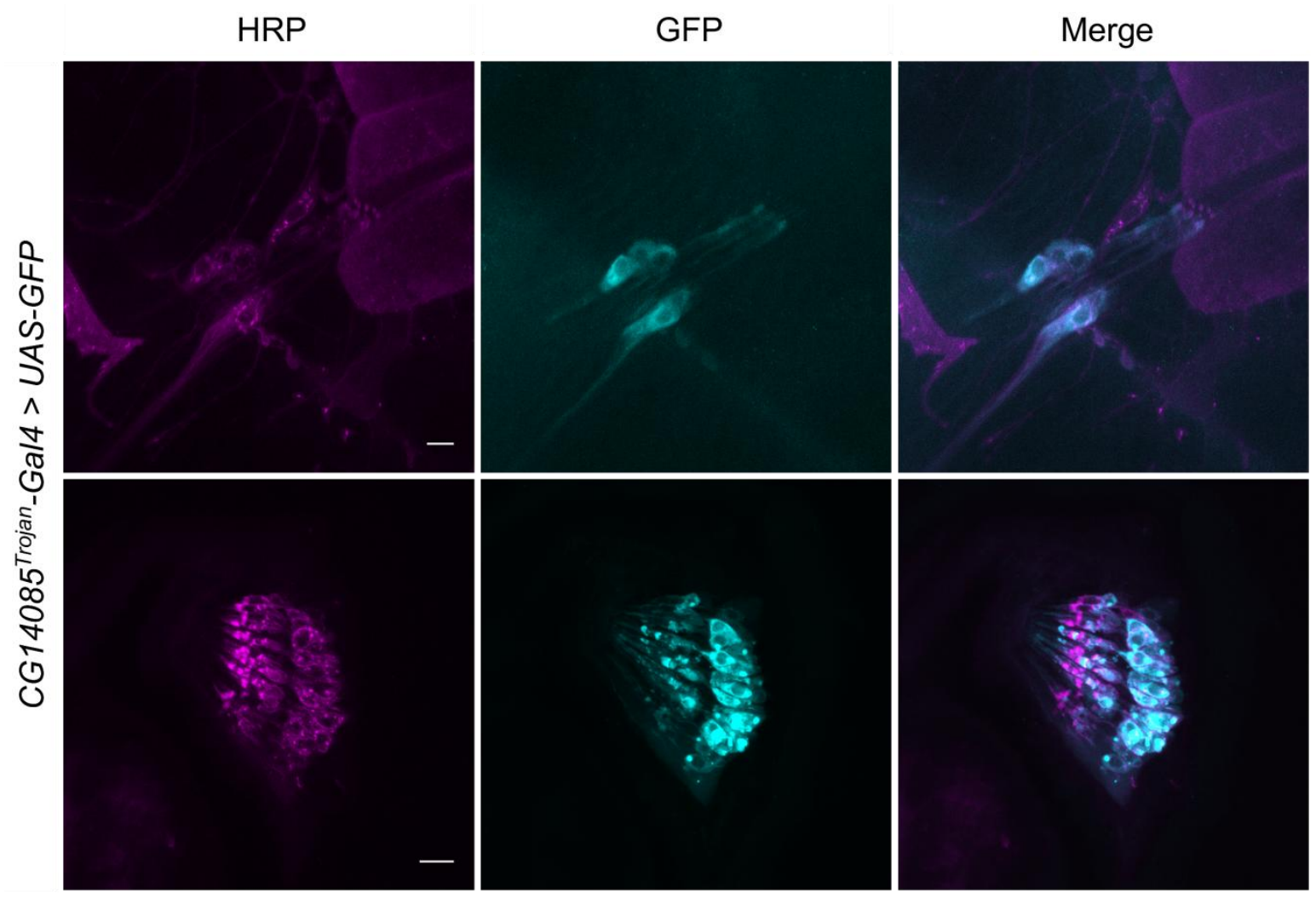

Figure 32. CG14085 expression pattern in chordotonal organs.

Top: Immumohistochemical staining of larval lch5 chordotonal organ. Neurons are stained with HRP magenta, GFP signal is shown in cyan. Overlap picture on the right. Scale bar $=10 \mu \mathrm{m}$.

Bottom: Adult $2^{\text {nd }}$ antennal segment staining. Neurons are stained with HRP - magenta, GFP signal is shown in cyan. Overlap picture on the right. Scale bar $=10 \mu \mathrm{m}$. 


\subsection{Discussion}

The aim of my study was to characterize the novel genes involved in hearing process in Drosophila. In order to identify them I used a data from previously published genetic screen (Senthilan et al., 2012) and recent RNA-seq data (unpublished, Zhang) of the genes expressed in $2^{\text {nd }}$ antennal segment. I also wanted to implement and take advantage of recently developed MiMIC genetic technique.

I decided to focus on two potential "hearing" genes that were highly enriched in Johnston's organ. I found that sosie, which was previously implicated in Drosophila oogenesis (Urwyler et al., 2012), is also functionally involved in hearing. Sosie MiMIC $^{\text {M }}$ mutants have severe defects in JO function, where mechanosensory neurons lack motility witness by loss of mechanical amplification. Additionally, sound-evoked CAPs recorded from the antennal nerve are almost abolished, suggesting that not only antennal mechanics is impaired but also electric signal transduction and propagation. Sosie seems to operate in JO neurons as confirmed by sosie ${ }^{\text {Trojan- }}$ Gal4 line. Yet, what is the cause of such a strong auditory phenotype is elusive. Since previous studies linked Sosie with cortical F-actin organization through $\beta_{\mathrm{H}}$-Spectrin in nurse cells during oogenesis (Urwyler et al., 2012), it also might play similar role in chordotonal neurons. Nonetheless, sosie mutants display typical F-actin organization in scolopale rods and ligament cells, thus mechanosensory role of Sosie seems to be not related with actin modeling.

The second gene selected for the analysis was CG14085 that encodes largely unknown protein. According to my results, CG14085 is required for normal mechanosensory function of antennal ear. CG14085 $5^{M i M I C}$ mutant flies display excessive antennal fluctuation power and slightly shifted individual best frequency. As a consequence, mechanical amplification gains are ca. 3 times higher than in wild types. The gene is also expressed in chordotonal neurons cell bodies as shown by $C G 14085^{\text {Trojan- }}$ Gal4 line. There is little known about CG14085 protein structure, biological process, molecular function and cellular localization besides the fact that it contains a conserved sequence motif QMW and DLW and belongs to the protein of unknown function DUF4495 family. According to flybase CG14085 is an ortholog of human KIAA0825 with $38 \%$ similarity and $22 \%$ identity. 
KIAA0825 is considered as a possible risk factor in Type II diabetes that might increase the glucose levels in the blood ( $\mathrm{Li}$ et al., 2016). It is predicted to shuttle back and forth across the nuclear membrane (Nakai and Horton, 1999). However, the precise function of this protein in humans remains unknown. The hearing performance of CG14085 ${ }^{\text {MiMIC }}$ mutants closely resembles the auditory defects seen in nan and iav mutants. In Drosophila these TRPV channels are believed to negatively control NOMPC dependent amplification, thus nan or iav mutant flies exhibit excessive antennal fluctuations and mechanical amplification (Göpfert et al., 2006). Having this in mind, one possibility might be that CG14085 influence NAN or Iav functions.

To narrow down the exact function of Sosie and GC14085 in JO mechanosensory neurons further research need to be done. This includes generation of $U A S$-sosie::GFP and UAS-CG14085::GFP lines which could help to reveal cellular localization of both proteins. The other possibility might be to swap MiMIC with GFP cassette; however expressing GFP within the protein sequence could result in incorrect localization or even protein degradation. GFP tagged protein would open possibility to perform coimmunoprecipitation in order to find interaction partners. Both genes are excellent candidates for further research in Drosophila hearing. 


\section{Summary}

During the past years, rhodopsins, besides serving vision, have been implicated in thermoand mechanosensation. Two out of seven Drosophila rhodopsins (Rh5, Rh6) were shown to be crucial for proper JO function in fly hearing. However, little was known about whether these non-visual functions involve the light-sensitive retinal chromophore or opsin apoprotein alone. In this thesis I showed that depriving wild-type flies from dietary carotenoids as well as disrupting proteins responsible for $\beta$-carotene uptake and cleavage do not impact Drosophila mechanosensory JO function, documenting biological function for opsin apoproteins alone. Rather surprisingly, fly hearing turned out to be nonetheless impaired in the flies lacking chromophore processing proteins and visual cycle enzymes. Moreover, expression studies revealed that respective proteins are present in accessory cells of chordotonal mechanosensory organs. Exact function of these proteins in Drosophila hearing is still elusive and will require further studies. I also looked at possible functions of Rh1 in adult hearing, but unlike Rh5 and Rh6, the fly's main visual opsin seems to be dispensable for JO function.

In the second part of my thesis I focused on sosie and CG14085 that were identified as a putative genes for hearing in JO gene expression screens. Testing MiMIC mutants, I found that both genes are required for JO function, with sosie ${ }^{\text {MiMIC }}$ flies showing abolished mechanical amplification and CG14085 $5^{\text {MiMIC }}$ mutants displaying excessive amplification. Replacing MiMIC cassettes with Trojan-Gal4 through RMCE revealed that both genes are expressed in chordotonal sensory neurons, both in larval lch5 organs and and JO. Apart from an initial characterization of sosie and CG14085 as "hearing genes", I showed that MiMIC is a powerful and versatile screening tool that can be applied for describing new genes in Drosophila audition. 


\section{Biblioghaphy:}

Ahmad, S.T., Joyce, M. V., Boggess, B., and O'Tousa, J.E. (2006). The role of Drosophila ninaG oxidoreductase in visual pigment chromophore biogenesis. J. Biol. Chem. 281, 9205-9209.

Albert, J.T., and Göpfert, M.C. (2015). Hearing in Drosophila. Curr. Opin. Neurobiol. 34, $79-85$.

Albert, J.T., Nadrowksi, B., and Göpfert, M.C. (2007a). Drosophila mechanotransduction linking proteins and functions. Fly (Austin). 1, 238-241.

Albert, J.T., Nadrowski, B., and Göpfert, M.C. (2007b). Mechanical Signatures of Transducer Gating in the Drosophila Ear. Curr. Biol. 17, 1000-1006.

Azusa Kamukouchi, Tkashi Shimada, K.I. (2006). Comprehensive Classification of the Auditory Sensory Projections in the Brain of the Fruit Fly Drosophila melanogaster. J. Comp. Neurol. 499, 317-356.

Baer, A., and Bode, J. (2001). Coping with kinetic and thermodynamic barriers: RMCE, an efficient strategy for the targeted integration of transgenes. Curr. Opin. Biotechnol. 12, $473-480$.

Bokolia, N.P., and Mishra, M. (2015). Hearing molecules, mechanism and transportation: Modeled in Drosophila melanogaster. Dev. Neurobiol. 75, 109-130.

Brewster, R., and Bodmer, R. (1995). Origin and specification of type II sensory neurons in Drosophila. Development 121, 2923-2936.

Caldwell, J.C., and Eberl, D.F. (2002). Towards a molecular understanding of Drosophila hearing. J. Neurobiol. 53, 172-189.

Caldwell, J.C., Miller, M.M., Wing, S., Soll, D.R., and Eberl, D.F. (2003). Dynamic analysis of larval locomotion in Drosophila chordotonal organ mutants. Proc. Natl. Acad. Sci. $100,16053-16058$.

Clish, C.B., Levy, B.D., Chiang, N., Tai, H.H., and Serhan, C.N. (2000). Oxidoreductases 
in lipoxin A4 metabolic inactivation: A novel role for 15-oxoprostaglandin 13reductase/leukotriene B4 12-hydroxydehydrogenase in inflammation. J. Biol. Chem. 275, $25372-25380$.

Colley, N.J., Baker, E.K., Stamnes, M.A., and Zuker, C.S. (1991). The cyclophilin homolog ninaA is required in the secretory pathway. Cell 67, 255-263.

Diao, F., and White, B.H. (2012). A novel approach for directing transgene expression in Drosophila: T2A-Gal4 in-frame fusion. Genetics 190, 1139-1144.

Diao, F., Ironfield, H., Luan, H., Diao, F., Shropshire, W.C., Ewer, J., Marr, E., Potter, C.J., Landgraf, M., and White, B.H. (2015a). Plug-and-play genetic access to drosophila cell types using exchangeable exon cassettes. Cell Rep. 10, 1410-1421.

Diao, F., Ironfield, H., Luan, H., Diao, F., Shropshire, W.C., Ewer, J., Marr, E., Potter, C.J., Landgraf, M., and White, B.H. (2015b). Plug-and-play genetic access to drosophila cell types using exchangeable exon cassettes. Cell Rep. 10, 1410-1421.

Diao, F., Ironfield, H., Luan, H., Diao, F., Shropshire, W.C., Ewer, J., Marr, E., Potter, C.J., Landgraf, M., and White, B.H. (2015c). Plug-and-play genetic access to Drosophila cell types using exchangeable exon cassettes. Cell Rep. 10, 1410-1421.

Dickson, B.J. (2008). Wired for sex: The neurobiology of Drosophila mating decisions. Science (80-. ). 322, 904-909.

Dolph, P.J., Ranganathan, R., Colley, N.J., Hardy, R.W., Socolich, M., and Zuker, C.S. (1993). Arrestin Function in Inactivation of G-Protein Coupled Receptor Rhodopsin Invivo. Science (80-. ). 260, 1910-1916.

Effertz, T., Wiek, R., and Göpfert, M.C. (2011). NompC TRP channel is essential for Drosophila sound receptor function. Curr. Biol. 21, 592-597.

Effertz, T., Nadrowski, B., Piepenbrock, D., Albert, J.T., and Göpfert, M.C. (2012). Direct gating and mechanical integrity of Drosophila auditory transducers require TRPN1. Nat. Neurosci. 15, 1198-1200. 
Endo, S., Miyagi, N., Matsunaga, T., Hara, A., and Ikari, A. (2016). Human dehydrogenase/reductase (SDR family) member 11 is a novel type of $17 \beta$-hydroxysteroid dehydrogenase. Biochem. Biophys. Res. Commun. 472, 231-236.

Fantini, J., Yahi, N., Fantini, J., and Yahi, N. (2015). Lipid Metabolism and Oxidation in Neurons and Glial Cells. Brain Lipids Synaptic Funct. Neurol. Dis. 53-85.

Fritzsch, B., Beisel, K.W., Pauley, S., and Soukup, G. (2007). Molecular evolution of the vertebrate mechanosensory cell and ear. Int. J. Dev. Biol. 51, 663-678.

Giovannucci, D.R., and Stephenson, R.S. (1999). Identification and distribution of dietary precursors of the Drosophila visual pigment chromophore: Analysis of carotenoids in wild type and ninaD mutants by HPLC. Vision Res. 39, 219-229.

Göpfert, M.C., and Robert, D. (2001). Turning the key on Drosophila audition. Nature 411, 908.

Göpfert, M.C., and Robert, D. (2002). The mechanical basis of Drosophila audition. J. Exp. Biol. 205, 1199-1208.

Göpfert, M.C., and Robert, D. (2003). Motion generation by Drosophila mechanosensory neurons. Proc. Natl. Acad. Sci. U. S. A. 100, 5514-5519.

Göpfert, M.C., Humphris, A.D.L., Albert, J.T., Robert, D., and Hendrich, O. (2005). Power gain exhibited by motile mechanosensory neurons in Drosophila ears. Proc. Natl. Acad. Sci. U. S. A. 102, 325-330.

Göpfert, M.C., Albert, J.T., Nadrowski, B., and Kamikouchi, A. (2006). Specification of auditory sensitivity by Drosophila TRP channels. Nat. Neurosci. 9, 999-1000.

Gramates, L.S., Marygold, S.J., Dos Santos, G., Urbano, J.M., Antonazzo, G., Matthews, B.B., Rey, A.J., Tabone, C.J., Crosby, M.A., Emmert, D.B., et al. (2017). FlyBase at 25: Looking to the future. Nucleic Acids Res. 45, D663-D671.

Grebler, R., Kistenpfennig, C., Rieger, D., Bentrop, J., Schneuwly, S., Senthilan, P.R., and Helfrich-Förster, C. (2017). Drosophila Rhodopsin 7 can partially replace the structural role 
of Rhodopsin 1, but not its physiological function. J. Comp. Physiol. A Neuroethol. Sensory, Neural, Behav. Physiol. 203, 649-659.

Greenspan, R.J. (2000). Courtship in Drosophila.

Groen, C.M., Spracklen, A.J., Fagan, T.N., and Tootle, T.L. (2012). Drosophila Fascin is a novel downstream target of prostaglandin signaling during actin remodeling. Mol. Biol. Cell 23, 4567-4578.

Halachmi, N., Nachman, A., and Salzberg, A. (2016). A newly identified type of attachment cell is critical for normal patterning of chordotonal neurons. Dev. Biol. 411, 6171.

Hartenstein, V. (1988). Development of Drosophila larval sensory organs: spatiotemporal pattern of sensory neurones, peripheral axonal pathways and sensilla differentiation. Development 102, 869-886.

Jarman, A.P., and Groves, A.K. (2013). The role of Atonal transcription factors in the development of mechanosensitive cells. Semin. Cell Dev. Biol. 24, 438-447.

Kallberg, Y., Oppermann, U.D.O., and Jörnvall, H. (2002). Short chain dehydrogenasereductase (SDR) relationships: A large family with eight clusters common to human, animal, and plant genomes. Protein Sci. 11, 636-641.

Kamikouchi, A., Inagaki, H.K., Effertz, T., Hendrich, O., Fiala, A., Göpfert, M.C., and Ito, K. (2009). The neural basis of Drosophila gravity-sensing and hearing. Nature 458, 165171.

Karak, S., Jacobs, J.S., Kittelmann, M., Spalthoff, C., Katana, R., Sivan-Loukianova, E., Schon, M.A., Kernan, M.J., Eberl, D.F., and Göpfert, M.C. (2015). Diverse Roles of Axonemal Dyneins in Drosophila Auditory Neuron Function and Mechanical Amplification in Hearing. Sci. Rep. 5, 1-12.

Kelly, L.A., Mezulis, S., Yates, C., Wass, M., and Sternberg, M. (2015). The Phyre2 web portal for protein modelling, prediction, and analysis. Nat. Protoc. 10, 845-858. 
Kiefer, C., Hessel, S., Lampert, J.M., Vogt, K., Lederer, M.O., Breithaupt, D.E., and Von Lintig, J. (2001). Identification and Characterization of a Mammalian Enzyme Catalyzing the Asymmetric Oxidative Cleavage of Provitamin A. J. Biol. Chem. 276, 14110-14116.

Kiefer, C., Sumser, E., Wernet, M.F., and Von Lintig, J. (2002). A class B scavenger receptor mediates the cellular uptake of carotenoids in Drosophila. Proc. Natl. Acad. Sci. U. S. A. 99, 10581-10586.

Kim, J., Chung, Y.D., Park, D.Y., Choi, S.K., Shin, D.W., Soh, H., Lee, H.W., Son, W., Yim, J., Park, C.S., et al. (2003). A TRPV family ion channel required for hearing in Drosophila. Nature 424, 81-84.

Kwon, Y., Shim, H.S., Wang, X., and Montell, C. (2008). Control of thermotactic behavior via coupling of a TRP channel to a phospholipase C signaling cascade. Nat. Neurosci. 11, 871-873.

Lane, M.A., and Bailey, S.J. (2005). Role of retinoid signalling in the adult brain. Prog. Neurobiol. 75, 275-293.

Leung, N.Y., and Montell, C. (2017). Unconventional Roles of Opsins. Annu. Rev. Cell Dev. Biol. 33, annurev-cellbio-100616-060432.

Li, J., Wei, J., Xu, P., Yan, M., Li, J., Chen, Z., and Jin, T. (2016). Impact of diabetesrelated gene polymorphisms on the clinical characteristics of type 2 diabetes Chinese Han population. Oncotarget 7, 85464-85471.

Lintig, J. Von, and Vogt, K. (2000). Filling the Gap in Vitamin A Research. J. Biol. Chem. $275,11915-11920$.

Montell, C. (2012). Drosophila visual transduction. Trends Neurosci. 35, 356-363.

Nadrowski, B., Albert, J.T., and Göpfert, M.C. (2008). Transducer-Based Force Generation Explains Active Process in Drosophila Hearing. Curr. Biol. 18, 1365-1372.

Nakai, K., and Horton, P. (1999). PSORT: A program for detecting sorting signals in proteins and predicting their subcellular localization. Trends Biochem. Sci. 24, 34-35. 
O’Tousa, J.E., Baehr, W., Martin, R.L., Hirsh, J., Pak, W.L., and Applebury, M.L. (1985). The Drosophila ninaE gene encodes an opsin. Cell 40, 839-850.

O’Tousa JE1, Leonard DS, P.W. (1989). Morphological defects in oraJK84 photoreceptors caused by mutation in R1-6 opsin gene of Drosophila.No Title. J Neurogenet. 6(1), 41-52.

Oberhauser, V., Voolstra, O., Bangert, A., von Lintig, J., and Vogt, K. (2008). NinaB combines carotenoid oxygenase and retinoid isomerase activity in a single polypeptide.

Proc. Natl. Acad. Sci. 105, 19000-19005.

Ozaki, K., Nagatani, H., Ozaki, M., and Tokunaga, F. (1993). Maturation of major drosophila rhodopsin, ninaE, requires chromophore 3-hydroxyretinal. Neuron 10, 11131119.

Pak, W.L., Shino, S., and Leung, H.T. (2012). PDA (Prolonged Depolarizing Afterpotential)-defective mutants: The story of nina's and ina's - Pinta and santa maria, too. J. Neurogenet. 26, 216-237.

Robert, D., and Göpfert, M.C. (2002). Acoustic sensitivity of fly antennae. J. Insect Physiol. 48, 189-196.

Sakmar, T.P., Menon, S.T., Marin, E.P., and Awad, E.S. (2002). Rhodopsin: Insights from Recent Structural Studies. Annu. Rev. Biophys. Biomol. Struct. 31, 443-484.

Salcedo, E., Zheng, L., Phistry, M., Bagg, E.E., and Britt, S.G. (2003). Molecular basis for ultraviolet vision in invertebrates. J. Neurosci. 23, 10873-10878.

Sarfare, S., Ahmad, S.T., Joyce, M. V., Boggess, B., and O'Tousa, J.E. (2005). The Drosophila ninaG oxidoreductase acts in visual pigment chromophore production. J. Biol. Chem. 280, 11895-11901.

Scheffer, D.I., Shen, J., Corey, D.P., and Chen, Z.-Y. (2015). Gene Expression by Mouse Inner Ear Hair Cells during Development. J. Neurosci. 35, 6366-6380.

Scott, K., Becker, a, Sun, Y., Hardy, R., and Zuker, C. (1995). Gq alpha protein function in vivo: genetic dissection of its role in photoreceptor cell physiology. Neuron 15, 919-927. 
Senthilan, P.R., Piepenbrock, D., Ovezmyradov, G., Nadrowski, B., Bechstedt, S., Pauls, S., Winkler, M., Möbius, W., Howard, J., and Göpfert, M.C. (2012). Drosophila auditory organ genes and genetic hearing defects. Cell 150, 1042-1054.

Shen, W.L., Kwon, Y., Adegbola, A.A., Luo, J., Chess, A., and Montell, C. (2011). Function of rhodopsin in temperature discrimination in Drosophila. Science (80-. ). 331, $1333-1336$.

Sokabe, T., Chen, H.C., Luo, J., and Montell, C. (2016). A Switch in Thermal Preference in Drosophila Larvae Depends on Multiple Rhodopsins. Cell Rep. 17, 336-344.

Steinbrecher, U.P. (1999). Receptors for oxidized low density lipoprotein. Biochim. Biophys. Acta 1436, 279-298.

Stork, T., Bernardos, R., and Freeman, M.R. (2012). Analysis of glial cell development and function in Drosophila. Cold Spring Harb. Protoc. 7, 1-17.

Styczynska-Soczka, K., and Jarman, A.P. (2015). The Drosophila homologue of Rootletin is required for mechanosensory function and ciliary rootlet formation in chordotonal sensory neurons. Cilia 1-11.

Todi, S. V., Sharma, Y., and Eberl, D.F. (2004). Anatomical and molecular design of the Drosophila antenna as a flagellar auditory organ. Microsc. Res. Tech. 63, 388-399.

Urwyler, O., Cortinas-Elizondo, F., and Suter, B. (2012). Drosophila sosie functions with $\beta$ $\mathrm{H}$-Spectrin and actin organizers in cell migration, epithelial morphogenesis and cortical stability. Biol. Open 1, 994-1005.

Venken, K.J.T., Schulze, K.L., Haelterman, N.A., Pan, H., He, Y., Evans-Holm, M., Carlson, J.W., Levis, R.W., Spradling, A.C., Hoskins, R.A., et al. (2011). MiMIC: A highly versatile transposon insertion resource for engineering Drosophila melanogaster genes. Nat. Methods 8, 737-747.

Vogt, K., and Kirschfeld, K. (1984). Chemical identity of the chromophores of fly visual pigment. Naturwissenschaften 71, 211-213. 
Voolstra, O., Oberhauser, V., Sumser, E., Meyer, N.E., Maguire, M.E., Huber, A., and Von Lintig, J. (2010). NinaB is essential for Drosophila vision but induces retinal degeneration in opsin-deficient photoreceptors. J. Biol. Chem. 285, 2130-2139.

Wald, G. (1938). ON RHODOPSIN IN SOLUTION. J Gen Physiol 795-832.

Wald, G. (1968). Molecular Basis of Visual Excitation.Pdf. 162.

Wang, T. (2005). Rhodopsin Formation in Drosophila Is Dependent on the PINTA Retinoid-Binding Protein. J. Neurosci. 25, 5187-5194.

Wang, T., Jiao, Y., and Montell, C. (2007). Dissection of the pathway required for generation of vitamin A and for Drosophila phototransduction. J. Cell Biol. 177, 305-316.

Wang, V.Y., Hassan, B.A., Bellen, H.J., and Zoghbi, H.Y. (2002). Drosophila atonal fully rescues the phenotype of Math1 null mice: New functions evolve in new cellular contexts. Curr. Biol. 12, 1611-1616.

Wang, X., Wang, T., Jiao, Y., von Lintig, J., and Montell, C. (2010a). Requirement for an Enzymatic Visual Cycle in Drosophila. Curr. Biol. 20, 93-102.

Wang, X., Wang, T., Jiao, Y., von Lintig, J., and Montell, C. (2010b). Requirement for an Enzymatic Visual Cycle in Drosophila. Curr. Biol. 20, 93-102.

Wang, X., Wang, T., Ni, J.D., von Lintig, J., and Montell, C. (2012). The Drosophila Visual Cycle and De Novo Chromophore Synthesis Depends on rdhB. J. Neurosci. 32, 3485-3491.

Yack, J.E. (2004). The structure and function of auditory chordotonal organs in insects. Microsc. Res. Tech. 63, 315-337.

Yoon, J., Matsuo, E., Yamada, D., Mizuno, H., Morimoto, T., Miyakawa, H., Kinoshita, S., Ishimoto, H., and Kamikouchi, A. (2013). Selectivity and Plasticity in a Sound-Evoked Male-Male Interaction in Drosophila. PLoS One 8, 1-13.

Yorozu, S., Wong, A., Fischer, B.J., Dankert, H., Kernan, M.J., Kamikouchi, A., Ito, K., and Anderson, D.J. (2009). Distinct sensory representations of wind and near-field sound in 
the Drosophila brain. Nature 458, 201-205.

Zanini, D., Giraldo, D., Warren, B., Katana, R., Andrés, M., Reddy, S., Pauls, S., Schwedhelm-Domeyer, N., Geurten, B.R.H., and Göpfert, M.C. (2018). Proprioceptive Opsin Functions in Drosophila Larval Locomotion. Neuron 98, 67-74.e4.

Zhang, W., Cheng, L.E., Kittelmann, M., Li, J., Petkovic, M., Cheng, T., Jin, P., Guo, Z., Göpfert, M.C., Jan, L.Y., et al. (2015). Ankyrin Repeats Convey Force to Gate the NOMPC Mechanotransduction Channel. Cell 162, 1391-1403. 


\section{List of figures:}

Figure 1. Hearing organ of Drosophila 10

Figure 2. Chordotonal organs in Drosophila 11

Figure 3. Experimental setup to probe antennal mechanics and electrophysiology 20

$\begin{array}{ll}\text { Figure 4. Rhodopsin sketch } & 27\end{array}$

Figure 5. Biomechanical and sound evoked nerve responses analyses of wild-type and 34 santa-maria ${ }^{l}$ mutant flies

Figure 6. santa-maria-Gal4 expression pattern.

Figure 7. Epifluorescent image of the santa-maria ${ }^{T-G E M}$-Gal4 expression pattern 36 in larva

Figure 8. santa-maria ${ }^{T-G E M}$-Gal4 expression in larval Ich5 chordotonal organ 36

Figure 9. santa-maria ${ }^{T-G E M}$-Gal4 expression in Johnston's organ 37

Figure 10. Localization of TRP channels in Ich5 organ in wild type and santa-maria ${ }^{l} \quad 38$ mutant larvae.

Figure 11. Localization of TRP channels in JO of wild type and santa-maria mutants 39

Figure 12. Laser Doppler analysis of santa-maria GAL4-UAS rescue 41

Figure 13. Auditory performance of ninaD $D^{l}$ and ninaB ${ }^{360 d}$ mutant flies 43

Figure 14. ERG recording from wild type and vitamin A depleted flies $\quad 45$

Figure 15. LDV measurements of Vitamin A depleted flies 46

Figure 16. JO function in pinta mutants and rescue flies 48

Figure 17. pinta expression in larval Ich5 organs $\quad 50$

Figure 18. pinta expression pattern in Johnston's organ 51

Figure 19. Auditory phenotype of ninaG mutant flies $\quad 52$

Figure 20. $\alpha \mathrm{Tub} 85 \mathrm{E}$ and nina $G$ expression pattern in larval Ich5 chordotonal organ $\quad 54$

Figure 21. nina $G$ expression pattern in adult JO 55

Figure 22. Auditory performance of the mutant flies implicated in chromophore recycle 57

Figure 23. Pdh-GAL4 expression in the eye of Drosophila 58

Figure 24. rdhB-Gal4 expression pattern in adult JO 59

Figure 25. Rhodopsin1 RT-PCR analysis $\quad 60$

Figure 26. Auditory performance of various nina $E^{17}$ mutant strains 62

Figure 27. Screenshot showing list of the genes detected in Drosophila JO from 27 Senthilian et al., 2012.

Figure 28. Laser Dopppler Vibrometer analysis of auditory defects in sosie 74 mutant flies.

Figure 29. sosie ${ }^{\text {Trojan }}$-Gal4 expression pattern in larval and adult chordotonal organs $\quad 75$

Figure 30. Johnston's organ staining of sosie ${ }^{M i M I C}$ mutants 76

Figure 31. Auditory phenotype of CG14085 ${ }^{\text {MiMIC }}$ mutant flies $\quad 78$

Figure 32. CG14085 expression pattern in chordotonal organs 79 


\section{List of abbreviations:}

$\begin{array}{ll}\text { AAMC } & \text { antennal mechanosensory and motor center } \\ \text { ato } & \text { atonal } \\ \text { Ibf } & \text { individual best frequency } \\ \text { CAP } & \text { compound ction potential } \\ \text { cs } & \text { cantonS } \\ \text { Dnai2 } & \text { dynein, axonemal, intermediate chain } 2 \\ \text { GFP } & \text { green fluorescence protein } \\ \text { iav } & \text { inactive } \\ \text { JO } & \text { Johnston's organ } \\ \text { Lch1 } & \text { lateral chordotonal organ } \\ \text { Lch5 } & \text { lateral pentaloscolopidial chordotonal organ } \\ \text { MET } & \text { mechanoelectrical ion channel } \\ \text { MiMIC } & \text { Minos-Mediated Integration Cassette } \\ \text { nan } & \text { nanchung } \\ \text { nina B/D/E/G } & \text { neither inactivation nor afterpotential B/D/E/G } \\ \text { nompC } & \text { no mechanoreceptor potential C } \\ \text { pdh } & \text { photoreceptor dehydrogenase } \\ \text { pinta } & \text { prolonged depolarization potential (PDA) is not apperent } \\ \text { PLC } & \text { phospholipase C } \\ \text { PSD } & \text { power spectral density } \\ \text { rdhB } & \text { retinol dehydrogenase } \\ \text { Rh } & \text { Rhodopsin } \\ \text { RMCE } & \text { recombinase-mediated cassette exchange } \\ \text { santa-maria } & \text { scavenger receptor acting in neural tissue and majority of rhodopsin is } \\ \text { TRP } & \text { absent } \\ \text { TRPN } & \text { Transient receptor potential } \\ \text { TRPV } & \text { Transient receptor potential nompC } \\ \text { VchA/B } & \text { ventral chordotonal organ A/B } \\ \text { WT } & \text { wild type } \\ & \end{array}$




\section{Curriculum Vitae}

\section{Personal details:}

Name:

Date of birth:

Place of birth:

Nationality:

\section{Education:}

10.2013 - Present

$10.2010-09.2012$

$10.2007-09.2010$
Radoslaw Katana

November $24^{\text {th }}, 1987$

Zielona-Gora

Polish
Phd student, Georg-August-Universität Göttingen

Department of Cellular Neurobiology

Phd thesis: "Chromophore-independent roles of Drosophila opsin apoproteins and visual cycle components"

MSc, University of Wroclaw - Faculty of Biology, Department of Animal Molecular Physiology, Master's thesis: „Phosphoglycerate mutase expression in the context of synaptic plasticity in rat hippocampal slices"

Bachelor degree : University of Wroclaw - Faculty of Biology, Specialization: Biology, Zoology

\section{Publications:}

Zanini, D., Giraldo, D., Warren, B., Katana, R., Andrés, M., Reddy, S., Pauls, S., SchwedhelmDomeyer, N., Geurten, B.R.H., and Göpfert, M.C. (2018). Proprioceptive Opsin Functions in Drosophila Larval Locomotion. Neuron 98, 67-74.e4.

Zazo Seco C, Castells-Nobau A, Joo SH, Schraders M, Foo JN, van der Voet M, Velan SS, Nijhof B, Oostrik J, de Vrieze E, Katana R, Mansoor A, Huynen M, Szklarczyk R, Oti M, Tranebjærg L, van Wijk E, Scheffer-de Gooyert JM, Siddique S, Baets J, de Jonghe P, Kazmi SA, Sadananthan SA, van de Warrenburg BP, Khor CC, Göpfert MC, Qamar R, Schenck A, Kremer H, Siddiqi S. A homozygous FITM2 mutation causes a deafness-dystonia syndrome with motor regression and signs of ichthyosis and sensory neuropathy.Dis Model Mech. 2017 Feb 1;10(2):105-118. doi: 10.1242/dmm.026476. Epub 2016 Dec 15. 
Karak, S., Jacobs, J.S., Kittelmann, M., Spalthoff, C., Katana, R., Sivan-Loukianova, E., Schon, M.A., Kernan, M.J., Eberl, D.F., and Göpfert, M.C. (2015). Diverse Roles of Axonemal Dyneins in Drosophila Auditory Neuron Function and Mechanical Amplification in Hearing. Sci. Rep. 5, 1-12.

Nesterov A, Spalthoff C, Kandasamy R, Katana R, Rankl NB, Andrés M, Jähde P, Dorsch JA, Stam LF, Braun FJ, Warren B, Salgado VL, Göpfert MC. TRP Channels in Insect Stretch Receptors as Insecticide Targets. Neuron. 2015 May 6;86(3):665-71. doi: 10.1016/j.neuron.2015.04.001.

\section{Conference presentations:}

09.2016

Neurofly 2016

$16^{\text {th }}$ European Neurobiology of Drosophila Conference, Platanias,Chania, Greece. Poster: "Dissecting the auditory relevance of the Drosophila visual chromophore pathway". 


\section{Acknowledgements}

Na wstępie chciałbym podziękować moim rodzicom, dzięki którym nie byłbym w tym miejscu w którym jestem. Chciałbym również podziękować moim przyjaciołom w szczególności: Piotrkowi, Przemkowi, Medykowi, Zającowi i Mierzwiemu za ich wsparcie podczas mojego doktoratu.

I would like to thank Prof. Dr. Gopfert for giving me the credit and chance to start my research carrier in such a wonderful scientific environment. He was always there to support me, give advice and discuss the project. It was a great fun to attend two DFG conferences with him. I would also like to show my gratitude for the second member of my thesis committee member Prof. Dr. Andre Fiala for his scientific input into my project.

I would also like to thank my colleagues:

- Dr. Damiano Zanini, who was my "unofficial supervisor" and one of the best friends. Thank you for all your scientific help, and great time during Neurofly conference, that I will never forget. I was very lucky to come across such a great person.

- Dr. Diego Giraldo for being always there to talk and help. It was a great fun to hang around with you, watch football matches and discuss scientific and nonscientific things.

- Dr. David Pipenbrock who taught me LDV measurements, and helped me mentally during the first year of my phd.

- Dr. Marta Andreas for her involvement in the initial part of the project, help with molecular biology and being extremely nice and kind person.

- Dr. Somdatta Karak for her help and involvement in the project and being a mentor.

- Dr. Philipp Hehlert for his advises and long scientific and non-scientific discussions.

- Dr. Bart Geurten for help with building PDA setup.

- Marvin Seifert, it was a great pleasure to meet such a friendly person. 
- Narges Bodaghabadi for being supportive and helping me during last weeks.

I would like to thank my office colleagues: Stephanie Pauls, Margareth Winkler, Nicola Schwedhelm-Domeyer for their technical support, help with german language and creating a kind and friendly atmosphere. I thank Gudrun Matthes for her help with all the formalities at the beginning of my phd. Last but not least, I would also like to thank all the other persons from the lab for being there, creating friendly and scientific atmosphere. 